(Prof. Dr. med. G. Hasenfuß)

Im Zentrum Innere Medizin

der Medizinischen Fakultät der Universität Göttingen

\title{
Mechanismen der Belastungseinschränkung von Patienten mit diastolischer Herzinsuffizienz im Vergleich zu Patienten mit diastolischer Dysfunktion unter besonderer Berücksichtigung der neurohumoralen Aktivierung
}

\author{
INAUGURAL-DISSERTATION \\ zur Erlangung des Doktorgrades \\ der Medizinischen Fakultät \\ der Georg-August-Universität zu Göttingen \\ vorgelegt von \\ André Duvinage \\ aus \\ Wittenberg
}

Göttingen 2010 
Dekan:

1. Berichterstatter:

2. Berichterstatter/in: Priv.-Doz. Dr. med. Sigler

3. Berichterstatter/in: Prof. Dr. med., Dr. rer. nat. Crozier
Prof. Dr. med. C. Frömmel

Prof. Dr. med. B. Pieske

Tag der mündlichen Prüfung: 28.09.2011 


\section{Inhaltsverzeichnis}

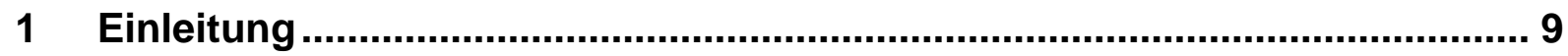

1.1 Definition und Formen der Herzinsuffizienz ......................................... 9

1.2 Definition der diastolischen Dysfunktion ............................................... 9

1.3 Definition der diastolischen Herzinsuffizienz .......................................... 10

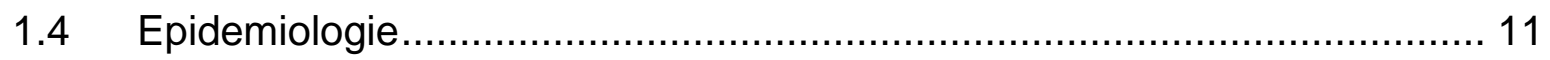

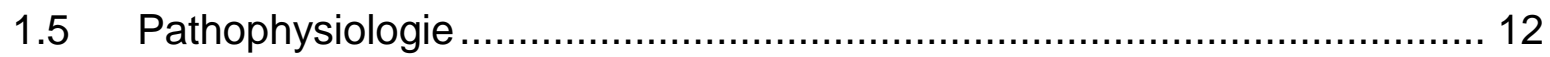

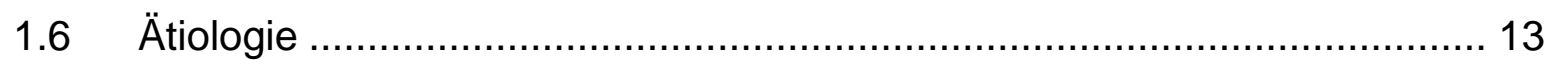

1.7 Neurohumorale Regulation und Diastolische Dysfunktion/ Herzinsuffizienz

1.7.1 Brain natriuretic peptid.......................................................... 14

1.7.2 Atriales natriuretisches Peptid ...................................................... 15

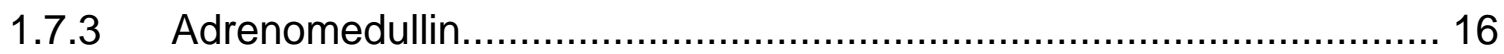

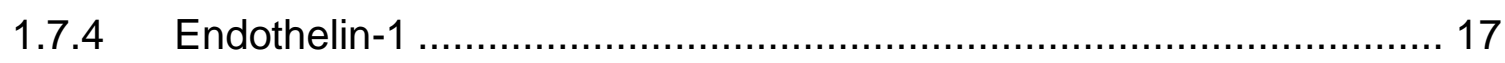

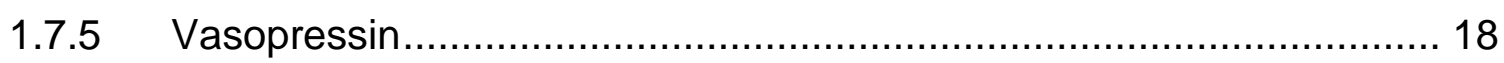

1.8 Therapie der diastolischen Dysfunktion und Herzinsuffizienz ................... 19

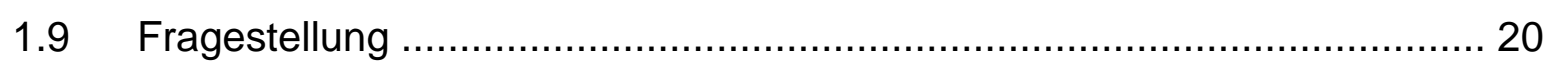

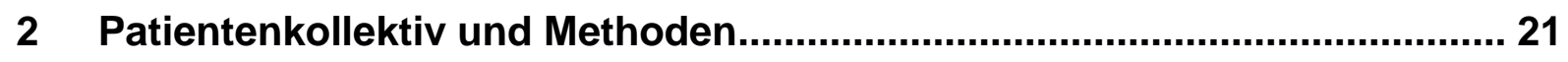

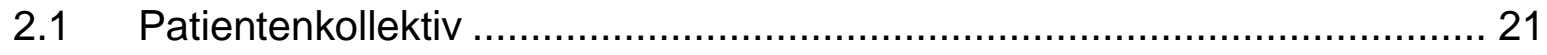

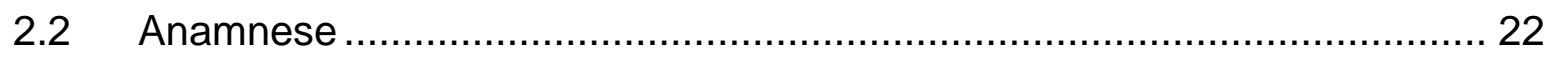

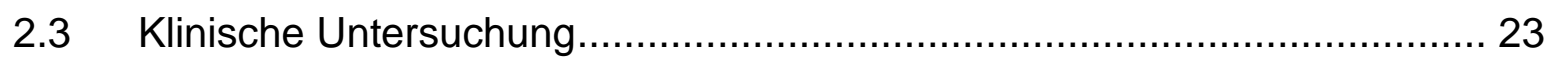

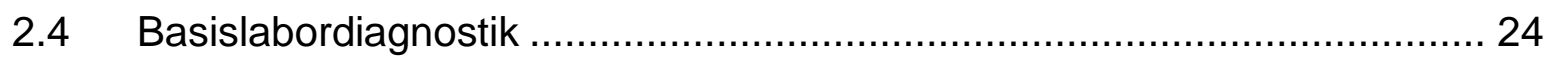

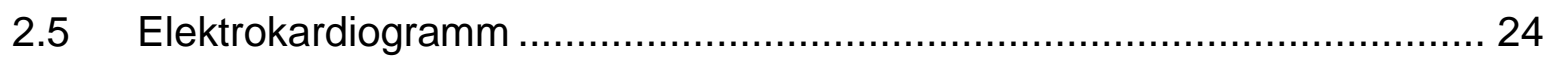

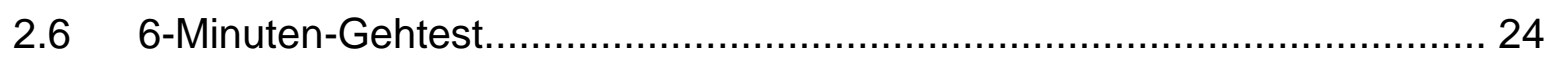

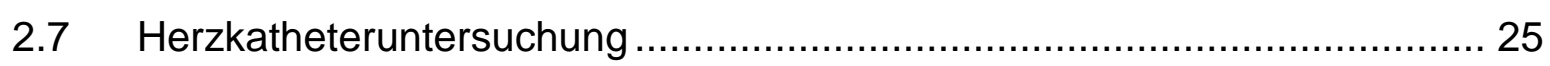

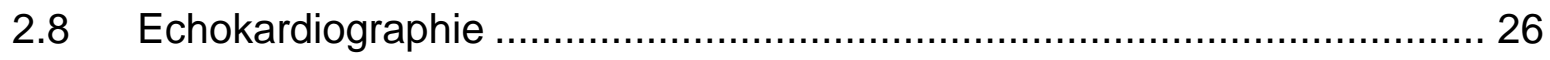

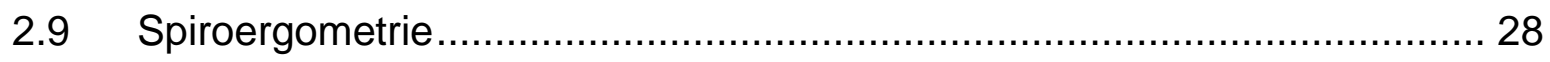

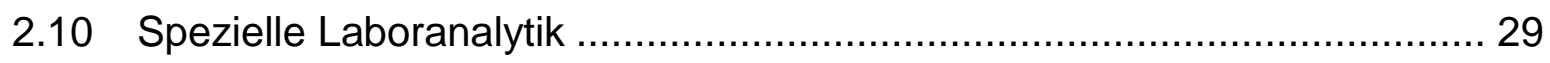

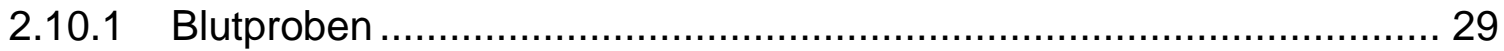

2.10.2 Bestimmung des Brain Natriuretic Peptids und NT-proBNP .............. 30

2.10.3 Bestimmung des Atrialen Natriuretischen Peptids und MR -proANP... 30

2.10.4 Bestimmung von Adrenomedullin und MR-proADM .......................... 31

2.10.5 Bestimmung von Endothelin-1 und CT -proET-1 ............................. 32

2.10.6 Bestimmung von Vasopressin und CT-proAVP ................................. 33

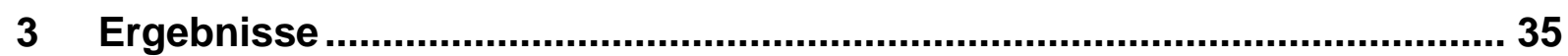


3.1 Deskriptive Statistik des Patientenkollektivs.......................................... 35

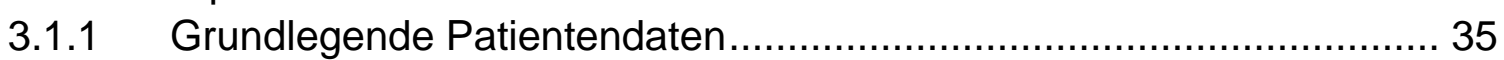

3.1.2 Risikofaktoren im Patientenkollektiv ............................................... 36

3.1.3 Symptome der Herzinsuffizienz im Patientenkollektiv ......................... 37

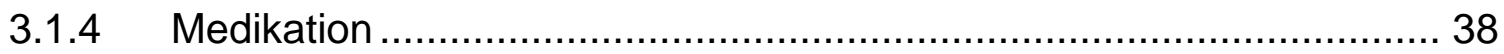

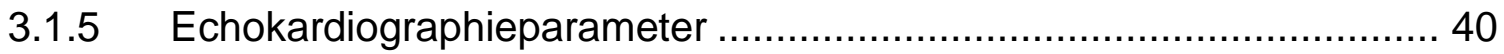

3.1.5.1 Graphische Darstellung von Echokardiographieparametern .......... 42

3.1.6 Belastbarkeit des Patientenkollektivs ............................................ 45

3.1.6.1 Graphische Darstellung von Belastungsparametern ..................... 47

3.1.7 Neurohumorale Aktivierung …................................................. 51

3.2 Zusammenhang zwischen Belastbarkeit, diastolischer Funktion und neurohumoraler Aktivierung ............................................................... 52

3.3 Gewichtung der Zusammenhänge von verschiedenen echokardiographischen und neurohumoralen Faktoren mit Parametern der

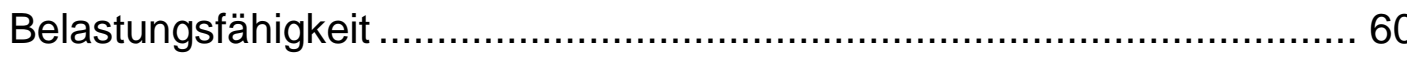

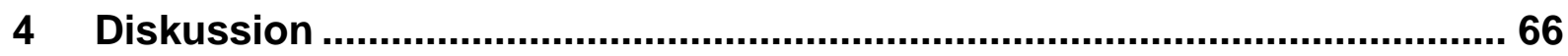

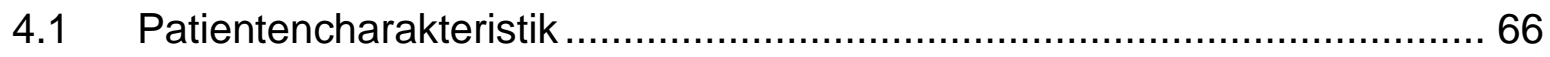

4.2 Belastbarkeit bei Patienten mit einer diastolischen Dysfunktion und einer diastolischen Herzinsuffizienz ......................................................... 71

4.3 Mechanismen der Belastungseinschränkung ...................................... 72

4.4 Einfluss der diastolischen Funktion auf die Belastbarkeit von Patienten mit einer diastolischen Dysfunktion und diastolischen Herzinsuffizienz ........... 72

4.5 Einfluss der neurohumoralen Aktivierung auf die Belastbarkeit ................ 74

$4.6 \quad$ Limitierung der Arbeit ...................................................................... 78

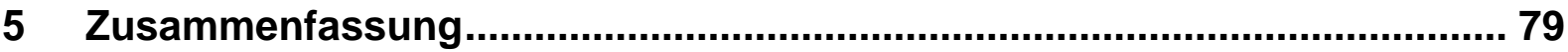

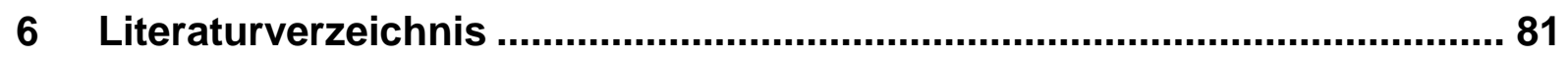

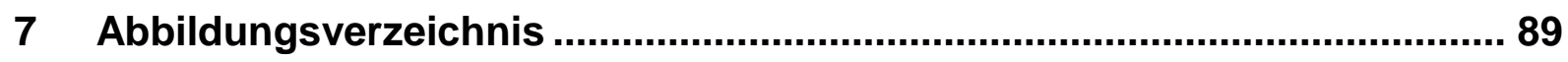

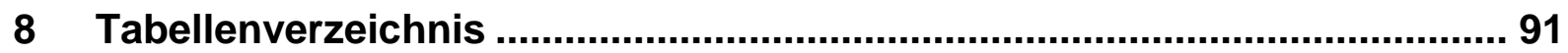




\section{Abkürzungsverzeichnis}

$\%$

A

ACC

ACE

$\mathrm{ADH}$

ADM

AF

AHA

ALT

ANP

ASS

AST

AT1-Antagonisten

AUC

aVF

$\mathrm{aVL}$

AVP

aVR

AZV

$\mathrm{BMI}$

BNP

$\mathrm{cm}$

COPD

CPAP

DD

DHF

D. $m$.

DT

$e^{\prime}$

E

$E / A$
Prozent

Spätdiastolische Myokardgeschwindigkeit

American College of Cardiology

Angiotensin Converting Enzym

Antidiuretisches Hormon

Adrenomedullin

Atemfrequenz

American Heart Association

Alanin-Aminotransferase

Atrial Natriuretic Peptide

Acetylsalicylsäure

Aspartat-Aminotransferase

Angiotensin1-Antagonisten

Area under the curve

Ableitung nach Goldberger

Ableitung nach Goldberger

Atriales Vasopressin

Ableitung nach Goldberger

Atemzugvolumen

Body Mass Index

Brain Natriuretic Peptide

Zentimeter

chronisch obstruktive Lungenerkrankungen

Continuous Positive Airway Pressure

diastolische Dysfunktion

diastolische Herzinsuffizienz

Diabetes mellitus

Dezelerationszeit

frühdiastolische Mitralanulusgeschwindigkeit

frühdiastolische Myokardgeschwindigkeit

Verhältnis aus früh- und spätdiastolischer Myokardgeschwindigkeit 
E/A $A_{\text {Valsalva }}$

$E / e^{\prime}$

EKG

ES

ESC

ET

ET-1

FEV1

GD

GFR

Y-GT

$\mathrm{HbA}_{1 \mathrm{c}}$

HDL

$\mathrm{HF}$

HFNEF

HFQ

HFREF

HIV

IV

IVRT

J

KG

$\mathrm{kg}$

KHK

$\mathrm{KNHI}$

।

LA

LA(ES)

LA-ES

LAVI
Verhältnis der maximalen frühdiastolischen Einstromgeschwindigkeit zur Einstromgeschwindigkeit nach der Vorhofkontraktion über der Mitralklappe während des Valsalvamanövers

Verhältnis der maximalen frühdiastolischen Einstromgeschwindigkeit über der Mitralklappe zur frühdiastolischen maximalen Geschwindigkeit des Mitralklappenringes im Gewebedoppler

Elektrokardiogramm

endsystolisch

European Society of Cardiology

Endothelin

Endothelin-1

Forced expiratory volume in 1 second

Gewebedoppler

Glomeruläre Filtrationsrate

Gamma-Glutamyl-Transferase

Glykohämoglobin

High Densitiy Lipoprotein

Herzinsuffizienz

heart failure with normal ejection fraction

Herzfrequenz

heart failure with reduced ejection fraction

Humanes Immundefizienz-Virus

interventrikulär

Isovolumetrische Relaxationszeit

Jahr

Kontrollgruppe

Kilogramm

koronare Herzkrankheit

Kompetenznetz Herzinsuffizienz

Liter

linker Vorhof

linksatrialer endsystolischer Durchmesser (parasternal)

linksatrialer endsystolischer Durchmesser

linksventrikulärer enddiastolischer Volumenindex 


\begin{tabular}{|c|c|}
\hline LDL & Low Densitiy Lipoprotein \\
\hline $\log$ & Logarithmus \\
\hline LV & linker Ventrikel, linksventrikulär \\
\hline LVD & linksventrikulärer Durchmesser \\
\hline $\operatorname{LVD}(E D)$ & linksventrikulärer enddiastolischer Ventrikeldurchmesser \\
\hline $\operatorname{LVD}(E S)$ & linksventrikulärer endsystolischer Ventrikeldurchmesser \\
\hline LVEDP & linksventrikulärer enddiastolischer Druck \\
\hline LVEF & linksventrikuläre Ejektionsfraktion \\
\hline LVMI & linksventrikulärer Masseindex \\
\hline LVV & linksventrikuläres Volumen \\
\hline LVV-ED & linksventrikuläres enddiastolisches Volumen \\
\hline LVV-ES & linksventrikuläres endsystolisches Volumen \\
\hline $\mathrm{m}$ & Meter \\
\hline $\max$. & maximal \\
\hline MD & Mitralisdoppler \\
\hline 6-MGT & 6-Minuten-Gehtest \\
\hline MI & Myokardinfarkt \\
\hline $\min$ & Minute \\
\hline $\mathrm{mm}$ & Millimeter \\
\hline $\mathrm{mmHg}$ & Millimeter Quecksilbersäule \\
\hline MMP & Matrixmetalloproteinasen \\
\hline $\mathrm{mPCW}$ & mittlerer pulmonaler Verschlussdruck \\
\hline MR-proADM & mittelregionaler Teil des pro-Adrenomedullin \\
\hline $\mathrm{n}$ & Anzahl \\
\hline $\mathrm{nmol}$ & Nannomol \\
\hline NT-proBNP & $\mathrm{N}$-terminales pro B-Typ natriuretisches Peptid \\
\hline NYHA & New York Heart Assoziation \\
\hline OSAS & obstruktives Schlafapnoe-Syndrom \\
\hline $\mathrm{p}$ & statistische Signifikanz \\
\hline Parox. & paroxysmal \\
\hline pAVK & periphere arterielle Verschlusskrankheit \\
\hline Peak $\mathrm{VO}_{2}$ & maximale Sauerstoffaufnahme \\
\hline $\mathrm{pg}$ & Picogramm \\
\hline
\end{tabular}




\begin{tabular}{|c|c|}
\hline pmol & Picomol \\
\hline post & nach Belastung \\
\hline PQ-Zeit & Abstand vom Beginn der P-Welle bis zum Beginn der Q-Zacke \\
\hline PV & Pulmonalvene \\
\hline PVF & pulmonalvenöser Fluss \\
\hline PW & Pulsed Wave (gepulster) Doppler \\
\hline QRS-Dauer & entspricht der Kammererregung im EKG \\
\hline QT-Zeit & Abstand vom Beginn der Q-Zacke bis zum Ende der T-Welle \\
\hline RAAS & Renin-Angiotensin-Aldosteron-System \\
\hline RF & Risikofaktor(en) \\
\hline ROC & Receiver Operated Characteristic Curve \\
\hline $\mathrm{RQ}$ & Respiratorischer Quotient \\
\hline $\mathrm{RR}$ & Riva Rocci/Blutdruck \\
\hline s & Sekunde \\
\hline$S / D$ & $\begin{array}{l}\text { Verhältnis des maximalen systolischen zum maximalen diastolischen } \\
\text { pulmonalvenösen Fluss }\end{array}$ \\
\hline SHF & systolische Herzinsuffizienz \\
\hline $\mathrm{T}$ & (tau) Zeitkonstante der Relaxation \\
\hline TIA & Transitorisch ischämische Attacke \\
\hline TIMP & Tissue inhibitors of metalloproteinases \\
\hline TP7 & Teilprojekt 7 im Rahmen des Kompetenznetz Herzinsuffizienz \\
\hline $\mathrm{VCO}_{2}$ & Kohlendioxidabgabe $\mathrm{ml} / \mathrm{min}$ \\
\hline VE & Atemminutenvolumen \\
\hline $\mathrm{VO}_{2}$ & Sauerstoffaufnahme $\mathrm{ml} / \mathrm{min}$ \\
\hline $\mathrm{VO}_{2} / \mathrm{kg}$ & Sauerstoffaufnahme $\mathrm{ml} / \mathrm{kg} / \mathrm{min}$ \\
\hline$V p$ & Flow-propagation-time \\
\hline vs. & Versus \\
\hline W & Watt \\
\hline Z. n. & Zustand nach \\
\hline
\end{tabular}




\section{Einleitung}

\subsection{Definition und Formen der Herzinsuffizienz}

Herzinsuffizienz (Heartfailure/HF) ist die Unfähigkeit des Herzens, das vom Körper benötigte Herzzeitvolumen bereit zu stellen. Sie basiert auf einer anormalen Struktur und Funktion des Herzens und geht mit einer neurohumoralen Aktivierung einher. Dabei ist sie mit klinischen Symptomen wie Dyspnoe, Müdigkeit und Flüssigkeitsretention, einer gesteigerten Inzidenz von Arrhythmien und einer eingeschränkten Prognose vergesellschaftet. Die Einteilung der Herzinsuffizienz kann nach verschiedenen Richtlinien erfolgen. Bei den gängigsten Modellen handelt es sich um eine Einteilung nach zeitlichem Verlauf in eine akute oder chronische Herzinsuffizienz, oder nach der betroffenen Herzkammer in eine Links-, Rechts- oder globale Herzinsuffizienz. Auch nach gestörter ventrikulärer Funktion kann in eine systolische oder diastolische Herzinsuffizienz unterteilt werden. Nach der Ejektionsfraktion (EF) wird die HF in eine mit verminderter oder erhaltener Ejektionsfraktion, nach dem Kompensationsgrad in eine kompensierte oder dekompensierte Herzinsuffizienz eingeteilt. Des Weiteren erfolgt die Unterteilung des klinischen Schweregrades mithilfe der NYHA- I-IV- Klassifikation. Anhand von Leitlinien der American Heart Association und des American College of Cardiology (AHA/ACC) wird die Herzinsuffizienz und deren Ätiologie in vier Stadien klassifiziert (Hunt et al. 2005). Im Stadium A sind Risikofaktoren (RF) für eine HF vorhanden, allerdings ohne nachweisbare strukturelle Herzerkrankung oder klinische Symptomatik. Das Stadium B ist durch vorhandene RF mit struktureller Herzerkrankung, aber ohne klinische Symptomatik der HF gekennzeichnet. Auch im Stadium C liegt eine strukturelle Herzerkrankung vor, aber mit früherer oder bestehender Symptomatik der HF. Das Stadium D ist als eine therapierefraktäre HF, die eine spezielle Therapie erfordert, definiert.

\subsection{Definition der diastolischen Dysfunktion}

Die diastolische Dysfunktion (DD) ist eine asymptomatische Störung der Relaxation und/oder der Compliance des Myokards bei erhaltener Ejektionsfraktion. Hinweise auf eine DD können dabei sowohl mit invasiven, als auch mit nicht-invasiven Methoden erhoben werden. 
Bei der invasiven Variante gelten eine Erhöhung der Konstante der linksventrikulären Relaxation ( $\mathrm{T}$ ) $>48 \mathrm{~ms}$, des linksventrikulären enddiastolischen Druckes (LVEDP) auf $>16 \mathrm{mmHg}$ oder des mittleren pulmonalen Verschlussdruckes (mPCW) auf $>12 \mathrm{mmHg}$ als beweisführend für das Vorliegen einer DD. Seit Jahren ist die Echokardiographie als kostengünstiges und nicht-invasives Verfahren in der Diagnostik der DD etabliert. Garcia et al. (Garcia et al. 1998) stellten eines der ersten Schemata zur nicht-invasiven Diagnose der DD auf. Sie beurteilen dabei zunächst transmitral das Verhältnis von frühdiastolischer Geschwindigkeit (E) zur vorhofkontraktionsbedingten, spätdiastolischen Geschwindigkeit (A). Anhand dieses E/A-Verhältnisses teilten sie die DD in verschiedene Schweregrade ein. Neuere Konzepte bedienen sich zusätzlich dem Gewebedoppler (GD) zur Diagnosefindung. Im Mittelpunkt steht hier vor allem die Bestimmung des Verhältnisses von E zur frühdiastolischen Mitralanulusgeschwindigkeit e‘. Eine weitere Möglichkeit zum Nachweis einer DD kann durch die Messung des natriuretischen Peptides in Verbindung mit konventionellen Doppleruntersuchungen, morphologischen Echokriterien sowie EKG- und Gewebedopplermessungen erfolgen (Paulus et al. 2007). Es gibt folglich verschiedene Schemata, die zur nicht-invasiven Bestimmung eingesetzt werden können.

\subsection{Definition der diastolischen Herzinsuffizienz}

Die Erstbeschreibung der diastolischen Herzinsuffizienz (DHF) erfolgte 1985 durch Topol et al. (Topol et al. 1985). Die diastolische Herzinsuffizienz muss von der (noch) asymptomatischen diastolischen Dysfunktion abgegrenzt werden, da diese aus der DD hervorgehen kann und mit typischen klinischen Symptomen der HF vergesellschaftet ist. Eine der wesentlichen Ursachen der DD ist die linksventrikuläre Hypertrophie. Sie ist ein wichtiger Faktor im Übergang von der asymptomatischen DD zur symptomatischen diastolischen HF (Melenovsky et al. 2007, de Simone et al. 2008).

Für die Diagnose der diastolischen Herzinsuffizienz werden die folgenden drei Kriterien gefordert: Zuerst müssen Zeichen oder Symptome der chronischen Herzinsuffizienz vorhanden sein. Weiterhin muss eine normale oder maximal leicht eingeschränkte linksventrikuläre EF von $\geq 50 \%$ und ein linksventrikulärer enddiastolischer Volumenindex (LAVI) von $<97 \mathrm{ml} / \mathrm{m}^{2}$ nachgewiesen werden. Als drittes Kriterium ist der Nachweis einer diastolischen Dysfunktion notwendig (Paulus et al. 2007). Dabei ist zu beachten, dass die diastolische Dysfunktion auch mit einer systolischen Herzinsuffizienz (SHF) einhergehen kann (Zile and Brutsaert 2002). Deshalb wurde in den letzten Jahren eine neue 
Nomenklatur vorgeschlagen, die die Begriffe heart failure with reduced ejection fraction (HFREF) für die systolische HF und heart failure with normal ejection fraction (HFNEF) statt diastolischer Herzinsuffizienz beinhaltet (Paulus et al. 2007). Ich werde mich in der folgenden Arbeit an die ältere, dafür aber klinisch stärker etablierte Nomenklatur halten.

\subsection{Epidemiologie}

Diverse Studien der vergangenen Jahre deuten auf eine vor allem altersabhängige und populationsbezogene Prävalenz der diastolischen Dysfunktion von 2,8\% bei 25- bis 35-Jährigen und 15,8\% bei über 65-Jährigen hin (Fischer et al. 2003). Bei einer, im Rahmen des Kompetenznetzes Herzinsuffizienz (KNHI) durchgeführten Studie wurden 1735 hausärztliche Patienten mit kardiovaskulären Risikofaktoren (arterielle Hypertonie, Diabetes mellitus) untersucht. In der Gruppe der Hypertoniker im Alter von 50 bis 85 Jahren wurde eine Prävalenz der diastolischen Dysfunktion von $72 \%$ gefunden (Pieske and Wachter 2008). Unklar ist weiterhin die geschlechtsspezifische Prävalenz der DD und DHF. Oft wird über eine Akkumulation des weiblichen Geschlechts berichtet, die Daten sind hier aber widersprüchlich. Während Klapholz et al. eher eine Häufung bei Frauen fanden (Klapholz et al. 2004), besagen die Untersuchungen von Fischer et al., dass diastolische Anomalitäten eher Männer betreffen (Fischer et al. 2003). Die Prävalenz der DD und DHF ist aufgrund des demographischen Wandels weiterhin steigend.

Des Weiteren ging man vor einigen Jahren davon aus, dass die DHF gegenüber Patienten mit einer SHF deutlich weniger häufig ist (Vasan et al. 1995). Nach neueren Studien zeigt sich allerdings, dass über 50\% der Patienten mit Zeichen einer HF eine erhaltene EF aufweisen (Owan et al. 2006). Weiterhin geht man nach neuesten Studien davon aus, dass die schlechte Überlebensrate der DHF mit der einer SHF vergleichbar ist (Bhatia et al. 2006, Tribouilloy et al. 2008). Auch schon die asymptomatische DD bedingt eine schlechtere Überlebensprognose im Vergleich zur altersentsprechenden Allgemeinbevölkerung (Okura et al. 2007). Anhand der hier aufgezeigten Studien ist also zu erkennen, dass es sich bei der DD und der DHF um Krankheitsbilder mit hoher Prävalenz, steigender Inzidenz und geringerer Überlebensrate handelt, von denen vor allem ältere Patienten betroffen sind. 


\subsection{Pathophysiologie}

Als diastolische Dysfunktion werden Relaxations-, Dehnbarkeits- und Füllungsstörung des Ventrikels bezeichnet. Die diastolische Relaxationsstörung stellt sich sowohl auf zellulärer wie auch auf subzellulärer Ebene dar. Für die Kontraktion der Herzmuskelzellen ist die Aktivierung der kontraktilen Proteine Aktin und Myosin durch Kalzium von entscheidender Bedeutung. Die Relaxation beginnt durch die Elimination des aus dem sarkoplasmatischen Retikulum freigesetzten Kalziums. Voraussetzung für die Relaxation ist demzufolge eine ungestörte Wiederaufnahme des Kalziums durch Kalziumpumpen des sarkoplasmatischen Retikulums. Eine Störung der Relaxation kann aus einer verzögerten Kalziumelimination, einer gesteigerten Kalziumempfindlichkeit der kontraktilen Proteine oder aus einer kalziumunabhängigen verlängerten Kopplung von Myosin und Aktin resultieren (Hasenfuss and Pieske 2002). Dies beeinträchtigt die Füllung des linken Ventrikels in der Diastole, häufig auf dem Boden einer konzentrischen linksventrikulären Hypertrophie (Katz and Zile 2006), und führt zu einem erhöhten enddiastolischen Druck. Als limitierende Komponente ist die Steifigkeit des Herzmuskels während der diastolischen Füllungsphase anzusehen. Sie wird durch die extrazelluläre Matrix und durch Strukturproteine der Kardiomyozyten determiniert. Myozytär spielt das von Z-Bande zu Z-Bande gespannte Titin-Molekül eine wesentliche Rolle bei der diastolischen Dehnung der Herzmuskelzellen. Verschiedene Isoformen des Titins gehen mit unterschiedlicher Dehnungsfähigkeit einher (Linke and Grutzner 2008). Extrazellulär von entscheidender Bedeutung für die Dehnungsstörung des Herzmuskels ist die Kollagenmatrix. Borbély et al. (Borbely et al. 2005) zeigten, dass Patienten mit einer DHF signifikant höhere Kollagen-Volumenfraktionen und eine erhöhte passive Ruhespannung bei gleicher Sarkomerlänge als die Patienten in der Kontrollgruppe aufwiesen. Als weitere myokardiale Ursachen konnten Änderungen im Gleichgewicht zwischen den Kollagen abbauenden Enzymen der Familie der Matrixmetalloproteinasen (MMP) und ihren Inhibitoren (TIMP) beobachtet werden. Eine vermehrte Hemmung der MMP durch erhöhte Expression von TIMP1 führt zu einem verminderten Kollagenabbau. Dabei korreliert die Schwere der Erkrankung mit den Spiegeln der Enzyme im Blut der Patienten (Ahmed et al. 2006).

Auch hormonelle Dysregulationen können zu einer Verschlechterung der DD beitragen. Eine ständige Überaktivierung des Renin-Angiotensin-Aldosteron-Systems (RAAS) führt aldosteronvermittelt zu einer Steigerung der Kollageneinlagerung am Herzen. Daraus folgt eine erhöhte Myokardsteifigkeit, welche in einer Relaxationsstörung des Herzens endet (Schunkert et al. 1997). Die in der Adventitia 
der intramyokardialen Arterien beginnende Einlagerung des Kollagens schreitet im Verlauf in die interzellulären Räume zwischen den Myozyten fort (Jalil et al. 1989). Des Weiteren führt auch Angiotensin II, ebenfalls ein Bestandteil des RAAS, zu einer Vermehrung des Bindegewebes und damit zur Entwicklung einer Hypertrophie (Li et al. 2001). Ein Therapieansatz ist also die Hemmung des RAAS durch Angiotensin2-Antagonisten, ACE-Hemmer oder Aldosteronantagonisten, welche eine Hypertrophie und das Auftreten von Vorhofflimmern verhindern können (Maggioni et al. 2005).

\section{6 Ätiologie}

Die diastolische Dysfunktion entsteht aus einer Vielzahl von Grunderkrankungen. Dazu zählt als eine der häufigsten Begleiterkrankungen die koronare Herzkrankheit (KHK), die bei 53\% der Patienten mit einer DD nachgewiesen wurde (Owan et al. 2006). Der pathophysiologische Zusammenhang besteht hier in der geringeren Energieversorgung der Kardiomyozyten und die daraus resultierende gestörte, energieabhängige Relaxation. Weiterhin sind viele kardiale Erkrankungen, die mit einer linksventrikulären Hypertrophie einhergehen, als Ursache einer diastolischen Dysfunktion anzusehen. Von Fischer et al. wurden weitere mit der DD assoziierte RF beschrieben (Fischer et al. 2003). Bei den meisten handelt es sich um bekannte kardiovaskuläre Risikofaktoren wie einen in der Anamnese vorhandenen Myokardinfarkt (MI), eine arterielle Hypertonie, Diabetes mellitus oder Übergewicht. Besonders hervorzuheben ist hier nochmals der Diabetes mellitus (Stahrenberg et al. 2010). Bei bis zu $80 \%$ der untersuchten Diabetiker wurde eine diastolische Dysfunktion diagnostiziert (Liu et al. 2001, Wachter et al. 2007). Als Folge der Erkrankung kommt es zu funktionellen, morphologischen und biochemischen Veränderungen am Myokard, die unabhängig von anderen Faktoren zu einer DD und DHF führen können. Auch ein obstruktives Schlafapnoe-Syndrom (OSAS) gilt als ein unabhängiger RF für die DHF. Durch eine gezielte Therapie mittels cPAP-Beatmung konnte hier bereits eine Besserung der diastolischen Funktion erreicht werden (Arias et al. 2005).

\subsection{Neurohumorale Regulation und Diastolische Dysfunktion/ Herzinsuffizienz}

Durch ein ESC-Konsensus-Papier zur Diagnose der diastolischen Herzinsuffizienz wurden für die natriuretischen Peptide BNP und NT-proBNP Grenzwerte definiert, die mithilfe von spezifischen Tests (Triage Biosite/ Roche Diagnostics) die Diagnose der diastolischen Herzinsuffizienz unterstützen 
können. Um die Diagnose vollständig zu sichern, müssen allerdings noch weitere echokardiographische Kriterien erfüllt werden (Lim et al. 2006). Die natriuretischen Peptide haben dadurch, wie auch bei der SHF in der Diagnostik und der Prognoseabschätzung der DHF, an Bedeutung gewonnen. Allerdings sind bezüglich der pathophysiologischen Zusammenhänge noch weitere Fragen offen. Die Rolle vasokonstriktorisch wirkender Hormone wie Endothelin-1, Vasopressin und des vasodilatatorisch wirkenden Adrenomedullins in der Entwicklung von DD und DHF ist im Gegensatz zur SHF noch nicht hinreichend erforscht.

\subsubsection{Brain natriuretic peptid}

Das BNP genannte brain natriuretic peptide wurde erstmals 1988 in Schweinegehirnen entdeckt (Sudoh, et al. 1988). In den frühen 90er-Jahren fand man heraus, dass es auch in den ventrikulären Kardiomyozyten des Menschen synthetisiert wird und aus 32 Aminosäuren besteht (Nakamura, et al. 1991).

Durch das aus 134 Aminosäuren bestehende präproBNP, resultiert durch Spaltung das proBNP, welches wiederum in ein biologisch aktives Fragment, das C-terminale BNP, und in das inaktive Nterminale Fragment zerlegt wird. Im Vergleich zum C-terminalen hat das $\mathrm{N}$-terminale Fragment eine wesentlich längere Halbwertzeit und wird demzufolge dem BNP bei der Quantifizierung im Blut vorgezogen. Die Freisetzung erfolgt durch kardiale Wanddehnung ähnlich dem analog wirkenden ANP (Piechota et al. 2008).

BNP und NT-proBNP sind für die SHF etablierte Marker. Auch für die DD und die DHF ist der Nutzen dieser Parameter im Vergleich zu ANP, ADM, ET-1 und AVP besser untersucht (Luers et al.2010). Allerdings kann mit Hilfe dieser Parameter eine nichtkardiale Ursache der Dyspnoe, die nicht mit einer Erhöhung von BNP oder NT-proBNP einhergeht, besser von kardialen Ursachen differenziert werden.

Tschöpe et al. untersuchten Patienten mit einer DHF bezüglich ihrer NT-proBNP-Werte. Hierbei zeigte sich ein Anstieg der Werte im Vergleich zu Kontrollpatienten mit normaler diastolischer Funktion. Weiterhin korrelierten sie auch mit der Schwere der Erkrankung. Bei Patienten mit höherer NYHAKlasse fanden sich demzufolge höhere Werte (Tschöpe et al. 2005). Eine Unterscheidung zwischen SHF und DHF allein anhand von NT-proBNP ist nicht möglich. Auch Lubien et al. kamen bei einem Schwellenwert vom $62 \mathrm{ng} / \mathrm{ml}$ für BNP zu dem Ergebnis, dass BNP einen Marker mit hoher Sensitivität 
und Spezifität für die DD darstellt (Lubien et al. 2002). Allerdings wurde hier das Vorliegen einer DD lediglich durch ein verändertes E/A-Verhältnis definiert.

BNP und NT-proBNP sind also bereits mit einigen morphologischen Kriterien und diagnostischen Parametern der DD und der DHF in Verbindung gebracht worden. Der Stellenwert für die Progression der Erkrankungen bleibt aber weitgehend unerforscht.

\subsubsection{Atriales natriuretisches Peptid}

Das aus 28 Aminosäuren bestehende atriale natriuretische Peptid (ANP) wurde erstmals 1981 durch Versuche an Ratten entdeckt (de Bold et al. 1981). ANP wird vor allem im linken Vorhof synthetisiert und durch einen Dehnungsreiz ausgeschüttet. Die renale Funktion ist ähnlich dem des BNP. Auch hier erfolgt vor allem eine Diurese und Natriurese sowie im Gegensatz zu ET-1 und Vasopressin eine Vasodilatation. Am Herzen erfolgt eine Senkung der Vorlast und der Nachlast. Weiterhin zeigt sich unter Einfluss von natriuretischen Peptiden eine verminderte Hormonfreisetzung aus der Nebennierenrinde, zum Beispiel von Aldosteron. Zudem besteht zwischen den natriuretischen Hormonen und dem Peptidhormon ET-1 eine Wechselwirkung. So hemmen ANP und BNP die Produktion von ET-1, während dieses die Synthese von natriuretischen Peptiden stimuliert (Emori et al. 1993).

Auch hier entsteht in der Synthese von ANP ein Spaltprodukt, dessen Konzentration Rückschlüsse auf die des ANP erlaubt. Durch eine Endopeptidase wird das aus 126 Aminosäuren bestehende biologisch inaktive proANP in ein biologisch aktives $\mathrm{C}$-terminales und $\mathrm{N}$-terminales Fragment gespalten (Piechota et al. 2008). Der N-terminale Teil des ANP, genannt NT-proANP, besitzt eine wesentlich längere Halbwertszeit als das ANP und wurde deshalb als Marker für ANP vorgeschlagen (Buckley et al. 1999).

In klinischen Studien ist eine Korrelation zwischen ANP und dem Vorhandensein eines idiopathischen arteriellen Hypertonus beschrieben. Auf dem Boden einer zusätzlichen konzentrischen Hypertrophie fanden sich weiter Steigerungen der Werte im Vergleich zu den Kontrollen (Irzmanski et al. 2007). Da die linksventrikuläre Hypertrophie eng mit dem Vorliegen einer DD assoziiert ist, könnten erhöhte ANP-Werte auf eine DD hinweisen (Fischer et al. 2003). In einer weiteren Studie von Lerman, et al zeigte das Fragment NT-proANP eine Sensitivität von 90\% und eine Spezifität von $92 \%$ bezüglich 
einer mittels Radionuklidangiografie nachgewiesenen asymptomatischen, linksventrikulären Dysfunktion (Lerman et al. 1993). Bei bestehender manifester HF konnten bereits 1986 erhöhte Werte des NT-proANP gemessen werden, die zudem auch mit der Schwere der Erkrankung korrelierten (Burnett et al. 1986). In neueren Studien wurden die Werte für BNP und ANP bei hypertensiven Patienten mit LVEF $\leq 40 \%$ der NYHA-Klasse III-IV und dilatativer Kardiomyopathie im Vergleich zu gesunden Kontrollpatienten untersucht. Diese waren für ANP signifikant erhöht und korrelierten negativ mit der LVEF. Unter der Therapie mit dem Angiotensinrezeptorblocker Irbesartan kam es nach sechs Monaten zu einer Reduktion der ANP-Konzentration, einer Verbesserung der NYHA-Klasse und einer erhöhten LVEF. Damit kommen sowohl ANP als auch BNP eine Bedeutung für die Therapiekontrolle dieser Patienten zu (Falcao et al. 2004).

Mittels der hier aufgezeigten Studienergebnisse zur systolischen Dysfunktion und Herzinsuffizienz ist es naheliegend, dass ANP auch bei der Diagnostik und Prognose der DD und DHF einen gewissen Stellenwert besitzt.

\subsubsection{Adrenomedullin}

Das im Phäochromozytom entdeckte und aus 52 Aminosäuren bestehende Adrenomedulin (ADM), besitzt eine starke vasodilatatorische und hypotensive Wirkung (Kitamura et al. 1993). ADM befindet sich im menschlichen Körper sowohl im Mark der Nebenniere, im Vorhof wie auch in der Lunge (Ichiki et al. 1994). Als Hauptort für Synthese und Sekretion gilt dabei das Gefäßendothel (Sugo et al. 1994).

Erhöhte Adrenomedullinwerte finden sich bei der Sepsis aber auch bei Patienten mit einer HF. Kobayashi et al. zeigten dies 1996 in einer Studie. Hier korrelierten die gesteigerten ADM-Werte auch mit der NYHA-Klassifikation (Kobayashi et al. 1996). An Patienten mit koronarer Herzkrankheit zeigten Elmas et al. eine negative Korrelation zwischen den Spiegeln des mittregionalen proAdrenomedullin (MR-proADM) und der LVEF. Unklar ist allerdings deren prognostischer Wert (Elmas et al. 2008). Auch mit der DD wurde ADM bereits in Verbindung gebracht (Yu et al. 2001). Diese Arbeitsgruppe untersuchte ein Kollektiv aus 77 Patienten mit HF, wovon 31 Patienten eine isolierte DD mit LVEF $>50 \%$ und 46 eine LVEF $<50 \%$ aufwiesen. Dabei zeigte sich, dass die Werte für ADM bei isolierter DD gegenüber Kontrollprobanden signifikant erhöht waren. Bei Vorliegen einer Kombination aus restriktivem Füllungsmuster und LVEF $<50 \%$ waren die Werte nochmals erhöht. Das E/A-Verhältnis zeigte eine positive Korrelation mit der Konzentration des ADM. Im Gegensatz zu der oben 
genannten Studie von Kobayashi konnte hier eine Korrelation zwischen der NYHA-Klasse und dem Adrenomedullinspiegel nicht nachgewiesen werden.

Im Bezug auf die DD und die DHF ist ADM, trotz der oben aufgezeigten Erkenntnisse, kaum untersucht, insbesonders die pathophysiologische Rolle.

\subsubsection{Endothelin-1}

Bei den Endothelinen (ET) handelt es sich um vasoaktive Polypeptide, von denen bisher die Unterformen Endothelin-1, -2 und -3 bekannt sind. Das aus 21 Aminosäuren bestehende Endothelin-1 (ET-1) wird als die biologisch aktivste Form angesehen (Inoue et al. 1989). 1988 wurde ET-1 aus aortalen Endothelzellen von Schweinen isoliert. Es stellte sich heraus, dass es sich hierbei um einen sehr potenten Vasokonstriktor handelt, der zu Hypertension führen kann (Yanagisawa et al. 1988). Trotz der kurzen Halbwertzeit von 1 bis 2 Minuten (Weitzberg et al. 1991) hält der Effekt an Rezeptoren des Endothels wesentlich länger an, da es sich hierbei um einen irreversiblen Vorgang handelt. ET ist ein Hormon, das nur wenig oder gar nicht im Kreislauf zirkuliert. Neben dem Gefäßendothel wird ET-1 auch in anderen Geweben wie dem Herzen, der Leber oder in Astrozyten des Gehirns sezerniert (Shah 2007). ET-1 entsteht aus einem größeren Propeptid, dem präproET-1, aus dem durch proteolytische Aktivität das biologisch inaktive bigET-1 gebildet wird. Mithilfe des Endothelin-Konversionsenzyms bildet sich aus bigET-1 das ET-1 (Xu et al. 1994). Seine Wirkung besteht in einer starken Vasokonstriktion sowohl in den Arterien als auch in den Venen. Dies geschieht auf autokrinem und parakrinem Weg bei der Bindung an den $\mathrm{ET}_{\mathrm{A}}$-Rezeptor der glatten Gefäßmuskelzellen. Dadurch kommt es zu einer Erhöhung des intrazellulären Kalziumspiegels (Yanagisawa et al. 1988). Über einen an den Endothelzellen sitzenden $\mathrm{ET}_{\mathrm{B}}$-Rezeptor erfolgen zusätzlich, mittels Stickstoffmonoxid, eine Vasodilatation sowie eine positive Rückkopplung auf die Endothelsynthese. Die Wirkung des $\mathrm{ET}_{\mathrm{A}}$-Rezeptors überwiegt allerdings (Iglarz and Schiffrin 2003).

McMurray et al. konnten in einer Studie zeigen, dass bei Patienten mit einer SHF erhöhte ET-1Spiegel im Blut vorlagen (McMurray et al. 1992). Bei den dabei erhöht vorgefundenen Werten konnte nicht genau unterschieden werden, ob es sich um eine gesteigerte Synthese oder eine insuffiziente Eliminierung handelte. ET-1 hat sich bei Patienten mit einer chronischen HF bei reduzierter LVEF und NYHA III-IV weiterhin als ein unabhängiger Prädiktor der Überlebensrate herausgestellt (Van Beneden et al. 2004). In einer weiteren Studie zeigte sich, dass es sich bei BigET-1 um einen unabhängigen 
Marker der Mortalität und Morbidität handelt, der außerdem mit der NYHA-Klasse und dem Körpermasseindex (BMI) positiv korreliert (Masson et al. 2006). Ein ähnliches Ergebnis erzielten Khan et al. in einer ihrer Studien. Hier untersuchten sie die Plasmakonzentration des C-terminalen Fragments von proET-1 (CT-proET-1) und NT-proBNP bei Patienten mit einem Myokardinfarkt. Dabei stellten sich beide Werte als unabhängige Prädiktoren, der Mortalität und der Entwicklung einer HF dar (Khan et al. 2007). Auch für klinische Parameter sind Korrelationen mit ET-1 beschrieben. So fand sich zum Beispiel eine signifikante Reduktion der ET-1-Werte bei übergewichtigen Patienten nach einer Diät (Maeda et al. 2006). Weiterhin besteht eine positive Korrelation mit dem systolischen Blutdruck und linksventrikulären systolischen Druck mit BigET-1 (Bergler-Klein et al. 2006). Da es sich bei Adipositas und Hypertonie um Risikofaktoren der DHF handelt, ist eventuell auch ET-1 mit dieser verbunden.

Aufgrund der hier beschriebenen Assoziationen zwischen ET-1 und der SHF sowie einiger klinischer Parameter, könnte sich ET-1 auch in der Schweregradbestimmung und Verlaufskontrolle der DHF als nützlich erweisen.

\subsubsection{Vasopressin}

Bei dem antidiuretisches Hormon (ADH), auch Vasopressin genannt, handelt es sich um ein im Hypothalamus synthetisiertes und in der Hypophyse gespeichertes Peptidhormon. Durch einen Abfall des Blutvolumens und eine erhöhte Osmolalität wird Vasopressin freigesetzt. Auch ET-1 hat einen positiven Einfluss auf die Sekretion (Yamamoto et al. 1992). Diese Freisetzung bewirkt an der Niere eine Wasserretention und an den peripheren Gefäßen eine Vasokonstriktion. Diese wiederum führt zu einem blutdrucksteigernde Effekt (Singh Ranger 2002). Ebenfalls ist eine Hypertrophie des Herzens, bedingt durch Vasopressin, beschrieben (Tahara et al. 1998).

Vasopressin geht wie das Neurophysin II und das Copeptin aus dem präproVasopressin hervor. Das aus 39 Aminosäuren bestehende Copeptin ist der C-terminale Teil des Vorläuferhormons. Das auch CT-proAVP genannte Fragment wird im gleichen Verhältnis wie Vasopressin freigegeben (de Bree and Burbach 1998).

Ähnlich wie im Falle von ET-1 ist für Vasopressin bezüglich der SHF eine Relevanz für Diagnosestellung und eine positive Korrelation mit der Mortalität eindeutig belegt. Inwieweit diese 
Ergebnisse auch auf die DHF übertragen werden können, ist bisher unklar. In einem Kollektiv von Patienten mit LVEF $\leq 35 \%$ zeigten Francis et al., dass Patienten mit systolischer Funktionsstörung signifikant höhere Werte für Vasopressin aufwiesen als Kontrollpatienten mit normaler linksventrikulärer Funktion (Francis et al. 1990). Bei vorhandenen klinischen Symptomen einer HF wurden nochmals höhere Werte gemessen. In einer anderen Studie (Gegenhuber et al. 2007) fand ein Vergleich zwischen NT-proBNP und Copeptin bezogen auf die prognostische Relevanz der dekompensierten HF statt. Es zeigte sich, dass beide Marker im Bezug auf ihren prognostischen Wert der 1-Jahres-Mortalität vergleichbar waren. In einer Studie von Stoiser et al., in der die Mortalität von Patienten mit einer fortgeschrittenen HF und NYHA III-IV untersucht wurde, stellte sich das CTproAVP gegenüber dem NT-proBNP als ein besserer Prädiktor heraus (Stoiser et al. 2006).

Aufgrund des vasokonstriktorischen Effektes und des hier beschriebenen Zusammenhangs mit der SHF ist Vasopressin ebenfalls ein möglicher serologischer Marker der DHF.

\subsection{Therapie der diastolischen Dysfunktion und Herzinsuffizienz}

Die DHF hat trotz ihrer beträchtlichen epidemiologischen Bedeutung erst in den letzten Jahren an Aufmerksamkeit gewonnen. Dadurch sind die „evidenzbasierten Therapiestrategien“ kaum durch große randomisierte oder placebokontrollierte Studien belegt. Die obersten Therapieziele bei der DHF sind die Beschwerdelinderung und die Prognoseverbesserung. Da derzeit eine prognostische Verbesserung nicht gezeigt werden konnte, bestehen die Grundpfeiler der Therapie in der optimalen Kontrolle der individuellen Risikofaktoren. Dazu gehören Gewichtsabnahme, Raucherentwöhnung und regelmäßiges körperliches Training. Der zweite Pfeiler besteht aus der kausalen Therapie ursächlicher Grunderkrankungen wie eine optimale Einstellung der Hypertonie, des Diabetes mellitus (Iribarren et al. 2001) und eine cPAP-Beatmung beim obstruktiven Schlafapnoesyndrom (Arias et al. 2005). Bei einer koronaren Herzerkrankung kann die DD durch Verminderung der Myokardischämie mittels interventionellen oder medikamentösen Maßnahmen verbessert werden. Wenn Herzklappenvitien eine auslösende Grunderkrankung darstellen, ist die Indikation zu einer Operation oder Katheterintervention, bei einer Perikardrestriktion die Notwendigkeit einer Operation zu prüfen. Der letzte Teil der Therapie der DHF besteht aus einer individuell adaptierten, medikamentösen Therapie. Diese Langzeittherapie umfasst folgende Wirkstoffgruppen: AT1-Antagonisten und ACEHemmer (Cleland et al. 2006) werden zur Blutdruck- und Nachlastsenkung, zur Hemmung des RAAS, 
zur Regression der myokardialen Hypertrophie und Fibrose sowie zur Vorbeugung von Vorhofflimmerrezidiven (Irbesartan) und zur Reduktion der Morbidität eingesetzt. Betablocker (Bergstrom et al. 2004) unterstützen die Frequenzreduktion und Rhythmuskontrolle mit Verlängerung der Diastole, hemmen die neurohumorale Stimulierung, tragen zur Blutdrucksenkung und zur Verbesserung der endothelialen Dysfunktion (Nebivolol) bei. Auch Kalziumantagonisten unterstützen die Blutdrucksenkung, die Regression der Hypertrophie, die Frequenzreduktion und Rhythmuskontrolle (Verapamil-Typ) sowie die Myokardrelaxation. Für eine weitere Reduktion der Myokardfibrose werden Aldosteronantagonisten eingesetzt, für die Frequenzsenkung bei Vorhofflimmern setzt man auf Digitalis. Weiterhin sollte die Behandlung akut auslösender Faktoren wie Infektionen, Herzrhythmusstörungen, hypertensive Krisen und akute Anämie nach den üblichen Richtlinien erfolgen.

\subsection{Fragestellung}

Diese Arbeit beschäftigt sich im Folgenden mit den Fragen:

1. Welche Faktoren liegen dem Auftreten einer Herzinsuffizienzsymptomatik bei Patienten mit einer diastolischen Dysfunktion zugrunde?

2. Besteht ein Zusammenhang zwischen körperlicher Belastbarkeit und Schweregrad der diastolischen Dysfunktion oder neurohumoralen Aktivierung? 


\section{Patientenkollektiv und Methoden}

\subsection{Patientenkollektiv}

Das hier untersuchte Kollektiv setzt sich aus Patienten der Studien Aldo-DHF (ISRCTN 94726526), Ex-DHF (ISRCTN 42524037) und Diast-DHF zusammen. Diese Studien wurden im Rahmen des Teilprojektes 7 (TP7) „Diastolische Dysfunktion“ des Kompetenznetzes Herzinsuffizienz (www.knhi.de) durchgeführt.

Bei Aldo-DHF handelt es sich um eine prospektive klinische Studie mit der Zielsetzung, die Bedeutung einer Aldosteron-Rezeptor-Blockade mit Spironolacton auf den Verlauf einer diastolischen Herzinsuffizienz zu untersuchen. Hierfür wurden Patienten Placebo-kontrolliert über einen Nachbeobachtungszeitraum von einem Jahr behandelt. Primäre Endpunkte waren die körperliche Leistungsfähigkeit durch Quantifizierung mittels Spiroergometrie und Doppler-echokardiographische Parameter der diastolischen Funktion. Sekundäre Endpunkte waren unter anderem die Lebensqualität und die Morbidität der Studienpatienten. In der prospektiven, randomisierten und kontrollierten Studie Ex-DHF wurde untersucht, ob strukturiertes körperliches Training die Belastbarkeit, die Lebensqualität und die diastolische Funktion der Studienteilnehmer beeinflusst. Diast-DHF ist eine prospektive epidemiologische Studie. Im Rahmen dieser wurden 1937 Patienten mit kardiovaskulären Risikofaktoren nach Auftreten und Verlauf der diastolischen Herzinsuffizienz untersucht.

Das in dieser Arbeit untersuchte Patientenkollektiv setzt sich aus 201 Patienten zusammen, die in drei Gruppen unterteilt wurden. In der ersten, der Kontrollgruppe, befinden sich 75 gesunde Patienten aus der Diast-DHF-Studie. Die zweite Gruppe besteht aus 14 Patienten mit einer echokardiographisch nachgewiesenen DD ohne subjektive Belastungseinschränkungen (NYHA I). Diese Patienten stammen aus einem asymptomatischen Arm der Ex-DHF-Studie. Die dritte Gruppe setzt sich aus 112 symptomatischen Patienten (NYHA $\geq I$ ) der Aldo-DHF-Studie mit einer DHF zusammen.

Als Studienpatienten kamen Männer und Frauen zwischen 45 und 85 Jahren in Betracht. Weiteres Einschlusskriterium war eine erhaltene LVEF $>50 \%$. Alle Patienten gaben nach Aufklärung durch den Arzt ihr schriftliches Einverständnis zur Teilnahme an der Studie. Ein positives Votum der Ethikkommission der Medizinischen Fakultät der Universität Göttingen liegt bei allen Studien vor. Die 
Rekrutierung der DHF-Patienten erfolgte überwiegend durch Sichtung von echokardiographischen Vorbefunden, der kardiologischen Ambulanz der Universität Göttingen sowie einer diagnostizierten DHF in vorangegangenen Arztbriefen.

Ausschlusskriterien für die DD und DHF Patienten waren eine persistierende Lungenerkrankung mit eingeschränkter Vitalkapazität $(<80 \%)$, eine FEV1 $<80 \%$, ein $\mathrm{BMI} \geq 36 \mathrm{~kg} / \mathrm{m}^{2}$, eine in der Krankengeschichte dokumentierte systolische Herzinsuffizienz (LVEF $\leq 40 \%$ ), eine signifikante unbehandelte Koronarstenose $>50 \%$, bestehende Angina-Pectoris-Beschwerden, ein Ischämienachweis in einem durchgeführten Belastungstest, psychische Instabilität mit fehlender Compliance für die Studiendurchführung, eine bestehende oder anstehende Schwangerschaft und eine zeitgleiche Teilnahme an weiteren Studien. Da es sich bei Aldo-DHF um eine Medikamentenstudie handelt, gab es hier zusätzliche Ausschlusskriterien, wie eine bekannte Unverträglichkeit gegenüber Aldosteronantagonisten, bekannte Kontraindikationen für die Einnahme von Spironolacton (Kalium $\geq 5,1 \mathrm{mmol} / \mathrm{l}$, Hämoglobin $\leq 11 \mathrm{~g} / \mathrm{dl}$, Hämatokrit $\leq 33 \%$, Kreatinin $>1,8$ $\mathrm{mg} / \mathrm{dl}$ ), eine signifikante Hypotonie ( $R R<90 \mathrm{mmHg}$ systolisch und/oder $<50 \mathrm{mmHg}$ diastolisch), eine wechselnde Medikation zwei Wochen vor Studieneinschluss, ein insulinabhängiger Diabetes mellitus mit stattgehabter Ketoacidose, sowie eine Behandlung mit Aldosteronrezeptor-Antagonisten in den vergangenen drei Monaten (Edelmann et al. 2010).

Da alle Studien anhand der Einschlusskriterien und Messparametern ein ähnliches Studienprotokoll aufweisen ist ein Vergleich der einzelnen Patientenkollektive sehr gut möglich. Lediglich die maximale Belastung mittels Spiroergometrie wurde bei der Diast-DHF-Studie nicht durchgeführt.

\subsection{Anamnese}

Von jedem Patienten wurde eine ausführliche Anamnese erhoben. Diese umfasste sowohl die Krankengeschichte als auch die aktuelle Symptomatik. Anschließend wurden eine Familien- und Sozialanamnese sowie die Lebensqualität des Patienten anhand eines standardisierten Fragebogens in Erfahrung gebracht. An aktuellen klinischen Symptomen und Zeichen der Herzinsuffizienz wurden Belastungs-, Ruhe-, paroxysmale nächtliche Dyspnoe sowie Orthopnoe, nächtlicher Husten, Müdigkeit/Leistungsschwäche und Nykturie erfragt. Die Patienten wurden auch zur Anzahl der Kontakte zum Hausarzt, zum Kardiologen, zu Krankenhaus- und stationären Reha- oder Kuraufenthalten in den letzten zwölf Monaten aufgrund einer bestehenden Herzinsuffizienz befragt. 
Weiterhin wurden kardiovaskuläre Risikofaktoren wie Diabetes mellitus, ein bekannter Hypertonus, Hyperlipidämie, Hyperurikämie, ein Schlafapnoesyndrom, eine Raucheranamnese und der Alkoholkonsum in Drinks per week in Erfahrung gebracht. Zu den anamnestischen Angaben gehörten auch die bisher durchgeführten kardiovaskulären Interventionen wie koronare oder periphere Revaskularisationen, Bypass-, Herzklappen- oder sonstige Gefäßoperationen. Auch Schrittmacher, Herztransplantationen und stattgefundene Reanimationsmaßnahmen wurden erfragt. Die Patienten wurden außerdem gebeten, über eventuelle Nebendiagnosen Auskunft zu geben. Im Detail handelte es sich hierbei um die pAVK inklusive klinischem Stadium, zerebrovaskuläre Erkrankungen wie die transitorisch ischämische Attacke (TIA) oder Apoplex, chronisch obstruktive Lungenerkrankungen, primäre pulmonale Hypertonie, Infektionskrankheiten wie HIV oder Hepatitis B/C, Depression, Leberzirrhose und maligne Erkrankungen. In der Familienanamnese wurde die Anzahl der noch lebenden Angehörigen (1. Grades) mit oder ohne Myokardinfarkt (MI) vor dem 60. Lebensjahr ermittelt. Bei Frauen wurde zusätzlich eine orientierende gynäkologische Anamnese erhoben, mit Fragen über den Zeitpunkt der Menarche und der Menopause, die Anzahl der Schwangerschaften und Lebendgeburten, die Zyklusregelmäßigkeit und die bisherigen gynäkologischen Operationen. Die aktuelle Medikation wurde mit dem Wirkstoffnamen und der Dosis in mg pro Tag erfasst.

\subsection{Klinische Untersuchung}

Bestandteile der klinischen Untersuchungen waren die Messung der Körpergröße, des Gewichtes, des Blutdruckes, der Herzfrequenz sowie die Messung des Umfanges der Taille und der Hüfte. Bei der weiteren orientierenden Untersuchung wurden besonders auf periphere Ödeme, Halsvenenstauung, pulmonale Rasselgeräusche, einen hepatojugulären Reflux, Hepatomegalie, Aszites und pathologische Herztöne geachtet. Durch eventuell vorhandene Krankenakten und Röntgen- Thorax- Befunden wurden weitere Zeichen der Herzinsuffizienz wie Lungenödem, -stauung, Pleuraerguss oder eine Kardiomegalie erfasst.

Mit Hilfe dieser erhobenen Werte und Angaben aus der Anamnese, beurteilte der Untersucher das etwaige Vorliegen einer symptomatischen Herzinsuffizienz anhand der Major- und Minor-Kriterien der Framingham-Definition (Ho et al. 1993). Die Voraussetzung für die Diagnose einer HF war das Vorliegen von mindestens einem Major-Kriterium oder zwei Minor-Kriterien. 


\subsection{Basislabordiagnostik}

Neben speziellen Analysen zu den neurohumoralen Laborparametern wurde von jedem Patienten ein Basislabor bestimmt. Dazu gehörten Hämoglobin, Hämatokrit, Leukozyten- und Thrombozytenzahl. Weiterhin wurden Serumkreatinin, Harnsäure, Natrium und Kalium, alkalische Phosphatase, das Gesamtcholesterin mit seinen Unterformen LDL-, HDL- Cholesterol und Triglyceride sowie die Leberwerte Aspartat-Aminotransferase (AST), Alanin-Aminotransferase (ALT), Bilirubin und GammaGlutamyl-Transferase ( $\mathrm{Y}-\mathrm{GT})$ erfasst. An speziellen Werten wurde das Glykohämoglobin $\left(\mathrm{HbA}_{1 \mathrm{c}}\right)$ bestimmt. Die glomeruläre Filtrationsrate (GFR) wurde nach der vereinfachten Formel der MDRDStudie von (Levey et al. 1999)) berechnet: GFR (ml/min/1,73m2) $=186 \times$ Serum-Kreatinin $^{-1,154} \times$ Alter $^{-}$ ${ }^{0,203}$ [x 0,742 nur bei Frauen] [x 1,21 bei Patienten mit schwarzer Hautfarbe].

\subsection{Elektrokardiogramm}

Es wurde über bipolare Extremitätenableitungen ein Elektrokardiogramm nach Einthoven abgeleitet. Die drei Elektroden wurden proximal der beiden Handgelenke und oberhalb des linken Knöchels angelegt. Zusätzlich wurden die unipolaren Extremitätenableitungen nach Goldberger erfasst, die in der Mitte zwischen den Einthoven-Ableitungen liegen. Aufgezeichnet wurden aVR, aVL und aVF. Weiterhin wurden die unipolaren präkordialen Ableitungen nach Wilson angelegt (V1-V6). Der Papiervorschub hatte eine Geschwindigkeit von $50 \mathrm{~mm} / \mathrm{s}$.

Die Auswertung beinhaltete neben der Frequenz und dem Rhythmus die Bestimmung der PQ- und QT-Zeit sowie der QRS-Dauer. Ferner wurde das EKG auf eventuelle Blockbilder wie Atrioventrikuläre- oder Schenkelblöcke untersucht.

\subsection{6-Minuten-Gehtest}

Der 6-Minuten-Gehtest (6MGT) ist ein submaximaler Belastungstest und gilt als ein einfach durchzuführendes, aber dennoch valides Mittel, um die Leistungsfähigkeit und auch die Prognose von Patienten mit Herzinsuffizienz abschätzen zu können (Guyatt et al. 1985). Bei Standardisierung ist er ein sehr gut reproduzierbarer Test (Demers et al. 2001). Auch zur Abschätzung von Morbidität und Mortalität kann der 6-Minuten-Gehtest ein geeignetes Mittel sein (Bittner et al. 1993). 
Bei der Gehstrecke handelte es sich um einen 100 Meter langen, gerade ausgerichteten sowie ebenen Flur. Die Patienten konnten ihre Gehgeschwindigkeit selbstständig bestimmen und gegebenenfalls die für sie nötigen Pausen einlegen. Alle 20 Meter waren entlang der Gehstrecke Sitzmöglichkeiten aufgestellt.

Die Patienten wurden aufgefordert, innerhalb von sechs Minuten die für sie größtmögliche Strecke zurückzulegen, ohne dabei zu rennen oder zu joggen, ein Fuß sollte stets den Boden berühren. Bei beispielsweise akuter Belastungsdyspnoe konnten die Patienten den Gehtest vorzeitig beenden. Dies wurde dann mit der genauen Abbruchzeit dokumentiert. Die Patienten wurden während der Testphase ermutigt, sobald sie sich physisch wieder dazu im Stande fühlten, den Test fortzusetzen. Während der eventuellen Pausen wurde die Zeit nicht angehalten. Der Versuchsleiter teilte dem Patienten alle zwei Minuten die verbleibende Zeit mit und ca. alle 30 Sekunden wurde der Patient verbal angefeuert. Dafür waren ausschließlich folgende Formulierungen vorgesehen: „Das machen Sie gut.“ und „Immer weiter so!“.

Der Untersucher blieb während dem gesamten Versuchsablauf in der Mitte der Teststrecke stehen, um das Ergebnis nicht zu beeinflussen. Nach Ablauf der Zeit wurde die zurückgelegte Distanz auf ganze Meter gerundet und dokumentiert. Zusätzlich wurde der Grund eines eventuellen Abbruches dokumentiert, beispielsweise Dyspnoe oder allgemeine Erschöpfung. Vor und nach dem Gehtest wurden der Blutdruck und die Herzfrequenz des Patienten gemessen. Zusätzlich wurde direkt nach den sechs Minuten die Borg-Skala abgefragt (Tabelle 2).

\subsection{Herzkatheteruntersuchung}

Im Fall von in der Vergangenheit durchgeführten Herzkatheterunteruntersuchungen erhob der Untersucher, sofern sie verfügbar waren, einige Daten der letzten Interventionen. Dazu gehörten bei einer Linksherzkatheteruntersuchung die linksventrikuläre Ejektionsfraktion und der linksventrikuläre enddiastolische Druck (LVEDP). Des Weiteren wurden der Grad einer eventuell vorhandenen koronaren Herzkrankheit sowie das Vorliegen von Sklerosen dokumentiert. Auch unbehandelte Stenosen (>50\%), entnommene Biopsien und ein durchgeführter Rechtsherzkatheter wurden erfasst. 


\subsection{Echokardiographie}

Im Rahmen der Aldo-DHF-, EX-DHF- und Diast-DHF-Studie wurde bei jedem Patienten ein standardisiertes transthorakales, zweidimensionales Echokardiogramm durchgeführt. Grundlage dafür waren die Echokardiographie-Richtlinien des Kompetenznetzes Herzinsuffizienz (Version vom 21.11.2003). Jede Untersuchung wurde auf einem Videoband fortlaufend gespeichert, alternativ konnten für jede Einstellung 2 EKG-Zyklen auf einer „Optical Disk“ aufgezeichnet werden. Von jeder Einstellung, die Messwerte enthält, existiert ein aussagekräftiger Ausdruck. Die Messungen erfolgten in Linksseitenlage des Patienten.

Die SHF wurde mit einer LVEF $<50 \%$ bestimmt nach Simpson und, oder anomalen Wandbewegungen zweier benachbarter Segmente definiert. Alle Patienten mit bestehender systolischer Herzinsuffizienz wurden von der Studie ausgeschlossen. Die DHF wurde unter nachstehenden Gesichtspunkten festgestellt und in vier Schweregrade eingeteilt. Das normale Füllungsmuster (Schweregrad 0) besitzt Kennzeichen eines normalen linksventrikulären Einstroms und Pulmonalvenenflusses. Gemessen wird das Verhältnis der maximalen frühdiastolischen Einstromgeschwindigkeit zur Einstromgeschwindigkeit nach der Vorhofkontraktion über der Mitralklappe $(E / A) \geq 1$. Außerdem mussten alle drei der folgenden Kriterien erfüllt sein: Verhältnis des maximalen systolischen zum maximalen diastolischen pulmonalvenösen Fluss $(S / D) \geq 1$, Verhältnis der maximalen frühdiastolischen Einstromgeschwindigkeit über der Mitralklappe zur frühdiastolischen maximalen Geschwindigkeit des Mitralklappenringes im Gewebedoppler $\left(E / e^{\prime}\right)<10$ und das Verhältnis der maximalen frühdiastolischen Einstromgeschwindigkeit zur Einstromgeschwindigkeit nach der Vorhofkontraktion über der Mitralklappe während des Valsalvamanövers $\left(E / A_{\text {Valsalva }}\right) \geq 1$.

Der Schweregrad I, die verzögerte Relaxation, ist mit $E / A<1$ definiert. Es überwiegt dabei die Einstromgeschwindigkeit nach der Vorhofkontraktion gegenüber der maximalen frühdiastolischen Einstromgeschwindigkeit.

Der Schweregrad II der Pseudonormalisierung zeichnet sich durch ein E/A-Verhältnis $\geq 1$ und $<2$ sowie eines der drei folgenden Kriterien aus: Verhältnis des maximalen systolischen zum maximalen diastolischen pulmonalvenösen Fluss $(S / D)<1$, Verhältnis der maximalen frühdiastolischen Einstromgeschwindigkeit über der Mitralklappe zur frühdiastolischen maximalen Geschwindigkeit des Mitralklappenringes im Gewebedoppler $\left(E / e^{c}\right) \geq 10$ und das Verhältnis der maximalen frühdiastolischen 
Einstromgeschwindigkeit zur Einstromgeschwindigkeit nach der Vorhofkontraktion über der Mitralklappe während des Valsalvamanövers $\left(E / A_{\text {Valsalva }}\right)<1$.

Das restriktive Füllungsmuster fasst die Schweregrade III und IV zusammen. Es liegt vor, wenn E/A $\geq 2$ und eines der zwei folgenden Kriterien erfüllt ist: Verhältnis des maximalen systolischen zum maximalen diastolischen pulmonalvenösen Fluss $(S / D)<1$, Verhältnis der maximalen frühdiastolischen Einstromgeschwindigkeit über der Mitralklappe zur frühdiastolischen maximalen Geschwindigkeit des Mitralklappenringes im Gewebedoppler $\left(E / e^{\prime}\right) \geq 10$. Mittels des Valsalva-Manövers gelingt schließlich die Einteilung in die Schweregrade III und IV. Wenn $E / A_{\text {Valsalva }}<1$ ist, handelt es sich um ein reversibles restriktives Füllungsmuster (Grad III). Ein irreversibles restriktives Füllungsmuster (Grad IV) liegt vor, wenn $E / A_{\text {Valsalva }} \geq 1$ ist. Zur Durchführung des Valsalva-Manövers wird der Patient gebeten, nach tiefer Inspiration eine Bauchpresse durchzuführen und bei geschlossener Glottis die Exspirationsmuskulatur anzuspannen. Durch diese Druckerhöhung in Thorax und Abdomen wird der venöse Rückfluss zum Herzen und damit das Schlagvolumen stark reduziert.

Tabelle 1: Einteilung des Schweregrades der diastolischen Dysfunktion nach KNHI TP 7

\begin{tabular}{|c|c|c|c|c|}
\hline $\begin{array}{l}\text { Diastolische } \\
\text { Funktion }\end{array}$ & $\begin{array}{l}\text { Normal } \\
\text { Grad } 0\end{array}$ & $\begin{array}{c}\text { Verzögerte } \\
\text { Relaxation } \\
\text { Grad I }\end{array}$ & $\begin{array}{c}\text { Pseudonormale } \\
\text { Füllung } \\
\text { Grad II }\end{array}$ & $\begin{array}{c}\text { Restriktion } \\
\text { reversibel/irreversibel } \\
\text { Grad III/IV }\end{array}$ \\
\hline \multirow[t]{2}{*}{$E / A$} & $\geq 1$ & $<1$ & $\geq 1$ und $<2$ & $\geq 2$ \\
\hline & $\begin{array}{c}\text { sowie } 3 \text { von } \\
3 \text { Kriterien }\end{array}$ & & $\begin{array}{c}\text { sowie } 2 \text { von } 3 \\
\text { Kriterien }\end{array}$ & $\begin{array}{c}\text { sowie } 1 \text { von } 2 \\
\text { Kriterien } \\
\text { UND } \\
\text { Valsalva }\end{array}$ \\
\hline $\mathrm{E} / \mathrm{e}^{\prime}$ & $<10$ & & $\geq 10$ & $\geq 10$ \\
\hline $\mathrm{PV}: \mathrm{S} / \mathrm{D}$ & $\geq 1$ & & $<1$ & $<1$ \\
\hline E/A valsalva & $\geq 1$ & & $<1$ & $\geq 1$ \\
\hline
\end{tabular}




\subsection{Spiroergometrie}

Zur Bewertung des kardiopulmonalen Systems ist die Spiroergometrie eine anerkannte und objektive Untersuchung. Die Ergebnisse bieten eine präzise Aussage über die aerobe und anaerobe Belastbarkeit der Patienten (Fletcher et al. 2001).

Die Spiroergometrie wurde mittels eines individuell angepassten Fahrradergometers durchgeführt. Wie der Blutdruck wurde auch das gemäß den Standards der American Heart Association angebrachte EKG während der Spiroergometrie durch einen Arzt am Monitor überwacht und in jeder Belastungsstufe einmal ausgedruckt. Der Blutdruck wurde regelmäßig alle 2 Minuten gemessen.

Der gesamte Testvorgang begann mit dem Messen und Wiegen des Patienten sowie der Gas- und Volumeneichung des Spirometers. Das Testprotokoll startet bei 20 Watt und erhöht sich alle zwei Minuten um weitere 20 Watt. Der Monitor zeigte zur Überwachung folgende Werte im zehn-SekundenMittel an: Arbeitslast (Watt), $\mathrm{VO}_{2}$ (Sauerstoffaufnahme, $\mathrm{ml} / \mathrm{min}$ ), $\mathrm{VO}_{2} / \mathrm{kg}$ (Sauerstoffaufnahme, $\mathrm{ml} / \mathrm{kg} / \mathrm{min}$ ), $\mathrm{VCO}_{2}$ (Kohlendioxidabgabe, $\mathrm{ml} / \mathrm{min}$ ), $\mathrm{RQ}$ (respiratorischer Quotient), $\mathrm{VCO} 2 \mathrm{NO}$, Herzfrequenz, VE (Atemminutenvolumen), VE/ $\mathrm{VCO}_{2}, \mathrm{VE} / \mathrm{VO}_{2}, \mathrm{AZV}$ (Atemzugvolumen), AF (Atemfrequenz) und RR (Blutdruck).

Nachdem der Patient auf dem Ergometer Platz genommen hatte, wurde inm die Atemmaske aufgesetzt und sichergestellt, dass diese dicht ist. Das 12-Kanal-EKG wurde angelegt und der Gasaustausch des Patienten in Ruhe über vier Minuten kontrolliert. Die Testvoraussetzungen waren erfüllt, wenn der RQ des Patienten weniger als 1 betrug und das Atemminutenvolumen zwischen 10 und $15 \mathrm{l} / \mathrm{min}$ lag. Die Übungsperiode begann sobald der Patient eine Trittfrequenz von 60 Umdrehungen/min bei 20 Watt erreicht hatte und die Geschwindigkeit für die Dauer des Tests konstant beibehalten wurde. Alle zwei Minuten, am Ende jeder Belastungsstufe, wurden Herzfrequenz und Blutdruck gemessen sowie die Borg-Skala abgefragt. Der Patient wurde während der gesamten Untersuchung intensiv ermuntert, so lang wie möglich durchzuhalten. Während der letzten 30 Sekunden der Untersuchung sollte ein $R Q>1$ erreicht worden sein, um die Kriterien einer Ausbelastung zu erfüllen. Falls der Patient mit einem RQ über 1 begonnen hatte, reichte es aus, dass der RQ um 0,3 Einheiten gegenüber dem Ruhezustand anstieg. Die Spiroergometrie wurde solange durchgeführt bis der Patient subjektive oder objektive Kriterien der Ausbelastung erfüllte, die zu einer Beendigung des Tests berechtigen. Zu diesen Kriterien zählte eine maximale Erschöpfung, ein 
Blutdruckabfall um 20mmHg nach zwei Messungen sowie die Einschätzung des zuständigen Arztes. Außerdem Thoraxschmerzen, extreme Dyspnoe, drei oder mehr ventrikuläre Extrasystolen in Folge oder ein RR systolisch> 240mmHg. Direkt nach Beendigung des Testes wurde erneut die Borg-Skala abgefragt. In der darauffolgenden sechsminütigen Erholungsphase wurde die Spirometrie fortgeführt.

Tabelle 2: Borg- Skala

\begin{tabular}{|l|l|}
\hline 0 & überhaupt keine Atemnot \\
\hline 0,5 & sehr, sehr milde (knapp wahrnehmbar) \\
\hline 1 & sehr milde \\
\hline 2 & Milde \\
\hline 3 & Mäßig \\
\hline 4 & recht schwer \\
\hline 5 & Schwer \\
\hline 6 & \\
\hline 7 & sehr schwer \\
\hline 8 & \\
\hline 9 & sehr, sehr schwer (fast maximal) \\
\hline 10 & maximale Atemnot \\
\hline
\end{tabular}

\subsection{Spezielle Laboranalytik}

\subsubsection{Blutproben}

Die Blutabnahme erfolgte im nicht nüchternen Zustand nach einer circa 30-minütigen Ruhephase im Liegen. Für die Analysen wurde ausschließlich das Plasma von in EDTA-Röhrchen gefülltem Blut verwendet. Nach Abnahme der Proben wurden diese umgehend mit der Eppendorf Centrifuge 5702R für zehn Minuten zentrifugiert, der Überstand abpipettiert und bei $-80^{\circ} \mathrm{C}$ eingefroren. Ein Auftauen und erneutes Einfrieren wurde bis zur endgültigen Analyse durch die Universitätsmedizin Göttingen im Falle von NT-proBNP beziehungsweise bei den restlichen Markern durch die Firma B.R.A.H.M.S. AG Hennigsdorf vermieden. Während der Transporte wurde die Aufrechterhaltung der Kühlkette gewährleistet. 


\subsubsection{Bestimmung des Brain Natriuretic Peptids und NT-proBNP}

Zur Bestimmung der NT-proBNP-Werte in der Universitätsmedizin Göttingen kam der Elecsys ${ }^{\circledR}$ proBNP-Test der Firma Roche Diagnostics zum Einsatz. In diesem nichtkompetitiven Elektrochemilumineszenz-Immunoassy wurden spezifische polyklonale Antikörper gegen definierte Regionen des Peptids verwendet. Diese definierten Regionen sind neben dem N-terminalen Epitop der Aminosäuren 1-21 die zentralen Aminosäuren 39-50 (Karl et al. 1999). In einer Studie von (Mueller et al. 2003) zeigte der Test die Tendenz zu niedrigeren Werten als ein ähnlicher Test der Firma Biomedica. Dieses Phänomen wurde deutlicher, je höher die Konzentration des NT-proBNP war. Die Autoren erklärten dieses Ergebnis damit, dass durch die Bindung an zwei Epitope kleinere und unvollständige Fragmente im zu analysierenden Medium nicht erfasst werden.

\subsubsection{Bestimmung des Atrialen Natriuretischen Peptids und MR -proANP}

Aufgrund der kurzen Halbwertszeit des Atrialen Natriuretischen Peptids (ANP) gab es Bestrebungen, Antikörper gegen Teile des langlebigeren Prohormons, proANP, einzusetzen. So wird in dieser Arbeit ein immunoluminometrischer Assay der Firma B.R.A.H.M.S. Hennigsdorf verwendet. Die Antikörper des SERISTRA® genannten Tests sind gegen die Aminosäuren 53-90 in der mittleren Region des proANP gerichtet (Morgenthaler et al. 2004). Dabei reagiert der an das Gefäß gebundene polyklonale Antikörper mit der Region der Aminosäuren 73-90 des proANP während der als Marker fungierende polyklonale Antikörper gegen die Regionen 52-73 gerichtet ist.

Bei einer Messbreite von 9,6-313 pmol/l ermittelte der Hersteller bei gesunden Probanden einen Medianwert von 45 pmol/l. Ein signifikanter Unterschied zwischen Männern und Frauen war nicht feststellbar (Morgenthaler et al. 2004). 


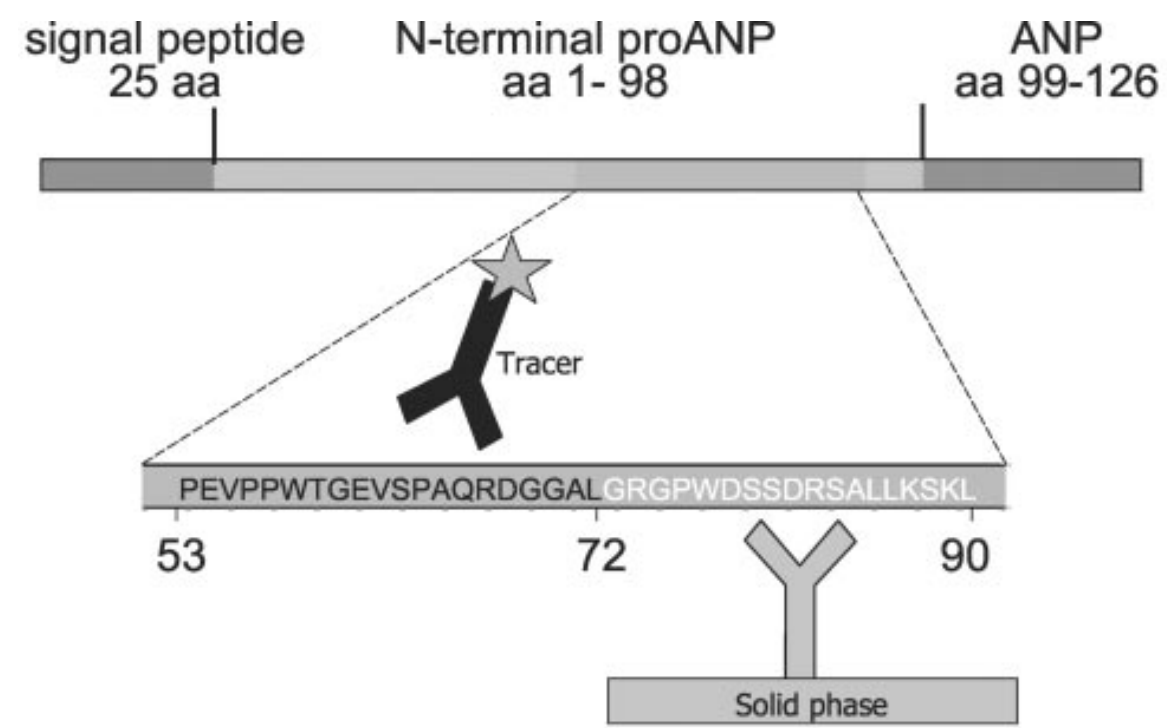

Abbildung 1: Der obere Teil zeigt das proANP, in der Mitte ist die Region der Aminosäuren 53$90 \mathrm{zu}$ sehen, die als Angriffspunkt der Antikörper dient. Mit „tracer“ ist der markierte Antikörper bezeichnet, während „solid phase“ den an das Gefäß gebundenen Antikörper darstellt (Morgenthaler et al. 2004).

\subsubsection{Bestimmung von Adrenomedullin und MR-proADM}

Die Bindung an den Komplementfaktor H (Pio et al. 2001) und die sehr kurze Halbwertzeit von ca. 22 Minuten (Meeran et al. 1997) erschweren die exakte Bestimmung von Adrenomedulin erheblich. Bei der Synthese des Hormons entsteht stöchiometrisch aus dem Vorläufer präpro-Adrenomedullin das pro-Adrenomedullin (proADM). Die mittlere Region des pro-Adrenomedullins, das MR-proADM, ist das Ziel des in dieser Arbeit verwendeten immunoluminometrischen Assays. Bisher ist keine physiologische Funktion des MR-proADM bekannt, es weist allerdings eine wesentlich höhere Stabilität als Adrenomedullin auf. Der Test zur Bestimmung von MR-proADM im EDTA-Plasma wird von der Firma B.R.A.H.M.S. Hennigsdorf als SEVADIL LIA® bezeichnet. Die darin enthaltenen, mit einem zusätzlichen N-terminalen Cysteinrest versehenen Antikörper sind gegen die Aminosäuren 68-86 beziehungsweise 83-94 des pro-Adrenomedullins gerichtet. Der Messbereich des Tests erstreckt sich von 0,12 bis $25 \mathrm{nmol} / \mathrm{l}$ bei einer Sensitivität von $0,12 \mathrm{nmol} / \mathrm{l}$. Auch gesunde Probanden weisen messbare Werte für MR-proADM auf (Morgenthaler et al. 2005). 


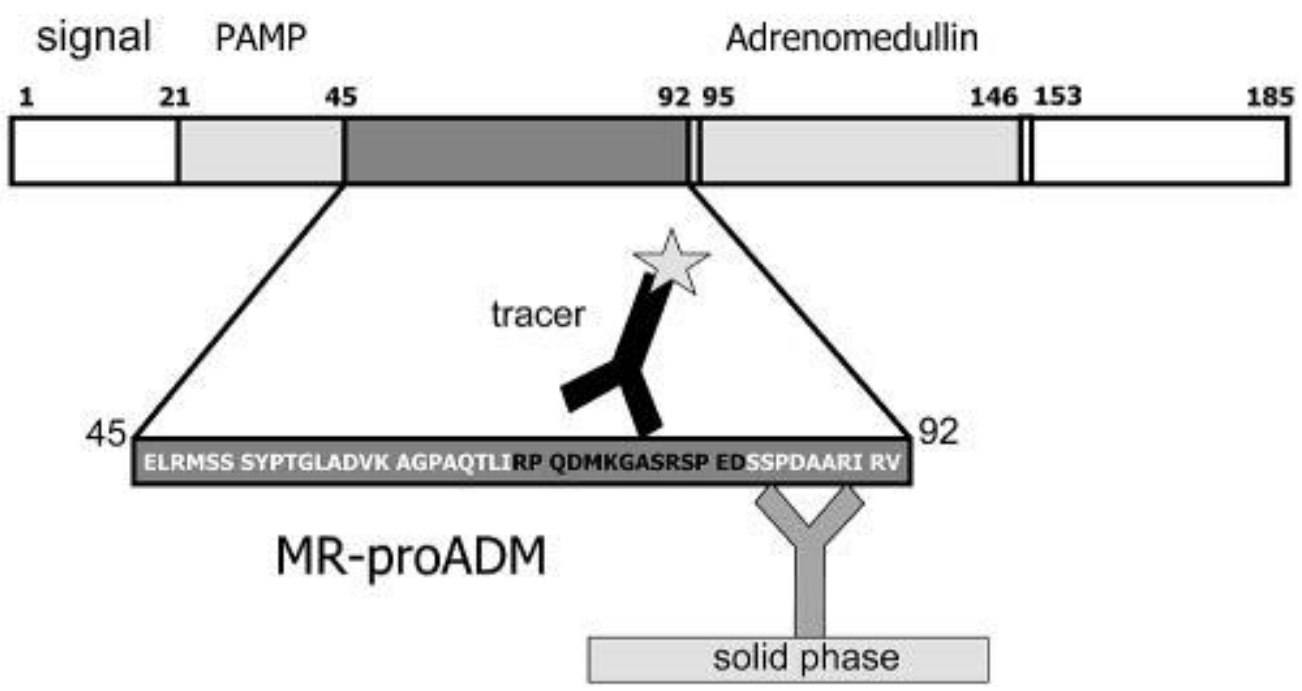

Abbildung 2: Struktur des präpro-Adrenomedullins. MR-proADM kennzeichnet den mittelregionalen Teil des entstehenden pro-Adrenomedullin. (Morgenthaler et al. 2005)

\subsubsection{Bestimmung von Endothelin-1 und CT -proET-1}

Durch die geringe Halbwertszeit von Endothelin-1 von nur ein bis zwei Minuten (Weitzberg et al. 1991) sowie anderen Faktoren, zum Beispiel der schnelle Umsatz des Hormons, ist die Bestimmung von Endothelin schwierig. Außerdem bindet Endothelin vorwiegend an Rezeptoren, die in der Nähe des eigenen Sezernierungsortes liegen. Es ist also kein Hormon, das den kompletten Kreislauf durchläuft (Masaki 2004). Dies erschwert eine Messung, die Rückschlüsse auf die tatsächliche Synthesemenge erlaubt, zusätzlich. Deshalb wird in dieser Arbeit die Messung des C-terminalen Fragments von ET-1 bestimmt, genannt CT-proET-1. Das Fragment unterliegt im Gegensatz zu ET-1 und bigET-1 keinem schnellen Umsatz (Struck et al. 2005).

In dieser Arbeit kommt ein Verfahren der Firma B.R.A.H.M.S AG Hennigsdorf zum Einsatz, genannt B.R.A.H.M.S. SEVACON LIA®. Hierbei handelt es sich um einen Sandwich-Assay, der zwei polyklonale Antikörper gegen die Aminosäuren 168-212 des präpro-ET-1 verwendet. Der als Tracer bezeichnete markierte Antikörper bindet dabei an die Aminosäuren 168-181 des präpro-ET-1, während der feste Antikörper an den Aminosäuren 200-212 angreift.

Bei gesunden Probanden fanden sich Werte zwischen 10,5 und 77,4 pmol/l. Bei Patienten mit chronischer HF oder Sepsis erhöhten sich diese Werte deutlich. Der Mittelwert lag bei gesunden Kontrollprobanden bei 44,3 pmol/l (Papassotiriou et al. 2006). 


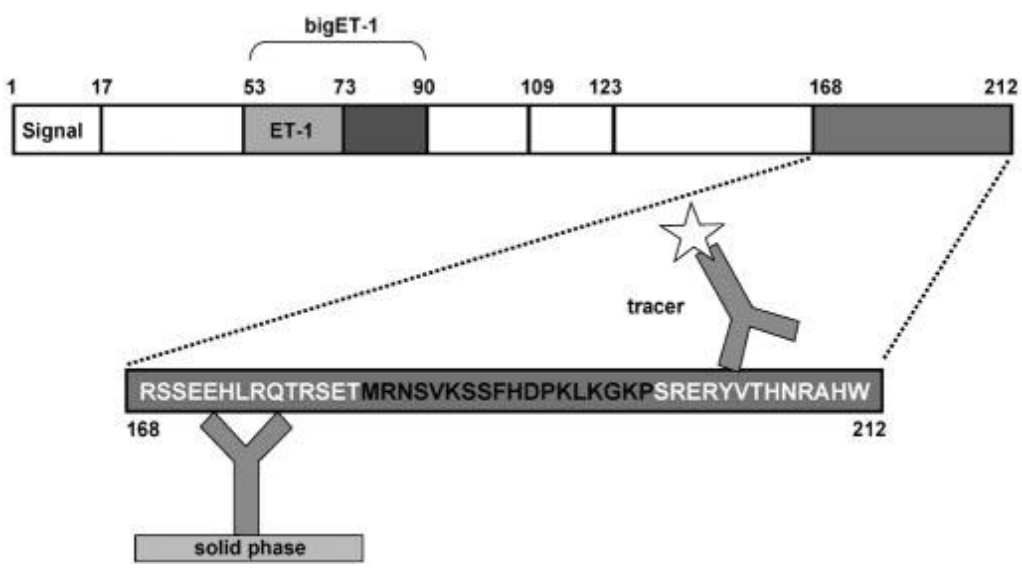

Abbildung 3: Assayprinzip zum Nachweis von CT-proET-1. (Papassotiriou et al. 2006)

\subsubsection{Bestimmung von Vasopressin und CT-proAVP}

Auch bei Vasopressin findet man das Problem der Instabilität und der schnellen Eliminierung, wenn die Konzentration im Blut gemessen werden soll. Des Weiteren liegt Vasopressin im Blutplasma mit bis zu 90\% an Thrombozyten gebunden vor (Preibisz et al. 1983). Daher wird in dieser Arbeit das Copeptin als stöchiometrisches Äquivalent des ADH gemessen. Copeptin repräsentiert die Sezernierung von Vasopressin (Morgenthaler et al. 2006). Dabei handelt es sich um den insgesamt 39-Aminosäuren-umfassenden C-terminalen Teil des Vorläuferhormons von Vasopressin. Aus diesem Grund wird auch die Bezeichnung CT-proAVP verwendet.

Für die Bestimmung der Werte in dieser Arbeit wurde ebenfalls ein Sandwich-Assay der Firma B.R.A.H.M.S. AG Hennigsdorf verwendet. Dabei kamen zwei polyklonale Antikörper zum Einsatz, die gegen die Regionen der Aminosäuren 132-164 des präproVasopressins gerichtet sind. Der Antikörper anti-PLAY17 ist gegen die Region 149-164 gerichtet und stellt den markierten Antikörper dar. Der gegen die Region 132-147 gerichtete Antikörper anti-PATV17 wird an die Röhrchenwand gebunden.

Der Messbereich wird vom Hersteller mit 2,25 bis $1215 \mathrm{pmol} / \mathrm{l}$ angegeben. In Voranalysen betrug der Median für gesunde Probanden 4,2 pmol/l. Dieser Wert ist ähnlich dem von (Robertson et al. 1973) berichteten Wert für Vasopressin. 
pre-provasopressin

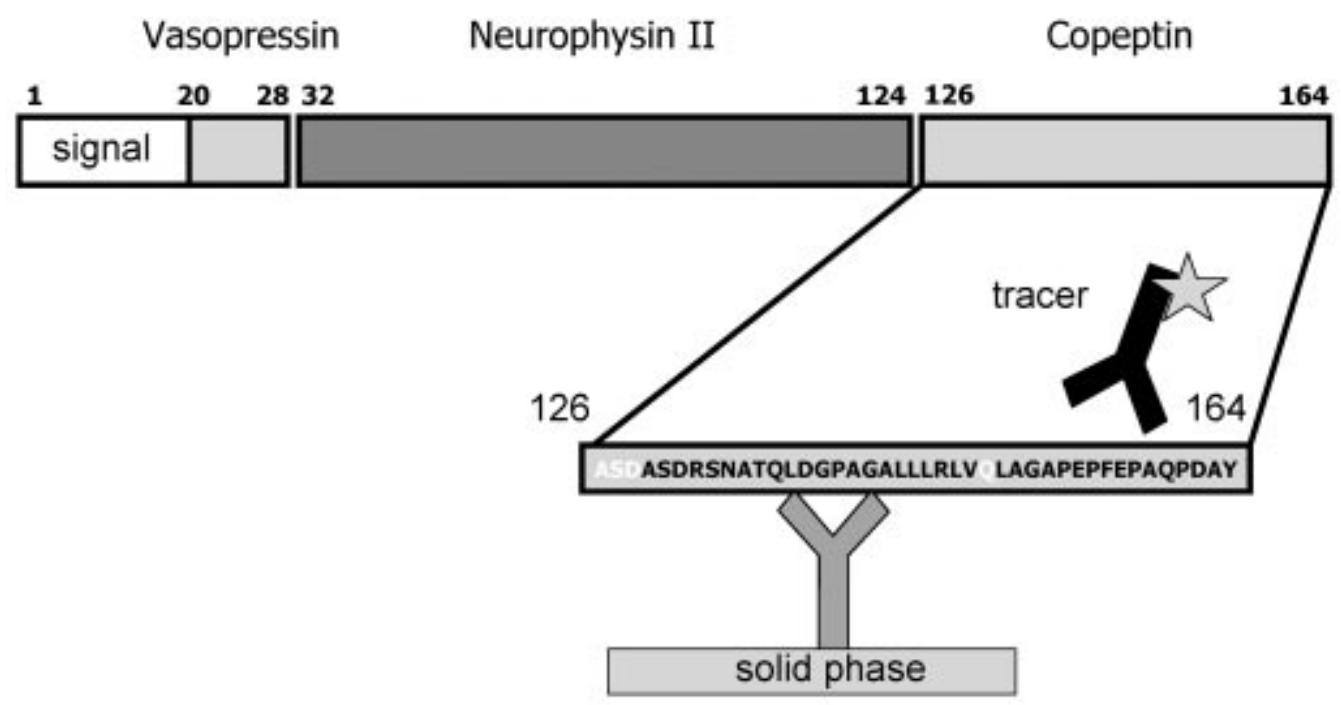

Abbildung 4: Struktur des präpro-Vasopressins mit Verdeutlichung des Assays. (Morgenthaler et al. 2006) 


\section{Ergebnisse}

\subsection{Deskriptive Statistik des Patientenkollektivs}

\subsubsection{Grundlegende Patientendaten}

In den Tabellen dieses Abschnittes sind die grundlegenden Charakteristika des untersuchten Patientenkollektivs aufgeführt. Insgesamt setzt sich das Kollektiv aus 201 Patienten zusammen, die in drei Gruppen unterteilt wurden. Bei der ersten Gruppe handelt es sich um eine 14-Patienten-starke Gruppe mit einer echokardiographisch nachgewiesenen diastolischen Dysfunktion (DD) ohne subjektive Belastungseinschränkung (NYHA I). In einer zweiten Gruppe befinden sich 112 Patienten mit einer bestehenden diastolischen Herzinsuffizienz (DHF) und vorhandenen klinischen Symptomen im Sinne von NYHA II-III. Zusätzlich wurde eine gesunde Kontrollgruppe (KG) mit 75 Probanden für die Vergleichbarkeit der neurohumoralen Aktivierung generiert.

In dem DD- und DHF-Kollektiv ist die Geschlechterverteilung mit 61 männlichen $(48,4 \%)$ und 65 weiblichen (51,6\%) Patienten annähernd ausgeglichen.

Tabelle 3: Klinische Charakterisierung des Patientenkollektivs

KG DD DHF

\begin{tabular}{llll}
\hline Anzahl (n) & 75 & 14 & 112 \\
Männlich & 27 & 10 & 61 \\
Weiblich & 48 & 4 & $65,4( \pm 7,6)^{\$ \otimes \diamond 0}$ \\
Alter (Jahre) & $55,8( \pm 6,4)$ & $57,9( \pm 5,6)$ & $169,0( \pm 10,7)$ \\
Größe (cm) & $168,6( \pm 16,0)$ & $174,5( \pm 7,2)$ & $87,1( \pm 15,7)$ \\
Gewicht (kg) & $71,1( \pm 14,3)$ & $92,2( \pm 19,7)$ & $30,4( \pm 4,4)$ \\
BMI (kg/m $\left.{ }^{2}\right)$ & $26,4( \pm 15,8)$ & $30,1( \pm 5,2)$ & $144,2( \pm 21,8)^{\$ \$ \$}$ \\
& $126,41( \pm 14,8)$ & $138,2( \pm 15,1)$ & \\
RR syst. (mmHg) & & & \\
\hline
\end{tabular}




\begin{tabular}{llll}
\hline RR diast. (mmHg) & $77,0( \pm 8,6)$ & $88,6( \pm 9,9)$ & $83,5( \pm 12,2)^{\$ \$}$ \\
HF (/min) & $69,2( \pm 8,5)$ & $69,9( \pm 7,6)$ & $68,3( \pm 12,3)$ \\
NYHA I (n=) & 0 & 14 & 0 \\
NYHA II (n=) & 0 & 0 & 93 \\
NYHA III (n=) & 0 & 0 & 19
\end{tabular}

${ }^{*} p<0,05,{ }^{* *} p<0,01,{ }^{\star * *} p<0,001$ KG vs. DD, ${ }^{\$} p<0,05,{ }^{\$ \$} p<0,01,{ }^{\$ \$ \$} p<0,001$ KG vs. DHF, ${ }^{\varnothing} p<0,05$, ${ }^{\infty} \mathrm{p}<0,01,{ }^{\infty} \mathrm{p}<<0,001$ DD vs. DHF, ( ) Standardabweichung

\subsubsection{Risikofaktoren im Patientenkollektiv}

In dem folgenden Abschnitt sind Angaben bezüglich der zum Untersuchungszeitpunkt bekannten kardiovaskulären Risikofaktoren und Vorerkrankungen aufgeführt. Dazu zählen das Rauchverhalten, der Diabetes mellitus, die Hypertonie, die Hyperlipidämie, die chronisch obstruktiven Lungenerkrankungen (COPD) sowie die koronare Herzkrankheit. Darüber hinaus finden sich weitere Häufigkeitsangaben zu eventuell erlittenen Myokardinfarkten und der Frage nach Familienmitgliedern, die in der Anamnese einen Myokardinfarkt vor dem 60. Lebensjahr aufwiesen. Auch andere Vorerkrankungen in Form einer peripheren arteriellen Verschlusskrankheit (pAVK), zerebrovaskulären Erkrankungen und Depressionen sind aufgeführt.

Tabelle 4: Häufigkeitsverteilung von Risikofaktoren in \%

\begin{tabular}{llll}
\hline & KG & DD & DHF \\
& $(\mathbf{n}=\mathbf{7 4})$ & $(\mathbf{n = 1 4 )}$ & $(\mathbf{n = 1 1 2})$ \\
\hline Hypertonie & $0(0)$ & $92,9(13)$ & $84,8(95)$ \\
Hyperlipidämie & $0(0)$ & $35,7(5)$ & $49,1(55)$ \\
Hyperurikämie & $0(0)$ & $21,4(3)$ & $8,9(10)^{\diamond 0}$ \\
Ex- Raucher & $12(9)$ & $42,9(6)$ & $49,1(55)$ \\
\hline
\end{tabular}




\begin{tabular}{llll}
\hline Diabetes mellitus & $0(0)$ & $0(0)$ & $16,1(18)$ \\
KHK & $0(0)$ & $0(0)$ & $21,4(24)$ \\
MI in der Familie & $0(0)$ & $28,6(4)$ & $22,3(25)$ \\
Raucher & $25,3(19)$ & $7,1(1)$ & $8,0(9)$ \\
Z. n. MI & $0(0)$ & $0(0)$ & $6,3(7)$ \\
COPD & $0(0)$ & $0(0)$ & $2,7(3)$ \\
zerebrovaskuläre & $0(0)$ & $7,1(1)$ & $8,9(10)$ \\
Erkrankungen & & $0(0)$ & $1,8(2)$ \\
pAVK & $0(0)$ & $0(0)$ & $9,8(11)^{\circ 00}$ \\
Depressionen & $0(0)$ & & \\
\hline
\end{tabular}

$p<0,05,{ }^{\circ} p<0,01,{ }^{006} p<0,001$ DD vs. DHF, ( ) Anzahl

Die Tabelle 4 zeigt, bis auf den Anstieg von Depressionen $(p<0,001)$ und einen prozentualen Abfall der Hyperurikämie $(p=0,009)$, keinen signifikanten Unterschied von Vorerkrankungen beziehungsweise Risikofaktoren zwischen den Patienten der symptomatischen DHF-Gruppe gegenüber der DD-Gruppe.

\subsubsection{Symptome der Herzinsuffizienz im Patientenkollektiv}

In der folgenden Tabelle werden die klinischen Symptome und ihre Häufigkeitsverteilung im gesamten Kollektiv dargestellt. Die Tabelle beinhaltet eine Auswahl der anamnestisch erhobenen, typischen Symptome der Herzinsuffizienz. Die Auswahl orientierte sich hierbei an den Framingham-Kriterien (Ho et al. 1993). 
Tabelle 5: Symptome der Herzinsuffizienz im Patientenkollektiv

\begin{tabular}{|c|c|c|c|}
\hline & KG & DD & DHF \\
\hline & $(n=75)$ & $(n=14)$ & $(n=112)$ \\
\hline & & Prozent & Prozent \\
\hline Belastungsdyspnoe & $0(0)$ & $0(0)$ & $100(112)^{000}$ \\
\hline Nykturie & $14,7(11)$ & $64,3(9)$ & $73,2(82)$ \\
\hline Müdigkeit/Leistungsschwäche & $8,0(6)$ & $57,1(8)$ & $50,9(57)$ \\
\hline Ödeme & $0(0)$ & $21,4(3)$ & $39,3(44)^{\infty}$ \\
\hline nächtlicher Husten & $1,3(1)$ & $7,1(1)$ & $13,4(15)^{\otimes}$ \\
\hline Parox. nächtliche Dyspnoe & $1,3(1)$ & $0(0)$ & $17,9(20)^{\infty}$ \\
\hline Orthopnoe & $0(0)$ & $0(0)$ & $9,8(11)^{\otimes}$ \\
\hline Ruhedyspnoe & $0(0)$ & $0(0)$ & $8,0(9)^{\otimes}$ \\
\hline
\end{tabular}

\footnotetext{
${ }^{*} \mathrm{p}<0,05,{ }^{* *} \mathrm{p}<0,01,{ }^{* \star *} \mathrm{p}<0,001$ KG vs. DD, ${ }^{\$} \mathrm{p}<0,05,{ }^{\$ \$} \mathrm{p}<0,01,{ }^{\$ \$ \$} \mathrm{p}<0,001$ KG vs. DHF, ${ }^{\circ} \mathrm{p}<0,05$, ${ }^{\diamond} p<0,01,{ }^{\infty \diamond} p<0,001$ DD vs. DHF, ( ) Anzahl
}

Die höchst signifikanten Unterschiede der in Tabelle 5 aufgeführten Symptome der Herzinsuffizienz resultieren aus den Einteilungskriterien des Patientenkollektivs. Bei der klinischen Untersuchung zeigten sich bei keinem Patienten im Gesamtkollektiv eine Halsvenenstauung, pulmonale Rasselgeräusche oder ein hepatojugulärer Reflux.

\subsubsection{Medikation}

Hier wird die zum Untersuchungszeitpunkt aktuelle Medikation der Patienten dargestellt. Die Auswahl beschränkt sich auf kardiovaskulär relevante Medikamente. 
Tabelle 6: Medikation im Gesamtkollektiv

\begin{tabular}{|c|c|c|c|}
\hline & KG & DD & DHF \\
\hline & $(n=75)$ & $(n=14)$ & $(n=112)$ \\
\hline & & Prozent & Prozent \\
\hline Betablocker & $0(0)$ & $21,4(3)$ & $57,1(64)$ \\
\hline ACE-Hemmer & $1,3(1)$ & $35,7(5)$ & $46,4(52)$ \\
\hline Thiazide & $1,3(1)$ & $42,9(6)$ & $36,6(41)$ \\
\hline Calcium-Antagonisten & $0(0)$ & $7,1(1)$ & $17,9(20)$ \\
\hline AT1-Antagonisten & $0(0)$ & $35,7(5)$ & $24,1(27)$ \\
\hline Schleifendiuretika & $0(0)$ & $7,1(1)$ & $13,4(15)$ \\
\hline Nitrate & $0(0)$ & $0(0)$ & $0(0)$ \\
\hline andere Diuretika & $0(0)$ & $0(0)$ & $4,5(5)$ \\
\hline Herzglykoside & $0(0)$ & $0(0)$ & $0(0)$ \\
\hline Aldosteron- & $0(0)$ & $0(0)$ & $0,9(1)$ \\
\hline \multicolumn{4}{|l|}{ Antagonisten } \\
\hline Antiarrhythmika & $0(0)$ & $0(0)$ & $2,7(3)$ \\
\hline Statine & $0(0)$ & $21,4(3)$ & $37,5(42)$ \\
\hline ASS & $2,7(2)$ & $14,3(2)$ & $35,7(40)$ \\
\hline
\end{tabular}

( ) Anzahl 


\subsubsection{Echokardiographieparameter}

Bei den unten aufgeführten Echoparametern wurde besonderen Wert auf die Dimensionen und Volumina der Diastolischen Funktion gelegt.

Tabelle 7: Echokardiographie

\begin{tabular}{|c|c|c|c|}
\hline & $\begin{array}{l}\text { KG } \\
(n=75)\end{array}$ & $\begin{array}{l}\text { DD } \\
(n=14)\end{array}$ & $\begin{array}{l}\text { DHF } \\
(n=112)\end{array}$ \\
\hline & Mittelwert & Mittelwert & Mittelwert \\
\hline LVD(ED) (mm) & $48,0( \pm 5,1)$ & $53,2( \pm 7,0)^{\star *}$ & $48,3( \pm 6,9)^{\circ}$ \\
\hline LVD(ES) (mm) & $29,6( \pm 4,6)$ & $33,0( \pm 6,5)^{\star}$ & $26,1( \pm 6,9)^{\$ \$ \$ 000}$ \\
\hline $\mathrm{LA}(\mathrm{ES})(\mathrm{mm})$ & $36,7( \pm 5,3)$ & $40,6( \pm 4,8)^{\star \star}$ & $44,4( \pm 5,9)^{\$ \$ \$ 0}$ \\
\hline IV Septum (ED) (mm) & $10,3( \pm 1,4)$ & $12,0( \pm 1,3)^{* \star *}$ & $12,3( \pm 2,0)^{\$ \$ \$}$ \\
\hline Hinterwand (ED) (mm) & $9,8( \pm 1,2)$ & $11,6( \pm 1,4)^{\star \star *}$ & $11,5( \pm 1,8)^{\$ \$ \$}$ \\
\hline LVV-ED (ml) & $86,3( \pm 27,3)$ & $105,07( \pm 39,6)^{*}$ & $76,0( \pm 28,5)^{\$ 00}$ \\
\hline LVV-ES (ml) & $32,9( \pm 12,8)$ & $38,0( \pm 14,0)$ & $24,5( \pm 12,1)^{000}$ \\
\hline LA-ES apikal längs (mm) & $49,8( \pm 8,4)$ & $55,1( \pm 6,2)^{*}$ & $54,9( \pm 7,8)^{\$ \$ \$}$ \\
\hline LA-ES apikal quer (mm) & $34,8( \pm 8,3)$ & $41,2( \pm 5,8)^{\star}$ & $42,0( \pm 6,3)^{\$ \$ \$}$ \\
\hline MD - E-Welle (cm/s) & $75,4( \pm 13,5)$ & $73,3( \pm 18,9)$ & $68,9( \pm 17,1)^{\$ \$}$ \\
\hline MD - A-Welle (cm/s) & $60,1( \pm 13,0)$ & $75,9( \pm 17,4)^{\star \star \star}$ & $80,7( \pm 15,7)^{\$ \$ \$}$ \\
\hline MD - Dezelerationszeit (ms) & $204,9( \pm 39,3)$ & $258,2( \pm 49,0)^{\star \star \star}$ & $236,8( \pm 56,3)^{\$ \$ \$}$ \\
\hline MD - IVRT (ms) & $96,0( \pm 44,9)$ & $91,8( \pm 25,4)$ & $88,1( \pm 23,1)^{\$}$ \\
\hline TEI - a (ms) & $449,8( \pm 35,3)$ & $426,5( \pm 63,4)$ & $457,7( \pm 51,3)^{\diamond}$ \\
\hline TEI - b (ms) & $305,1( \pm 30,2)$ & $268,5( \pm 50,8)^{\star *}$ & $326,3( \pm 40,2)^{\$ \$ \$ 000}$ \\
\hline
\end{tabular}




\begin{tabular}{|c|c|c|c|}
\hline $\begin{array}{l}\text { GD- med. Mitralanulus: e'-Welle } \\
(\mathrm{cm} / \mathrm{s})\end{array}$ & $8,4( \pm 1,5)$ & $6,8( \pm 0,7)^{\star \star \star}$ & $5,7( \pm 1,2)^{\$ \$ \$ \bigotimes 0}$ \\
\hline $\begin{array}{l}\text { GD-med. Mitralanulus: a'-Welle } \\
(\mathrm{cm} / \mathrm{s})\end{array}$ & $9,8( \pm 2,0)$ & $10,6( \pm 1,4)$ & $9,1( \pm 1,6)^{\$ \diamond \diamond}$ \\
\hline PVF - systolisch (cm/s) & $58,8( \pm 10,4)$ & $58,3( \pm 11,5)$ & $61,5( \pm 9,9)$ \\
\hline PVF - diastolisch (cm/s) & $45,9( \pm 9,4)$ & $43,4( \pm 13,6)$ & $44,1( \pm 11,3)$ \\
\hline PVF - Atrialer Rückfluss (cm/s) & $28,4( \pm 6,1)$ & $30,2( \pm 5,1)$ & $30,2( \pm 6,4)$ \\
\hline$V p(\mathrm{~cm} / \mathrm{s})$ & $36,1( \pm 9,7)$ & $50,5( \pm 19,4)^{\star * *}$ & $35,7( \pm 9,1)^{000}$ \\
\hline E/e' medial & $9,3( \pm 2,1)$ & $11,3( \pm 3,3)^{\star *}$ & $12,4( \pm 3,2)^{\$ \$ \$}$ \\
\hline LAVI $\left(\mathrm{ml} / \mathrm{m}^{2}\right)$ & $18,5( \pm 6,1)$ & $23,4( \pm 5,9)^{*}$ & $27,3( \pm 8,0)^{\$ \$ \$}$ \\
\hline LVMI $\left(g / \mathbf{m}^{2}\right)$ & $97,3( \pm 19,9)$ & $123,5( \pm 23,0)^{\star \star \star}$ & $112,7( \pm 33,2)^{\$ \$ \$}$ \\
\hline LVEF (\%) & $62,2( \pm 6,4)$ & $66,9( \pm 6,4)^{*}$ & $68,8( \pm 7,6)^{\$ \$ \$}$ \\
\hline E/A- Verhältnis & $1,3( \pm 0,3)$ & $1,1( \pm 0,7)^{*}$ & $0,9( \pm 0,3)^{\$ \$ \$ 0}$ \\
\hline Grad DD I (n=) & 0 & 10 & 89 \\
\hline Grad DD II (n=) & 0 & 4 & 23 \\
\hline Grad DD III (n=) & 0 & 0 & 0 \\
\hline
\end{tabular}

${ }^{*} p<0,05,{ }^{* *} p<0,01,{ }^{* * *} p<0,001$ KG vs. DD, ${ }^{\$} p<0,05,{ }^{\$ \$} p<0,01,{ }^{\$ \$ \$} p<0,001$ KG vs. DHF, ${ }^{p} p<0,05$, ${ }^{\otimes} \mathrm{p}<0,01,{ }^{\infty \otimes \otimes} \mathrm{p}<0,001$ DD vs. DHF, ( ) Standardabweichung, $\mathrm{MD}=$ Mitralisdoppler, $\mathrm{GD}=$ Gewebedoppler, PVF= pulmonalvenöser Fluss

Signifikante Unterschiede zwischen den Kollektiven mit der diastolischen Dysfunktion und der diastolischen Herzinsuffizienz wurden bei folgenden Werten festgestellt: $\operatorname{LVD}(E D)(p=0,012), \operatorname{LVD}(E S)$ $(p=0,001), \operatorname{LA}(E S)(p=0,022), \operatorname{LVV}-E D(p=0,001), \operatorname{LVV}-E S(p<0,001), M D-A-D U R(p=0,005), T E I-a$ $(p=0,045)$, TEI - $b(p<0,001), G D-$ med. Mitralanulus: e'-Welle $(p=0,002), G D$ - med. Mitralanulus: a'- 
Welle $(p=0,001)$, E/A- Verhältnis $(p=0,035)$ sowie bei $V p(p<0,001)$. Hingegen konnten keine signifikant abweichenden Werte bei den, die diastolische Dysfunktion definierenden Werte wie E/e' medial $(p=0,245)$ und der A-Welle $(p=0,288)$ zwischen der DD- und DHF-Kohorte, festgestellt werden.

\subsubsection{Graphische Darstellung von Echokardiographieparametern}

In den Abbildungen 5-10 werden signifikant unterschiedliche Echoparameter zwischen dem DD- und DHF-Kollektiv graphisch dargestellt. In allen folgenden Abbildungen gilt ${ }^{*}=p<0,05, \quad{ }^{* *} p<0,01$, ${ }^{* * *} \mathrm{p}<0,001$ und $n . s .=$ nicht signifikant.

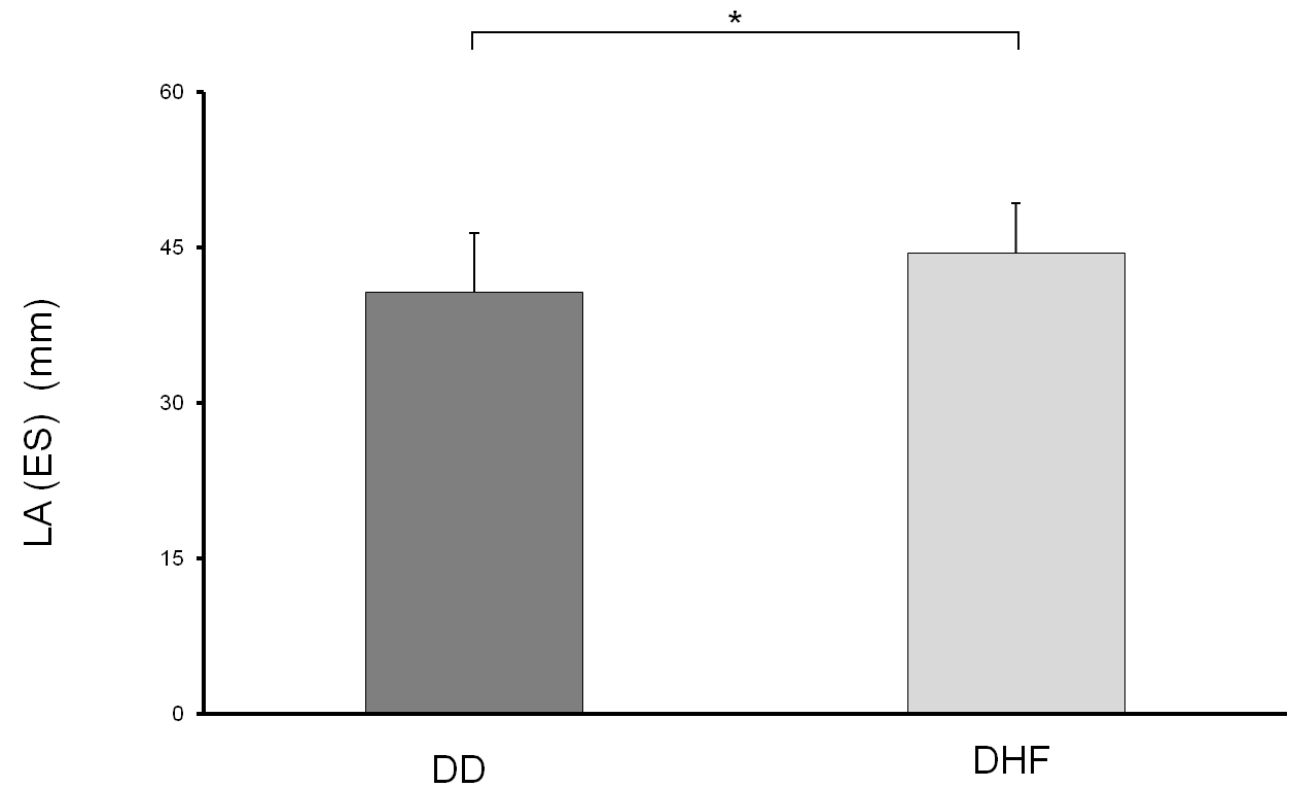

Abbildung 5: LA(ES) 
n.s.

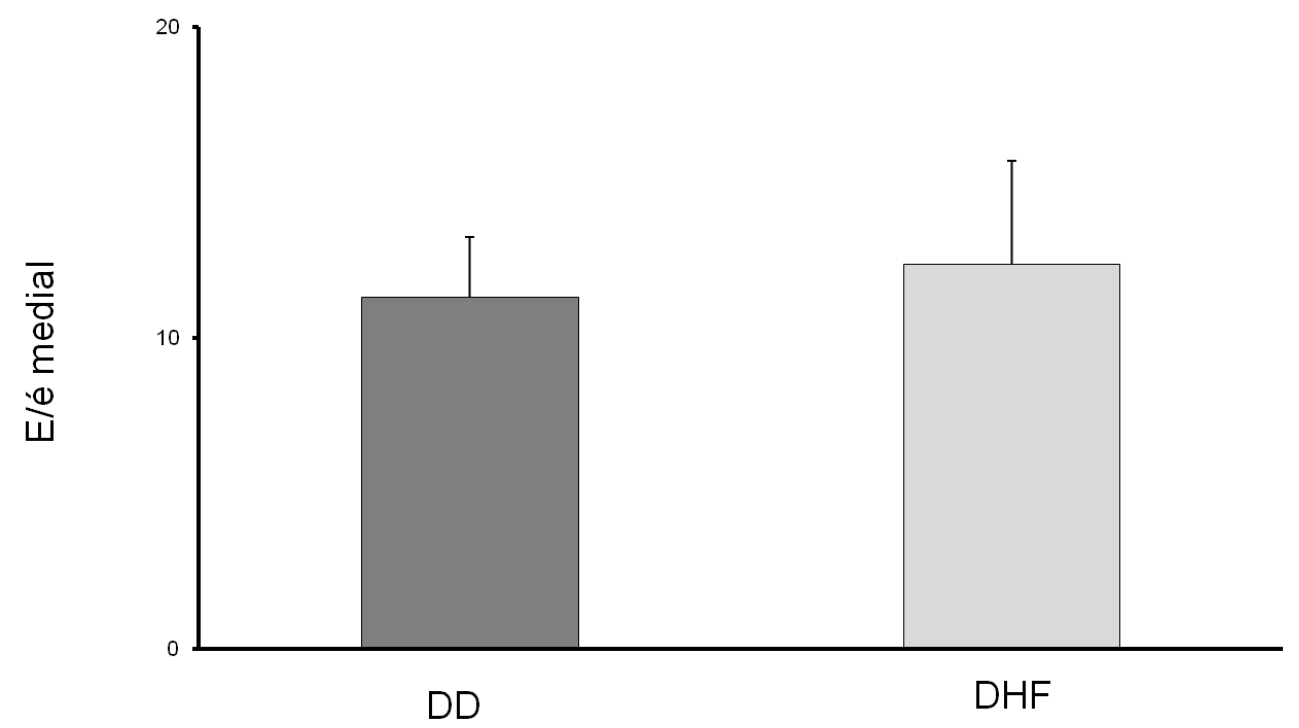

Abbildung 6: E/é medial

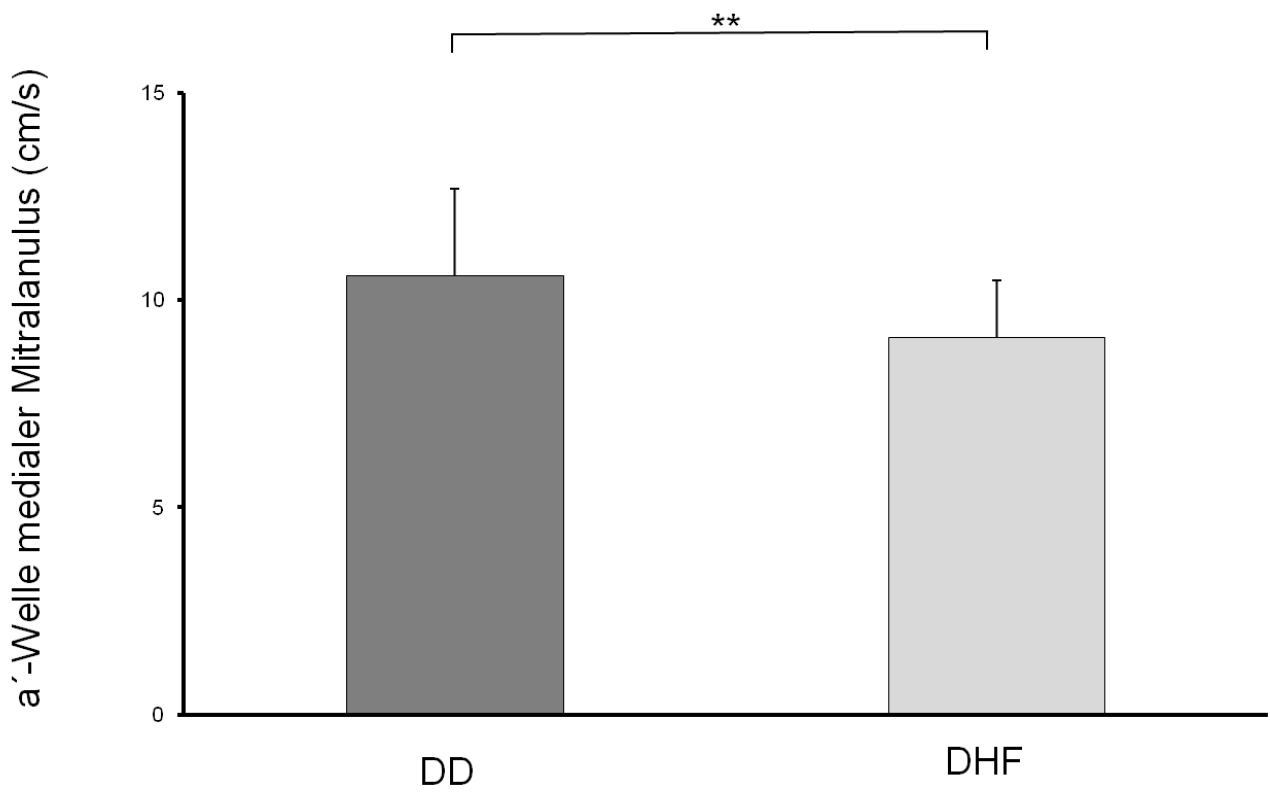

Abbildung 7: a'-Welle medialer Mitralanulus 


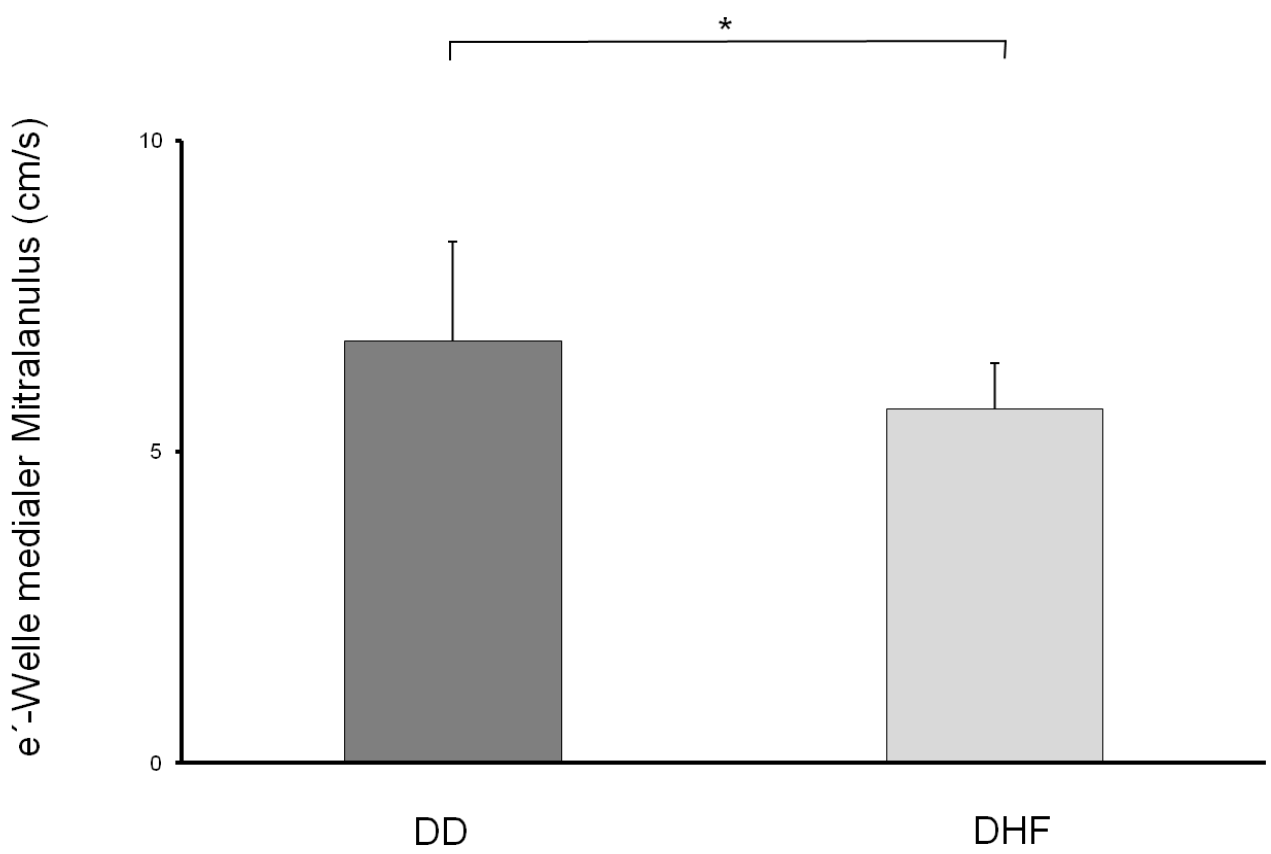

Abbildung 8: e'-Welle medialer Mitralanulus

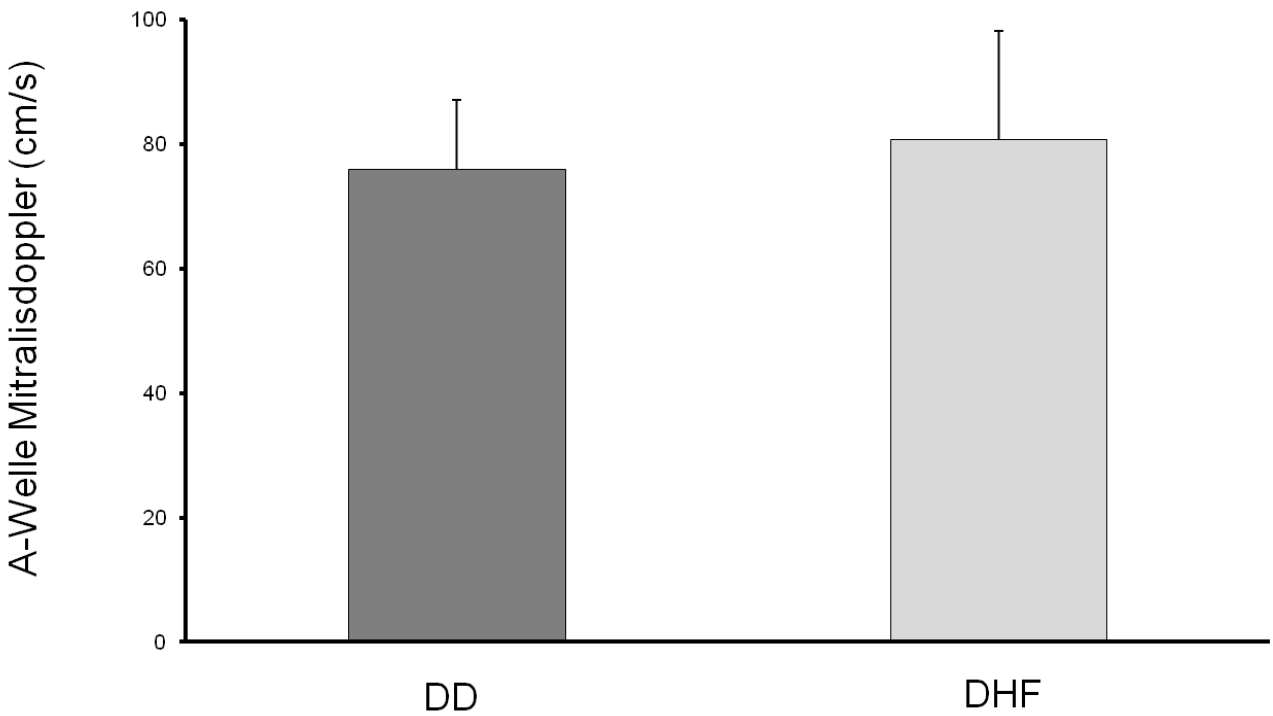

Abbildung 9: A-Welle im Mitralisdoppler 


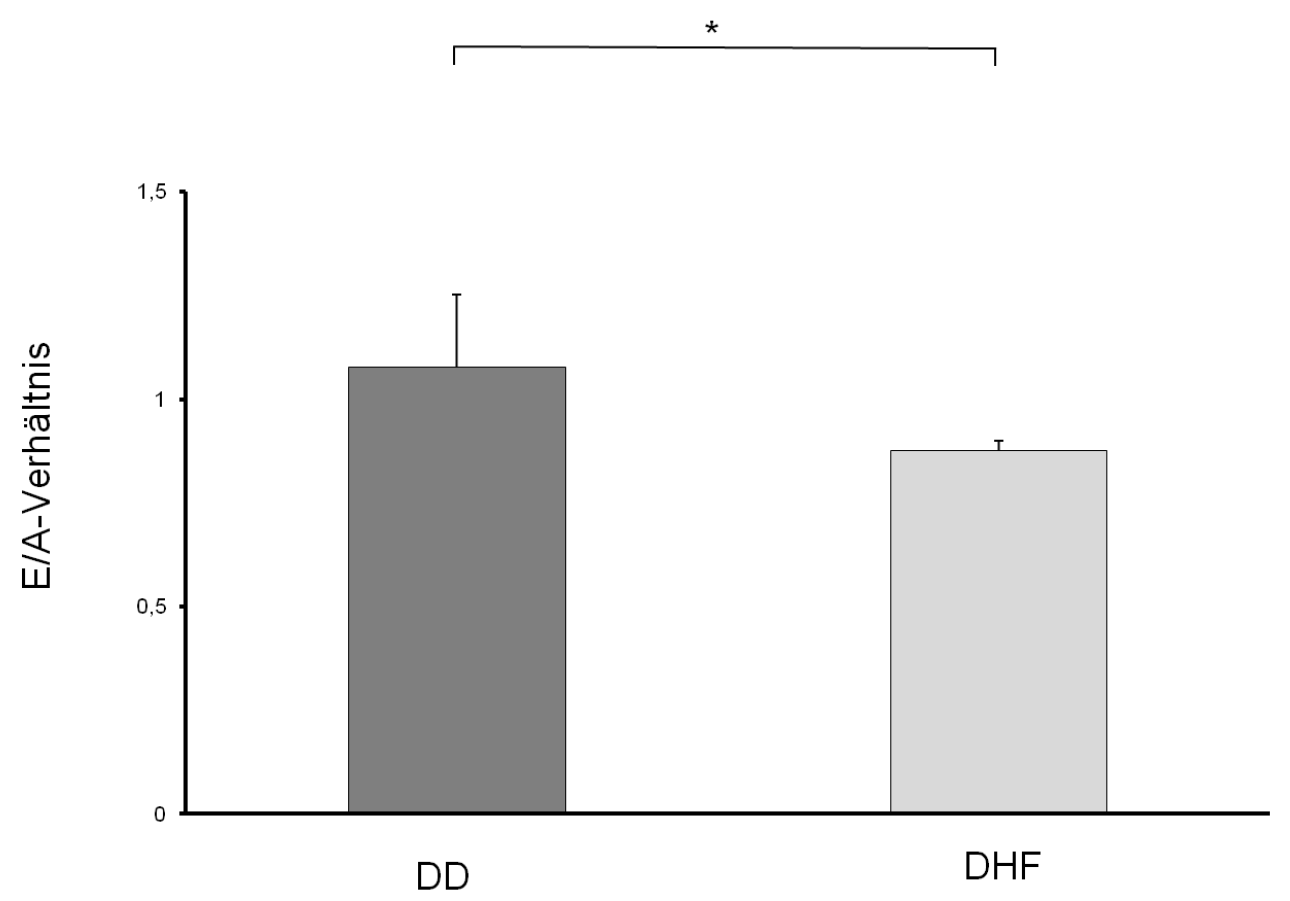

Abbildung 10: E/A-Verhältnis

\subsubsection{Belastbarkeit des Patientenkollektivs}

Die unten stehende Tabelle 8 zeigt die, durch den 6-Minuten-Gehtest und eine Spiroergometrie ermittelte Belastbarkeit der Patientengruppen mit der diastolischen Dysfunktion und der diastolischen Herzinsuffizienz.

Es zeigten sich zu erwartende signifikante Unterschiede bei der maximalen Belastungsstufe $(p<0,001)$ und -dauer $(p<0,001)$, dem maximalen RR systolisch $(p<0,001)$, der maximalen Herzfrequenz/min $(p=0,011)$, dem Respirationsquotienten in Ruhe $(p<0,001)$, bei maximaler Belastung $(p=0,026)$ und nach Belastung $(p<0,001)$. Darüber hinaus werden signifikante Unterschiede bei der maximalen VE $(p<0,001)$, der Peak $\mathrm{VO}_{2}(p<0,001)$, der anaerobe Schwelle $(p<0,001)$, der $\mathrm{ATVO}_{2}(p<0,001)$ sowie der Gehstrecke $(p<0,001)$ beobachtet. 
Tabelle 8: Spiroergometrie und 6-Minuten-Gehtest

\begin{tabular}{|c|c|c|}
\hline & DD & DHF \\
\hline & $(n=14)$ & $(n=112)$ \\
\hline Max. Belastungsstufe (W) & $191,4( \pm 51,3)$ & $111,3( \pm 31,9)^{000}$ \\
\hline Max. Belastungsdauer (s) & $1129,3( \pm 318,0)$ & $611,0( \pm 192,2)^{000}$ \\
\hline RR systolisch max. (mmHg) & $221,1( \pm 26,9)$ & $177,5( \pm 31,8)^{000}$ \\
\hline RR diastolisch max. (mmHg) & $97,5( \pm 16,0)$ & $90,4( \pm 18,4)$ \\
\hline HF max. (min) & $152,9( \pm 20,4)$ & $124,1( \pm 19,3)^{000}$ \\
\hline$R Q$ ruhe & $0,83( \pm 0,06)$ & $0,87( \pm 0,07)^{\diamond}$ \\
\hline$R Q$ max & $1,09( \pm 0,04)$ & $1,18( \pm 0,14)^{\diamond}$ \\
\hline$R Q$ post & $1,20( \pm 0,08)$ & $1,46( \pm 0,18)^{\triangleright, 0}$ \\
\hline VE ruhe $(I / \min )$ & $11,5( \pm 2,0)$ & $9,8( \pm 13,3)$ \\
\hline VE max. (I/min) & $92,3( \pm 31,8)$ & $48,1( \pm 13,7)^{000}$ \\
\hline Peak VO $2(\mathrm{ml} / \mathrm{kg} / \mathrm{min})$ & $30,5( \pm 8,4)$ & $16,0( \pm 4,0)^{000}$ \\
\hline Anaerobe Schwelle (W) & $151,3( \pm 56,6)$ & $57,4( \pm 20,4)^{000}$ \\
\hline $\mathrm{ATVO}_{2} \mathrm{ml} / \mathrm{kg} / \mathrm{min}$ & $24,3( \pm 7,9)$ & $10,0( \pm 2,6)^{000}$ \\
\hline $\mathrm{VE} / \mathrm{VCO}_{2}$ slope & $27,3( \pm 4,63)$ & $28,3( \pm 3,6)$ \\
\hline Borg-Score max. & $7,4( \pm 2,5)$ & $8,5( \pm 8,5)$ \\
\hline Gehstrecke (m) & $663,9( \pm 52,8)$ & $537,6( \pm 92,3)^{\diamond 00}$ \\
\hline Vorzeitiges Abbrechen & 0 & 4 \\
\hline
\end{tabular}




\subsubsection{Graphische Darstellung von Belastungsparametern}

In den Abbildungen 11 bis 17 werden signifikante Belastungsparameter zwischen der DD-Gruppe und der DHF Gruppe graphisch dargestellt. Die genauen Werte können der Tabelle 8 entnommen werden.

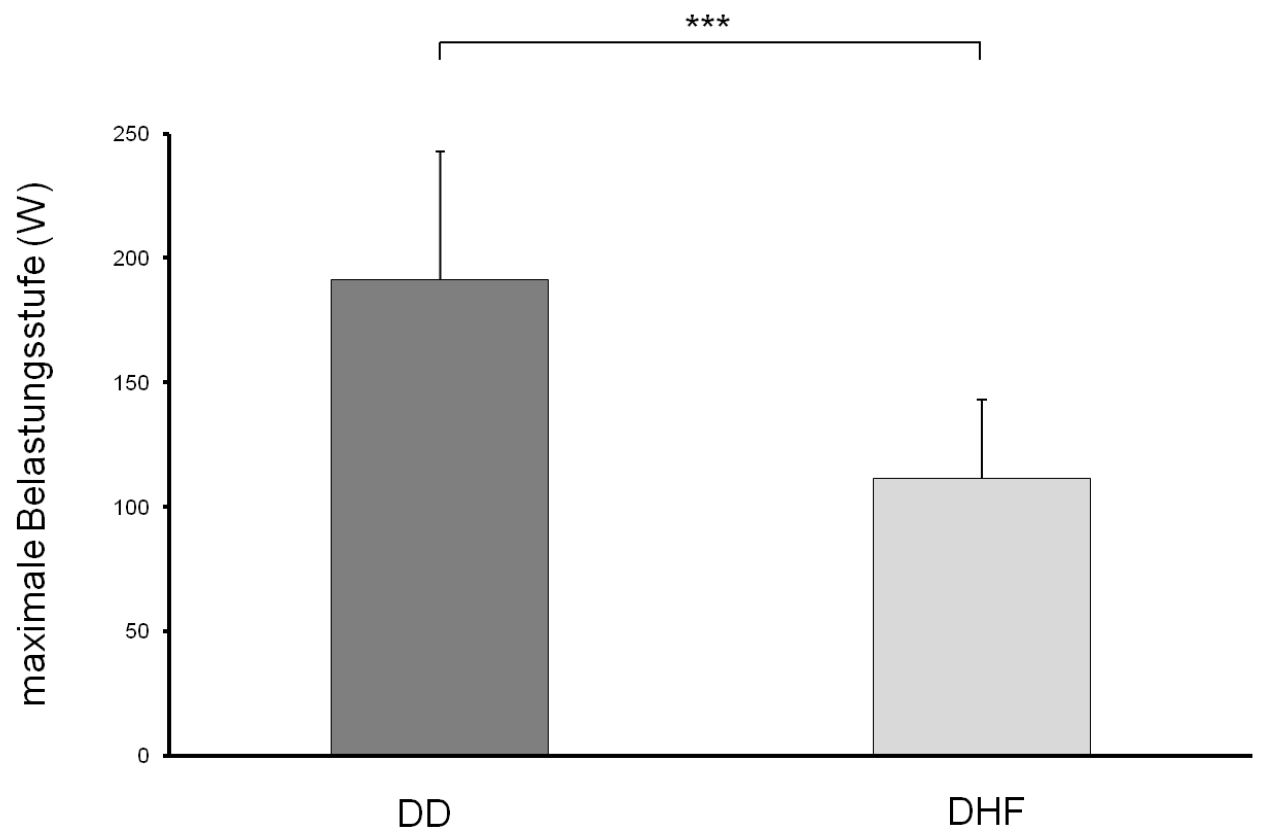

Abbildung 11: maximale Belastungsstufe bei der Spiroergometrie 


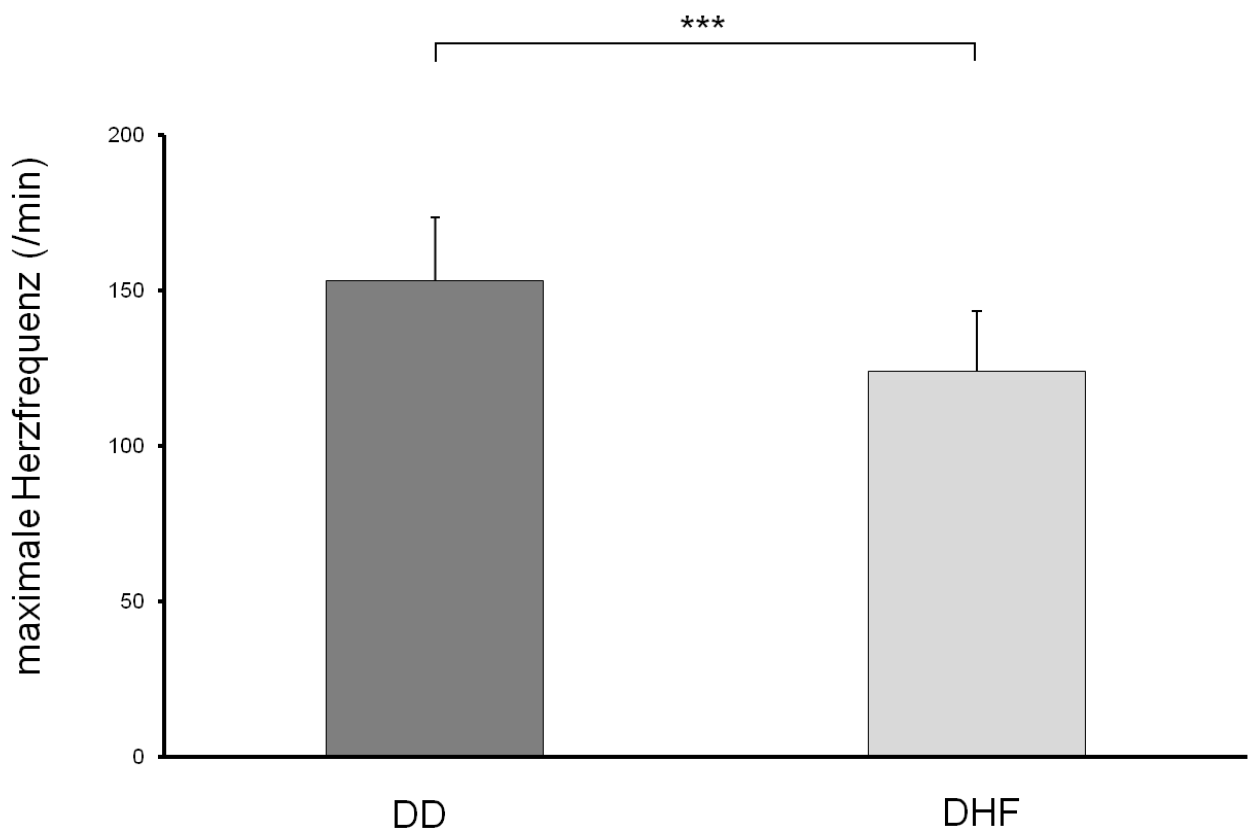

Abbildung 12: maximale Herzfrequenz bei der Spiroergometrie

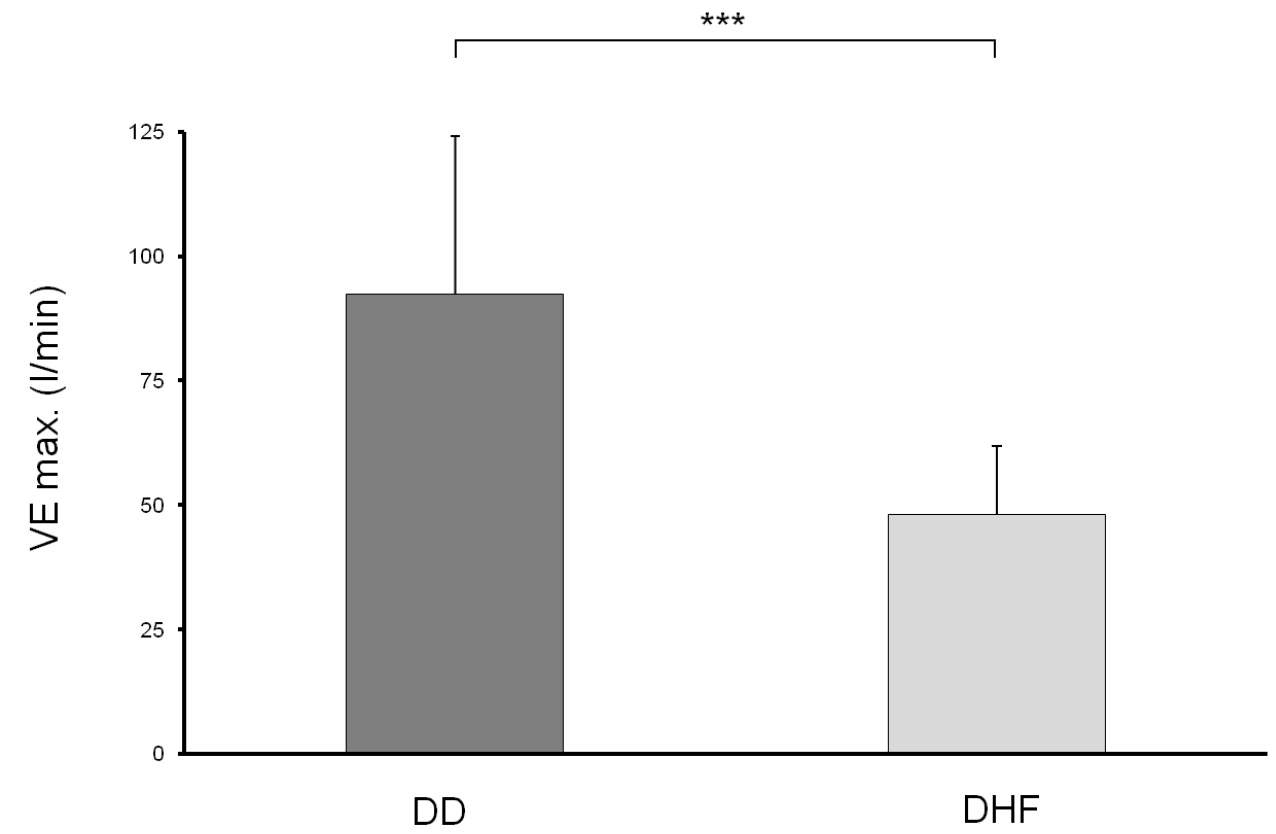

Abbildung 13: VE maximal bei der Spiroergometrie 


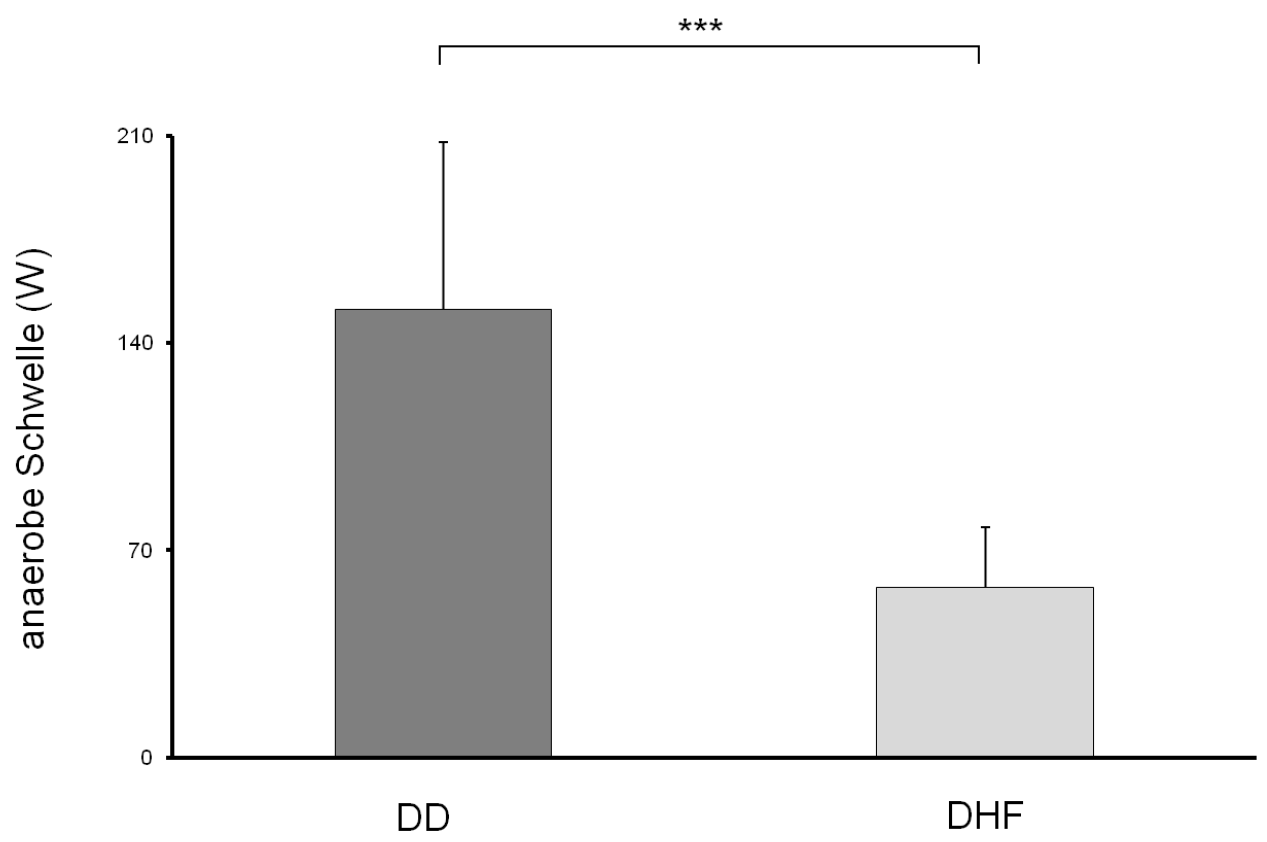

Abbildung 14: anaerobe Schwelle bei der Spiroergometrie

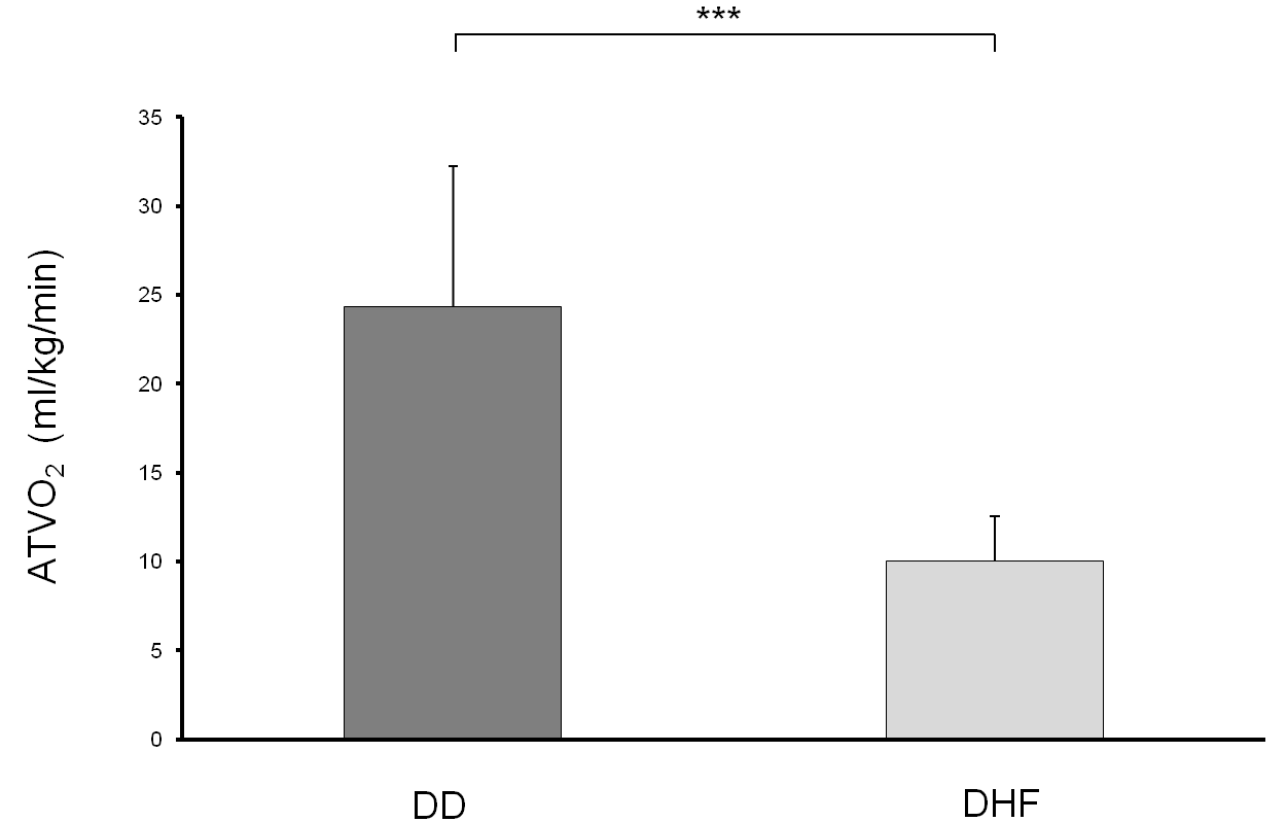

Abbildung 15: $\mathrm{ATVO}_{2}$ bei der Spiroergometrie 


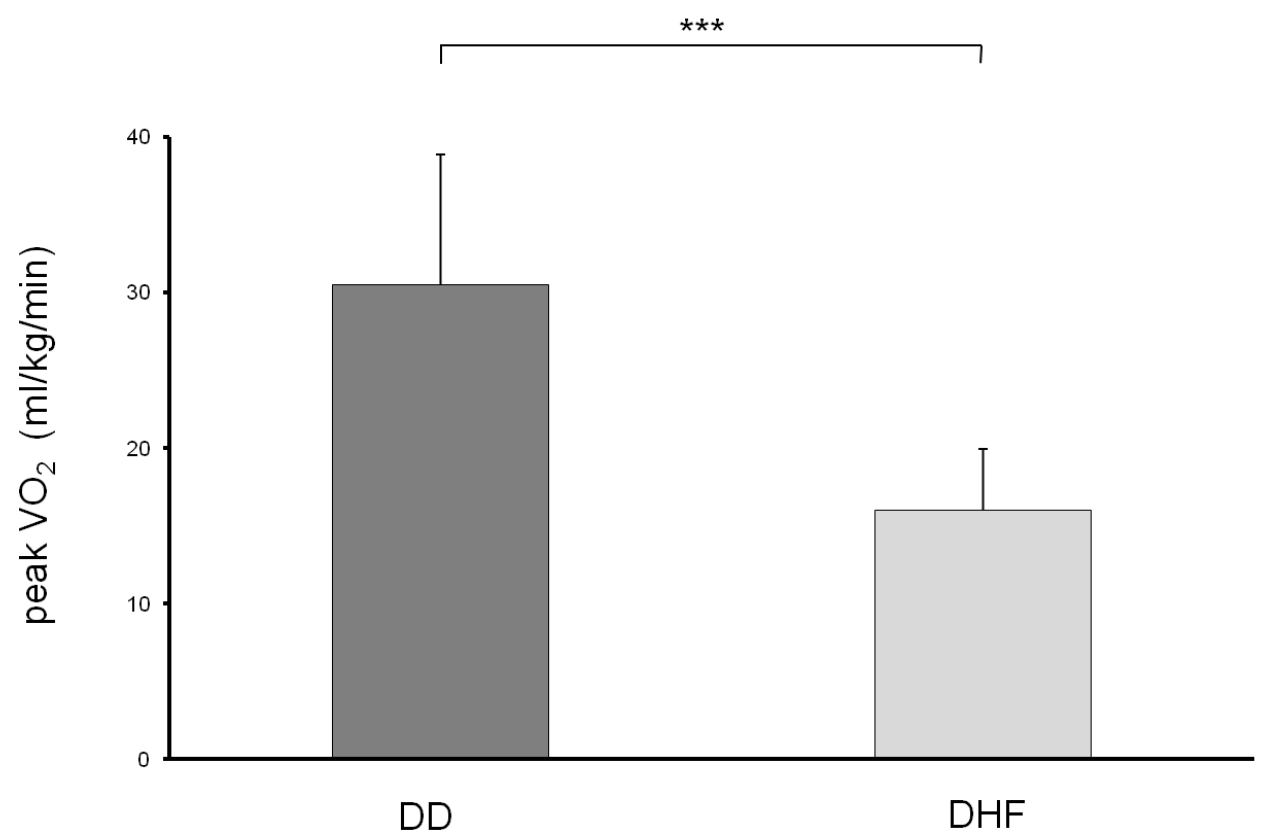

Abbildung 16: peak $\mathrm{VO}_{2}$ bei der Spiroergometrie
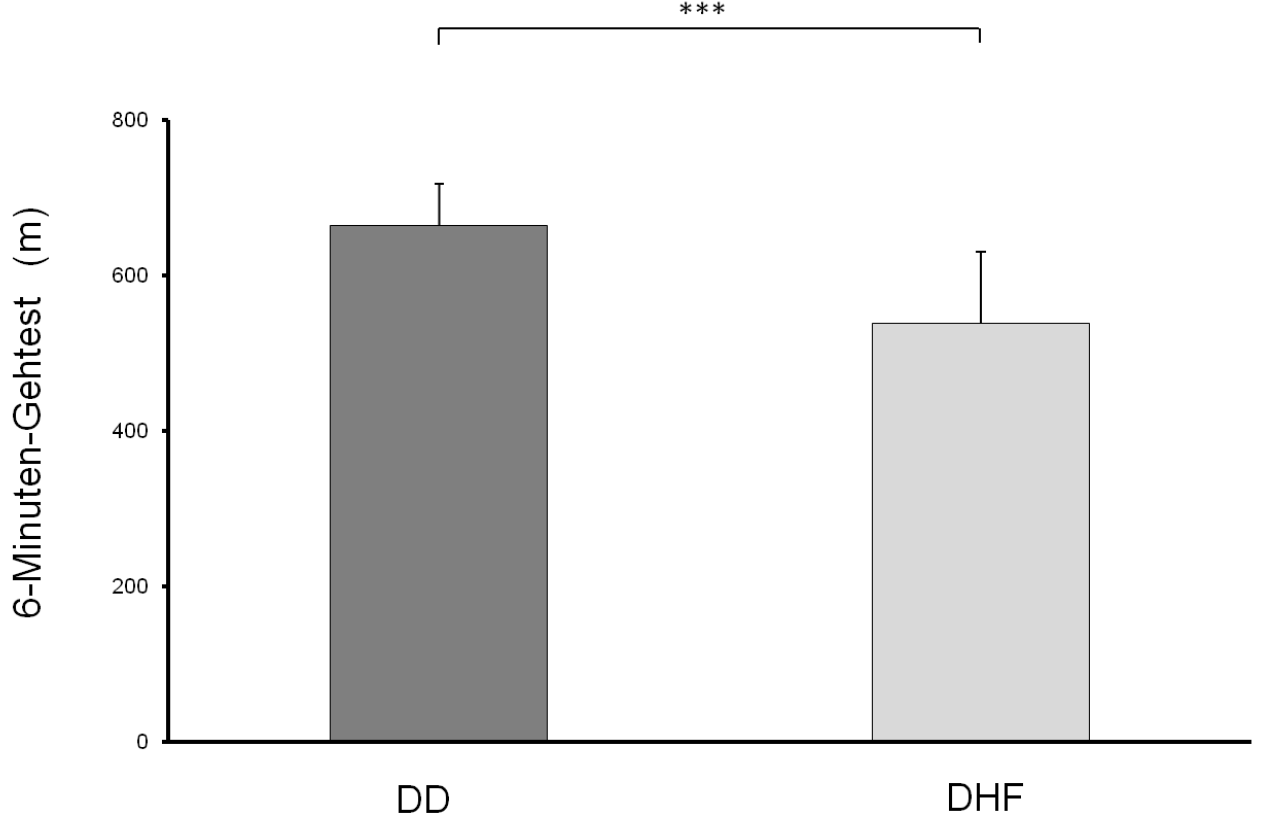

Abbildung 17: maximale Gehstrecke im 6-Minuten-Gehtest 


\subsubsection{Neurohumorale Aktivierung}

In der folgenden Tabelle wird die humorale Aktivierung des Patientenkollektivs zum Zeitpunkt der Baselineuntersuchung gezeigt. Um eine bessere Vergleichbarkeit der erhobenen Werte zu erreichen, wurde für diesen Zweck eine KG-Gruppe generiert.

Tabelle 9: Neurohumorale Aktivierung

KG DD DHF

$(n=75) \quad(n=14) \quad(n=112)$

\begin{tabular}{|c|c|c|c|}
\hline $\begin{array}{l}\text { NT-proBNP } \\
(\mathrm{pg} / \mathrm{ml})\end{array}$ & $81,58( \pm 72,83)$ & $76,62( \pm 81,68)$ & $171,93( \pm 143,48)^{\$ \$ \$ \triangleright}$ \\
\hline $\begin{array}{l}\text { MR-proANP } \\
(\mathrm{pmol} / \mathrm{l})\end{array}$ & $69,53( \pm 23,1)$ & $92,86( \pm 35,71)^{\star *}$ & $107,05( \pm 46,89)^{\$ \$ \$}$ \\
\hline $\begin{array}{l}\text { MR-proADM } \\
\text { (nmol/l) }\end{array}$ & $0,46( \pm 0,09)$ & $0,51( \pm 0,12)$ & $0,58( \pm 0,15)^{\$ \$ \$}$ \\
\hline $\begin{array}{l}\text { CT-proET-1 } \\
(\text { pmol/l) }\end{array}$ & $52,19( \pm 10,96)$ & $53,43( \pm 10,21)$ & $59,55( \pm 12,74)^{\$ \$ \$}$ \\
\hline $\begin{array}{l}\text { CT-proAVP } \\
\text { (pmol/l) }\end{array}$ & $4,10( \pm 4,75)$ & $6,24( \pm 4,00)$ & $5,09( \pm 3,46)$ \\
\hline
\end{tabular}

${ }^{*} \mathrm{p}<0,05,{ }^{* *} \mathrm{p}<0,01,{ }^{* * *} \mathrm{p}<0,001$ KG vs. DD, ${ }^{\$} \mathrm{p}<0,05,{ }^{\$ \$} \mathrm{p}<0,01,{ }^{\$ \$ \$} \mathrm{p}<0,001$ KG vs. DHF, ${ }^{\circ} \mathrm{p}<0,05$, ${ }^{\otimes} \mathrm{p}<0,01,{ }^{\otimes \diamond} \mathrm{p}<0,001$ DD vs. DHF, ( ) Standardabweichung

In der Tabelle 9 zeigt sich ein durchweg signifikanter Anstieg der neurohumoralen Aktivierung von der KG gegenüber der DHF-Gruppe. Nur bei CT-proAVP ist dieser nicht nachweisbar. Ein signifikanter Unterschied zwischen der KG und DD-Gruppe zeigt sich lediglich bei MR-proANP ( $p=0,02)$.

Zudem zeigt sich eine signifikante Erhöhung der NT-proBNP-Werte $(p=0,016)$ der DD-Gruppe von $76,62 \mathrm{pg} / \mathrm{ml}( \pm 81,68 \mathrm{pg} / \mathrm{ml})$ gegenüber der DHF-Gruppe auf $171,93 \mathrm{pg} / \mathrm{ml}( \pm 143,48 \mathrm{pg} / \mathrm{ml})$. Auch bei 
MR-proADM $(p=0,093)$ und CT-proET-1 $(p=0,086)$ erkennt man einen leichten allerdings nicht signifikanten Anstieg der humoralen Aktivierung zwischen der DD- und DHF-Gruppe.

\subsection{Zusammenhang zwischen Belastbarkeit, diastolischer Funktion und neurohumoraler Aktivierung}

Im Folgenden wird der Zusammenhang zwischen neurohumoralen sowie echokardiographischen Parametern mit Kennungsgrößen der maximalen und submaximalen Belastung aufgeführt.

Tabelle 10: Korrelation zwischen ausgewählten Belastungs- und Echoparametern der diastolischen und systolischen Funktion

$\begin{array}{llll}\text { Anaerobe } & \mathrm{ATVO}_{2} & \text { Peak VO } & \\ & & \text { 6-Minuten- } \\ \text { Schwelle } & & & \text { Gehtest }\end{array}$

\begin{tabular}{|c|c|c|c|c|c|}
\hline \multirow[t]{2}{*}{ LAVI } & $r$ & 0,158 & 0,093 & $0,264^{\star \star}$ & $0,208^{\star}$ \\
\hline & $p$ & 0,083 & 0,309 & 0,003 & 0,024 \\
\hline \multirow[t]{2}{*}{ LA(ES) } & $r$ & $0,179^{*}$ & $-0,009$ & 0,163 & $0,187^{\star}$ \\
\hline & $p$ & 0,045 & 0,923 & 0,068 & 0,038 \\
\hline \multirow[t]{2}{*}{ A-Welle (MD) } & r & $-0,166$ & $-0,057$ & $-0,170$ & $-0,135$ \\
\hline & $p$ & 0,064 & 0,527 & 0,058 & 0,137 \\
\hline$a^{\prime}-$ Welle med. & $r$ & $0,206^{*}$ & $0,237^{\star \star}$ & $0,230^{\star \star}$ & 0,129 \\
\hline \multicolumn{5}{|l|}{ Mitralanulus (GD) } & 0,155 \\
\hline e'- Welle med. & $r$ & $0,270^{\star *}$ & 0,145 & $0,235^{\star \star}$ & $0,228 *$ \\
\hline \multicolumn{6}{|l|}{ Mitralanulus (GD) } \\
\hline \multirow[t]{2}{*}{ Vp } & $r$ & $0,191^{*}$ & 0,143 & 0,102 & 0,094 \\
\hline & $\mathrm{p}$ & 0,033 & 0,112 & 0,259 & 0,300 \\
\hline E/e' medial & $r$ & $-0,024$ & $-0,022$ & $-0,116$ & $-0,108$ \\
\hline
\end{tabular}




\begin{tabular}{lccccc}
\hline & $p$ & 0,787 & 0,803 & 0,195 & 0,232 \\
LVEF & $r$ & $-0,129$ & $-0,019$ & 0,042 & $-0,036$ \\
& $p$ & 0,267 & 0,872 & 0,721 & 0,763 \\
LVMI & $\mathrm{r}$ & $\mathbf{0 , 2 1 5 ^ { * }}$ & $\mathbf{0 , 1 8 5 ^ { \star }}$ & $\mathbf{0 , 2 4 8 ^ { \star \star }}$ & 0,142 \\
& $\mathrm{p}$ & $\mathbf{0 , 0 1 6}$ & 0,040 & 0,006 & 0,119 \\
E/A & $\mathrm{r}$ & $\mathbf{0 , 2 0 5 ^ { \star }}$ & 0,017 & 0,084 & 0,101 \\
& $\mathrm{p}$ & $\mathbf{0 , 0 2 2}$ & 0,853 & 0,354 & 0,268
\end{tabular}

${ }^{*} \mathrm{p}<0,05, \quad{ }^{* *} \mathrm{p}<0,01, \quad{ }^{* * *} \mathrm{p}<0,001, \quad \mathrm{r} \quad=$ Korrelationskoeffizienten, $\quad \mathrm{p}=$ Signifikanz $\quad$ (2-seitig), $\quad \mathrm{MD}=$ Mitralisdoppler, GD= Gewebedoppler

In der Tabelle 10 erkennt man, dass die diastolische Dysfunktion definierende Parameter wie E/A oder E/e' nicht mit den Belastungsparametern $\mathrm{ATVO}_{2}$, Peak $\mathrm{VO}_{2}$ und 6-Minuten-Gehtest korrelieren. Mit dem 6-Minuten Gehtest korrelieren signifikant lediglich die Echoparameter $L A(E S)(p=0,038)$, der LAVI $(p=0,024)$ und die $e^{\prime}-$ Welle (med. Mitralanulus) $(p=0,011)$. Die Peak $\mathrm{VO}_{2}$ korrelieren sehr signifikant mit der $a^{\prime}-(p=0,01)$ und $e^{\prime}-$ Welle (med. Mitralanulus), dem LAVI $(p=0,003)(p=0,008)$ sowie der LVMI $(p=0,006)$. Der LVMI $(p=0,04)$ und die $a^{\prime}-$ Welle (med. Mitralanulus) $(p=0,008)$ sind weiterhin die einzigen beiden Echoparameter, die mit der $\mathrm{ATVO}_{2}$ im signifikanten Zusammenhang stehen. Die meisten signifikanten Korrelationen zwischen Echo- und Belastungsparametern finden sich bei der anaeroben Schwelle. LA(ES) quer $(p=0,045), a^{\prime}-(p=0,02)$ und $e^{\prime}-$ Welle (med. Mitralanulus) $(p=0,002), \operatorname{Vp}(p=0,033), \operatorname{LVMI}(p=0,016)$ und $E / A(p=0,022)$ korrelieren alle mit der anaeroben Schwelle. 
Tabelle 11: Korrelationen zwischen Belastungsparametern und der neurohumoralen Aktivierung

\begin{tabular}{|c|c|c|c|c|c|c|}
\hline & & $\begin{array}{l}\log \text { NT- } \\
\text { proBNP }\end{array}$ & $\begin{array}{l}\text { log MR- } \\
\text { proANP }\end{array}$ & $\begin{array}{l}\text { log MR- } \\
\text { proADM }\end{array}$ & $\begin{array}{l}\log \mathrm{CT}- \\
\text { proET-1 }\end{array}$ & $\begin{array}{l}\log \text { CT- } \\
\text { proAVP }\end{array}$ \\
\hline Anaerobe & $r$ & $-0,213^{\star}$ & $-0,033$ & $-0,0307^{\star \star \star}$ & $-0,275^{\star \star}$ & $0,295^{\star \star}$ \\
\hline Schwelle & $p$ & 0,017 & 0,717 & 0,000 & 0,002 & 0,001 \\
\hline Peak $\mathrm{VO}_{2}$ & $r$ & $-0,195^{\star}$ & $-0,08$ & $-0,401^{\star \star \star}$ & $-0,272^{\star \star}$ & $0,280^{\star \star}$ \\
\hline & $p$ & 0,028 & 0,928 & 0,000 & 0,002 & 0,001 \\
\hline 6-Minuten- & $r$ & $-0,211^{*}$ & $-0,010$ & $-0,392^{\star \star \star}$ & $-0,271^{\star *}$ & 0,163 \\
\hline Gehtest & $p$ & 0,019 & 0,916 & 0,000 & 0,002 & 0,070 \\
\hline ATVO $_{2}$ & $r$ & $-0,194^{\star}$ & $-0,350$ & $-0,293^{\star \star}$ & $-0,235^{\star \star}$ & $0,243^{\star \star}$ \\
\hline & $p$ & 0,030 & 0,701 & 0,001 & 0,008 & 0,006 \\
\hline
\end{tabular}

${ }^{*} p<0,05,{ }^{* *} p<0,01,{ }^{* * *} p<0,001, p=$ Signifikanz (2-seitig), $r=$ Korrelationskoeffizienten

In der oben aufgeführten Tabelle 11 erkennt man, dass log NT-proBNP, log CT-proET-1 und log MRproADM mit allen hier beschriebenen Belastungsparametern signifikant korrelieren. Log CT-proAVP korreliert ebenfalls mit den dargestellten Belastungsparametern, außer mit dem 6-Minuten Gehtest. Log MR-proANP hingegen hat keine signifikante Beziehung zu einem der hier untersuchten Messwerte.

Im Einzelnen sind signifikante $(\mathrm{p}<0,05) \quad$ Korrelationen zwischen log NT-proBNP und den Belastungsparametern anaerobe Schwelle $(p=0,017)$, peak $\mathrm{VO}_{2}(p=0,028)$ und dem 6-MinutenGehtest $(p=0,019)$ zu erkennen. Eine sehr signifikante $(p<0,01)$ Korrelation zeigt sich zwischen den zuvor beschriebenen Werten und log CT-proET-1. Log MR-proADM korreliert mit allen Belastungsparametern und davon höchst signifikant $(p \leq 0,01)$ mit der anaeroben Schwelle, Peak $\mathrm{VO}_{2}$ und dem 6-Minuten-Gehtest.

In den Abbildungen 18 bis 25 folgt die graphische Darstellung der in Tabelle 11 beschriebenen Werte. 


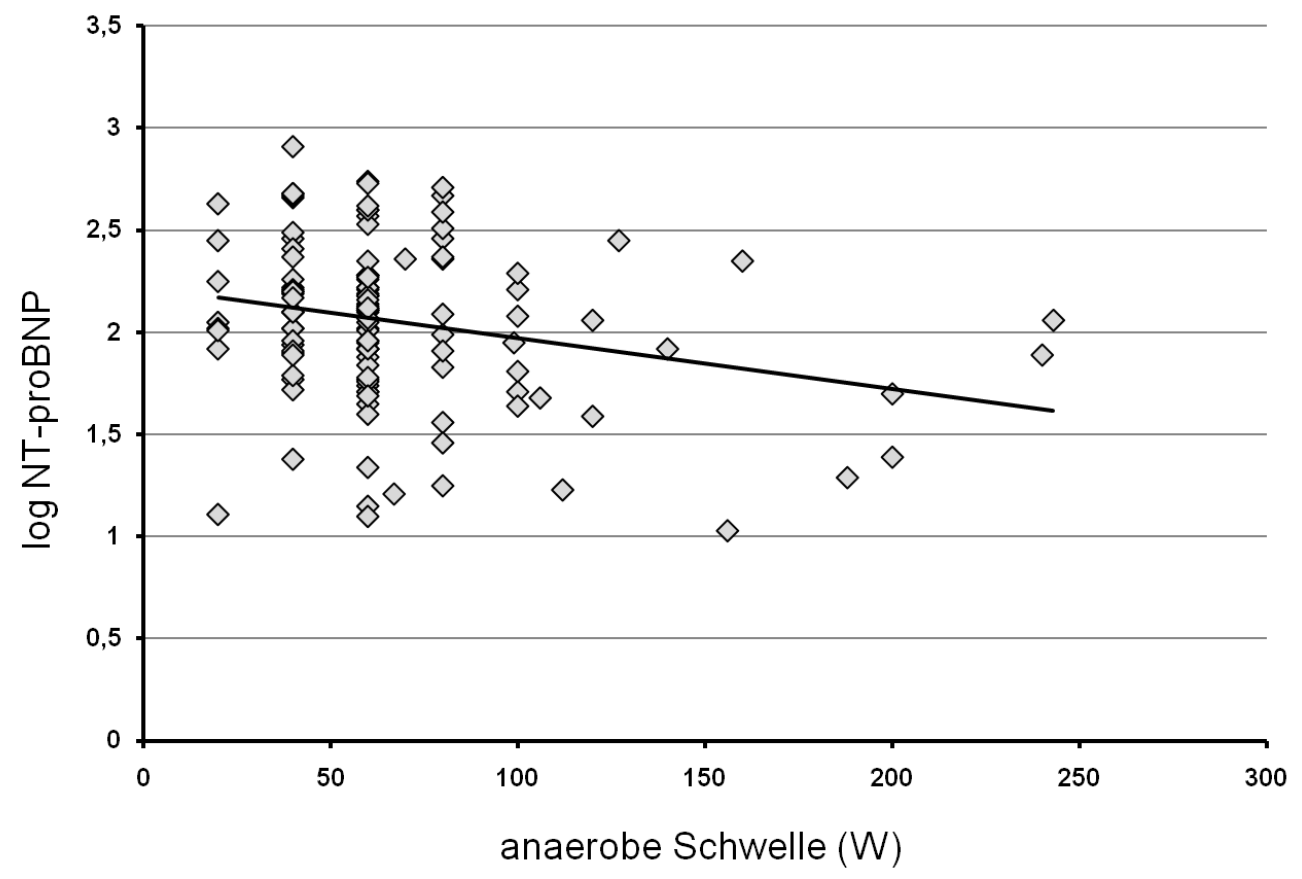

Abbildung 18: Darstellung der Korrelation zwischen log NT-proBNP und der anaeroben Schwelle $(p=0,017)$

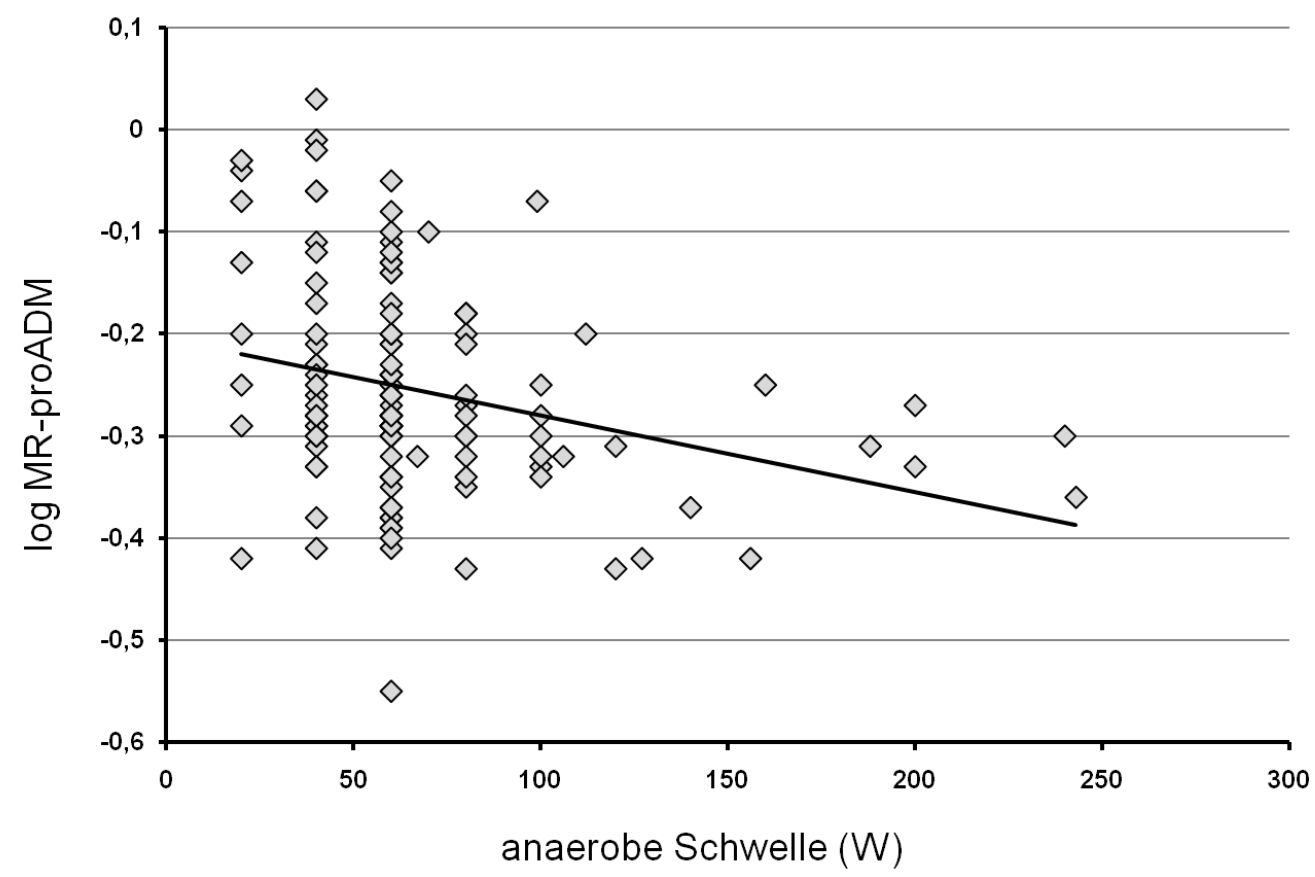

Abbildung 19: Darstellung der Korrelation zwischen log MR-proADM und der anaeroben Schwelle $(p<0,001)$ 


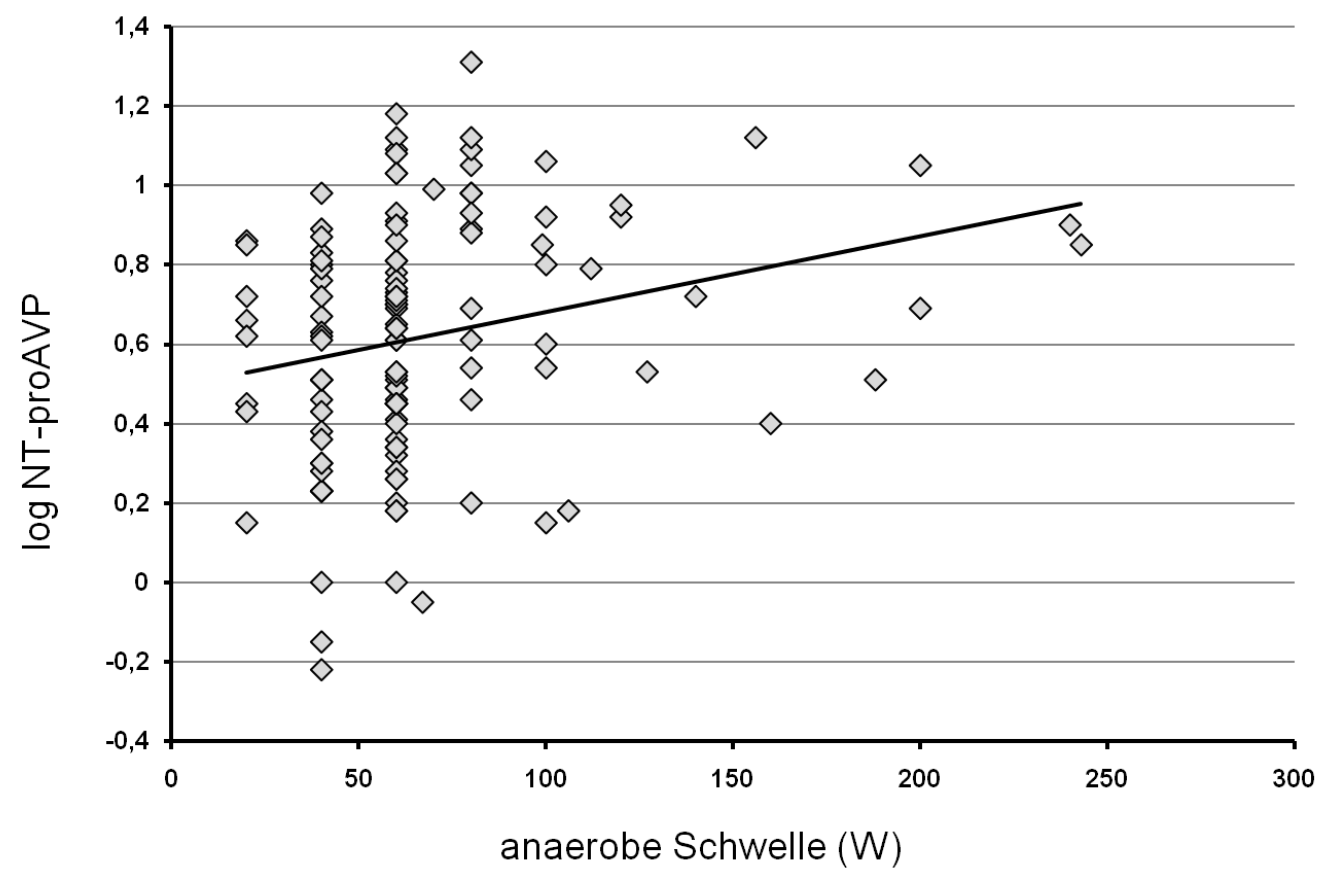

Abbildung 20: Darstellung der Korrelation zwischen log CT-proAVP und der anaeroben Schwelle $(p=0,001)$

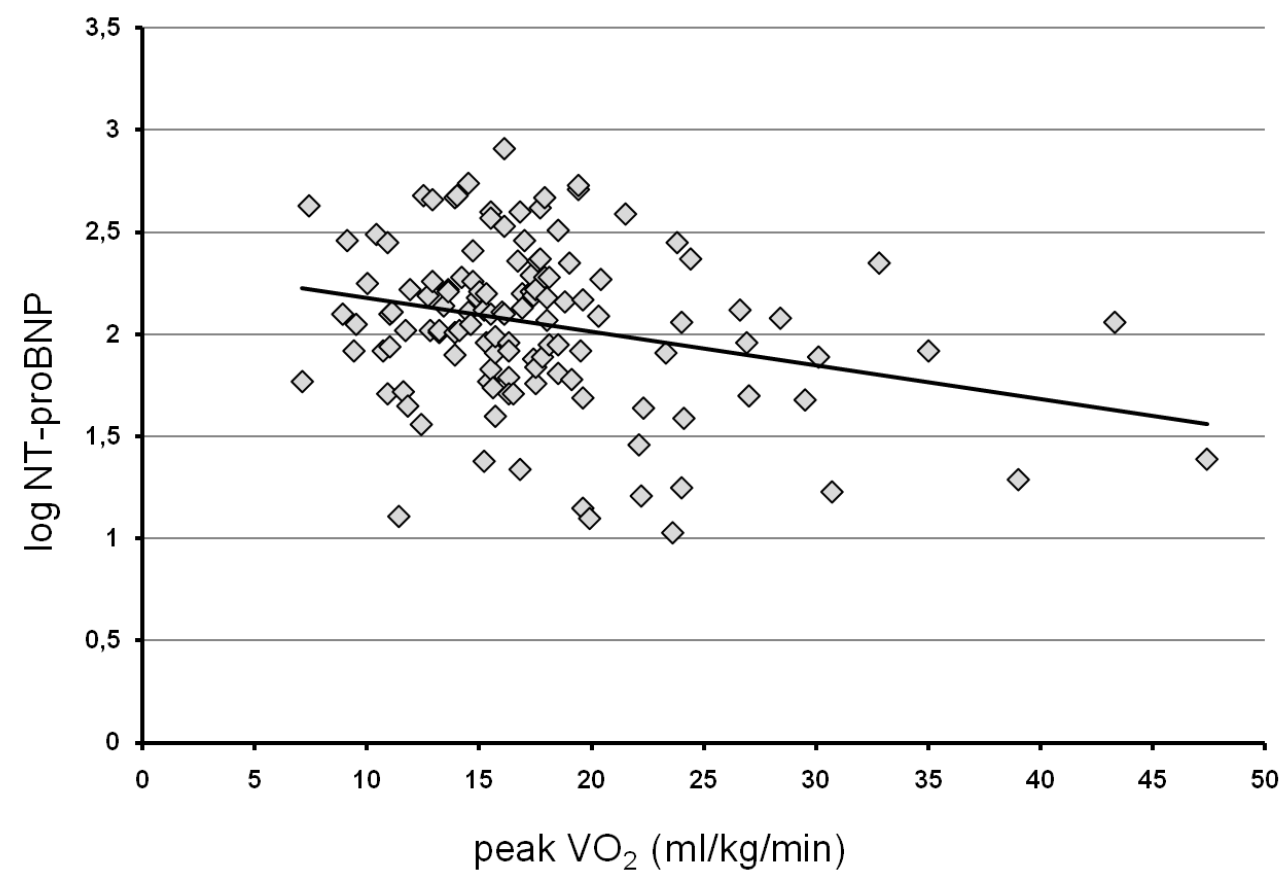

Abbildung 21: Darstellung der Korrelation zwischen log NT-proBNP und der peak VO2 $(p=0,028)$ 


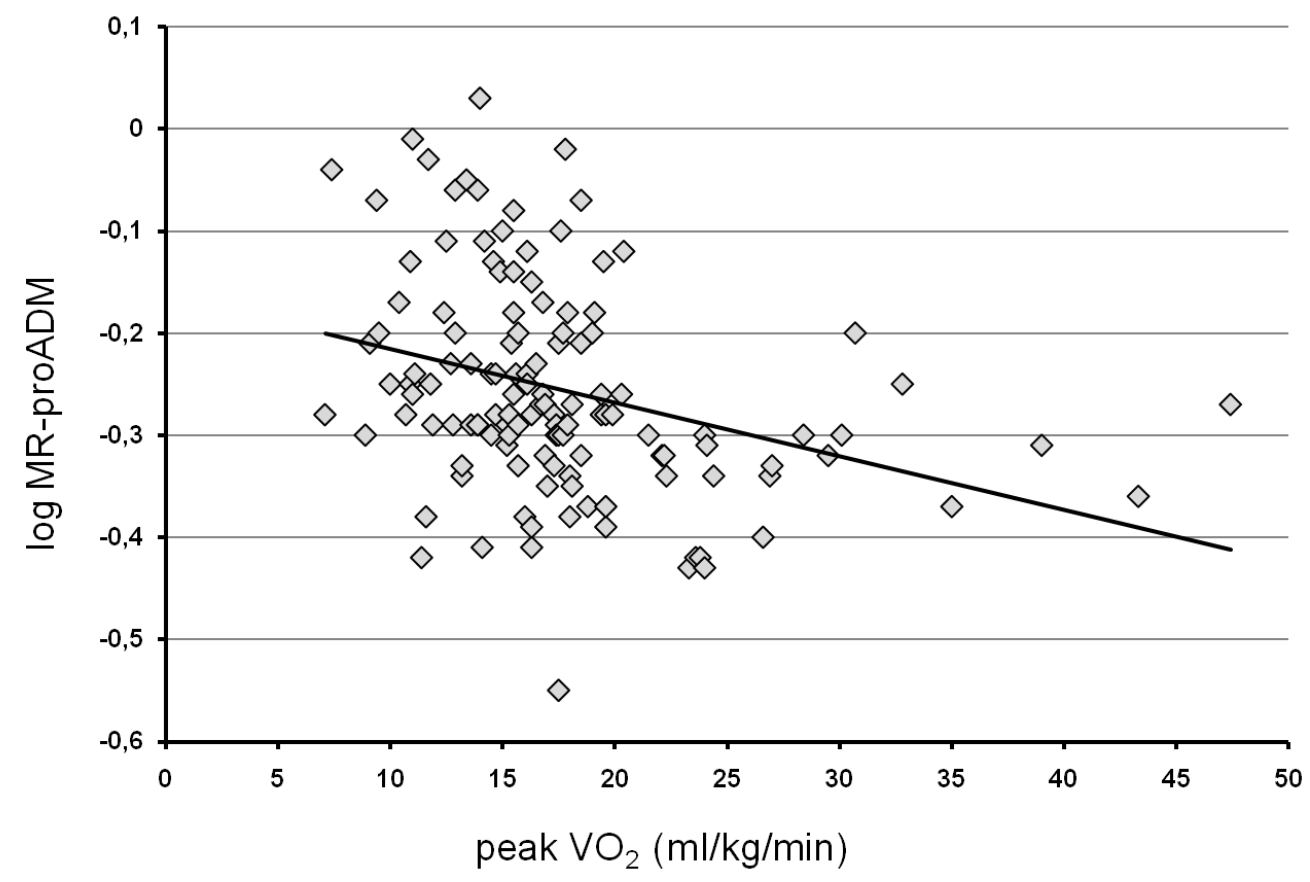

Abbildung 22: Darstellung der Korrelation zwischen log MR-proADM und der peak VO2 $(p<0,001)$

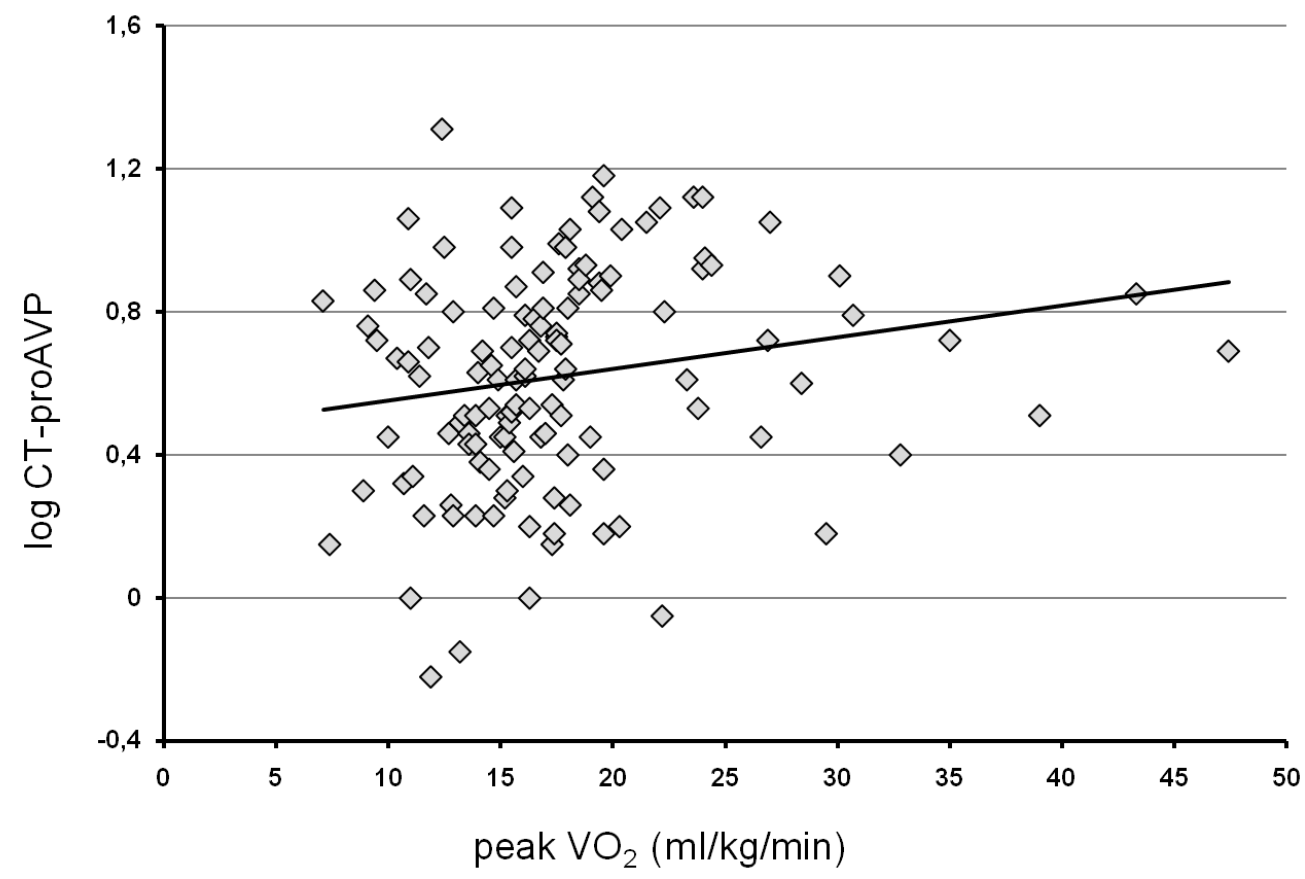

Abbildung 23: Darstellung der Korrelation zwischen log CT-proAVP und der peak VO2 $(p=0,001)$ 


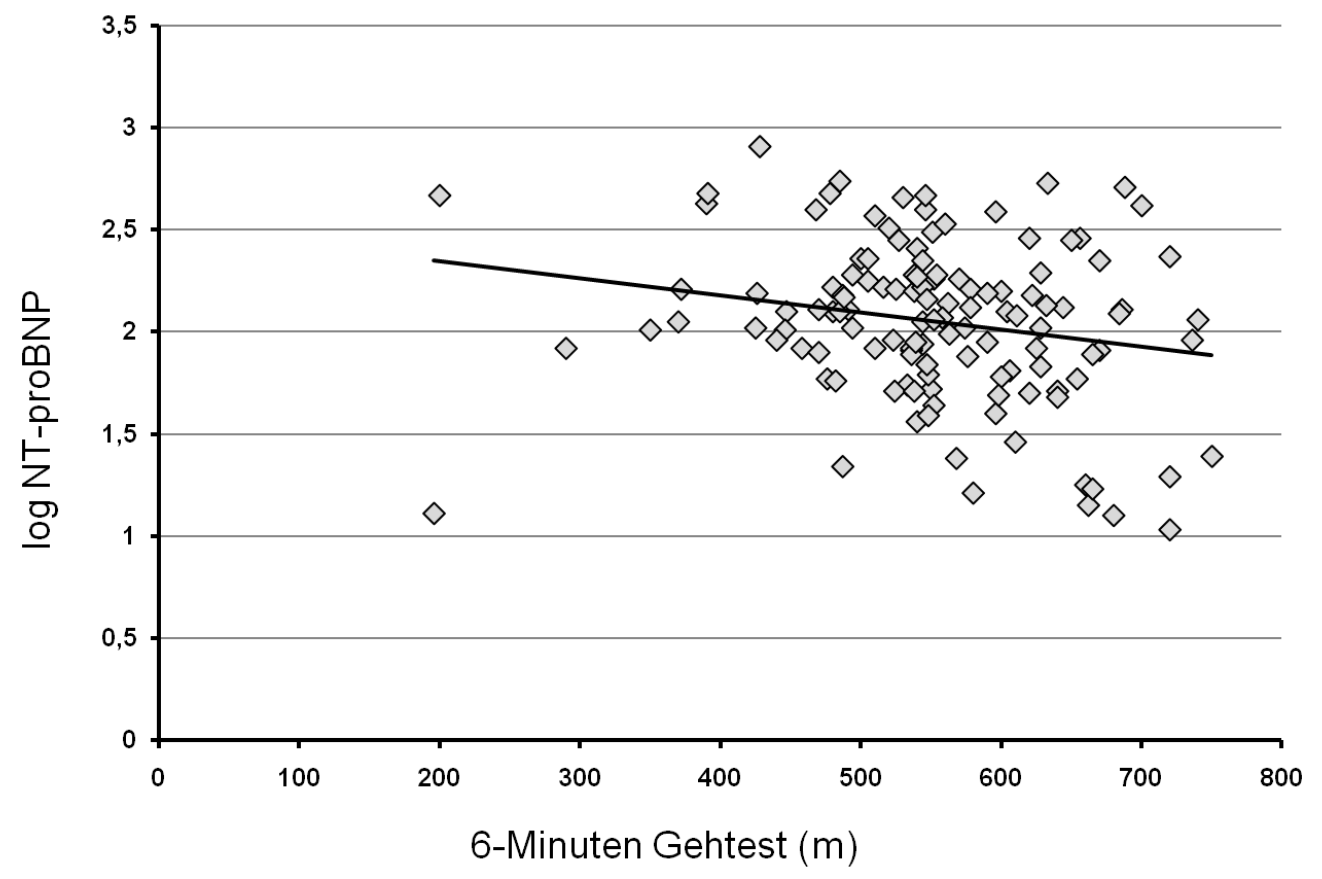

Abbildung 24: Darstellung der Korrelation zwischen log NT-proBNP und dem 6-MinutenGehtest $(p=0,019)$

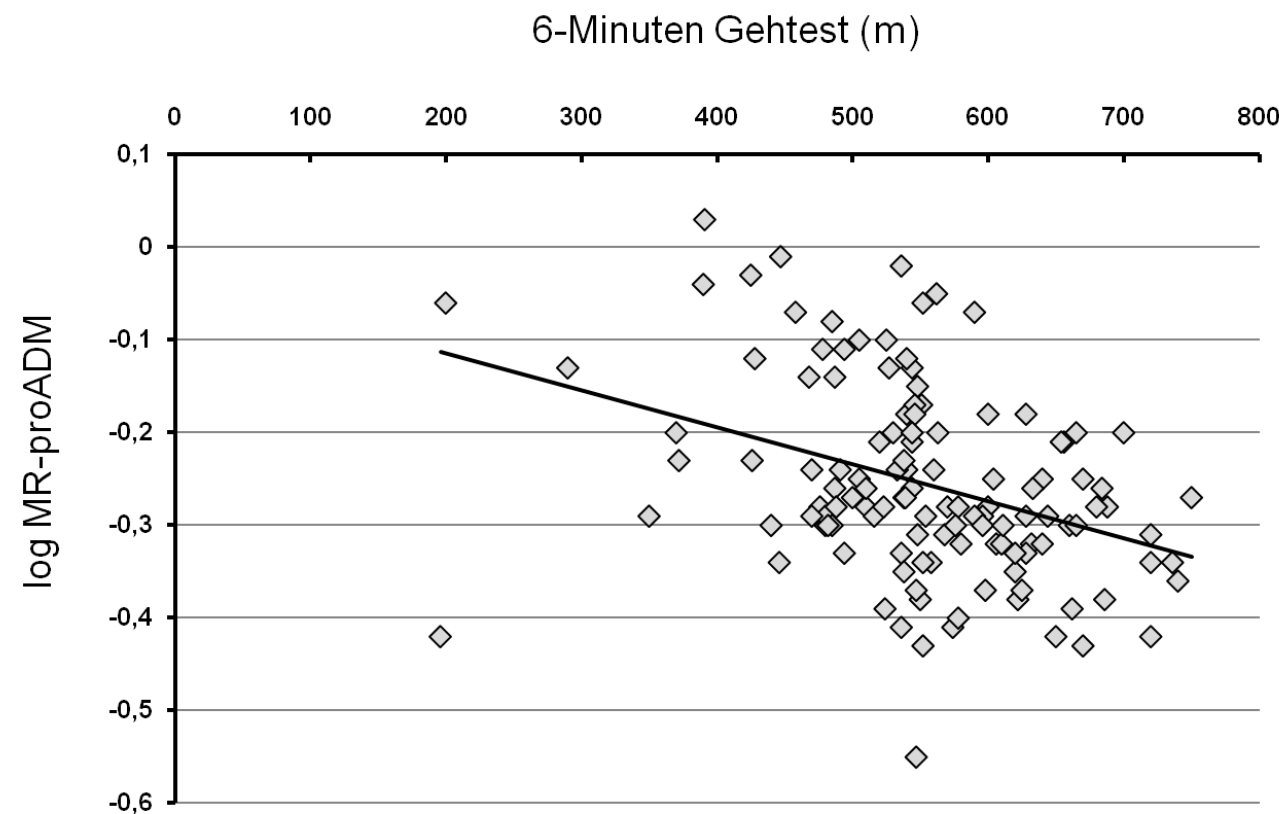

Abbildung 25: Darstellung der Korrelation zwischen log MR-proADM und dem 6-Minuten Gehtest $(p<0,001)$ 
In der Tabelle 12 wurde die Korrelation zwischen der neurohumoralen Aktivierung und ausgewählten Echoparametern der diastolischen Funktion untersucht. Hierbei zeigte sich, dass die Laborparameter nur partiell mit einigen wenigen Echoparametern korrelieren. Log NT-proBNP korreliert mit der a'Welle $(p<0,001)$, der $e^{\prime}-$ Welle $(p=0,003)$, LAVI $(p=0,007)$ sowie $E / e^{\prime}(p=0,007)$. Zwischen $E / e^{\prime}$ und log MR-proANP zeigt sich mit $p=0,019$ ein Zusammenhang. Eine ähnliche Beziehung zu MR-proANP zeigte auch der LAVI $(p=0,01)$. Die Echoparameter $a^{\prime}$-Welle $(p=0,004)$ und e'-Welle (med. Mitralanulus) $(p=0,003)$ korrelieren mit log MR-proADM. Auch log CT-proET-1 korreliert mit der e'Welle (med. Mitralanulus) $(p=0,003)$, der A-Welle $(p=0,05)$ sowie mit dem E/A-Verhältnis $(p=0,039)$. Als einziger neurohumoraler Marker zeigt sich bei log CT- proAVP ein signifikanter Zusammenhang mit LA-ES $(p=0,008)$.

Tabelle 12: Korrelation zwischen der neurohumoralen Aktivierung und ausgewählten Echoparametern

\begin{tabular}{|c|c|c|c|c|c|c|}
\hline & & $\begin{array}{l}\log \text { NT- } \\
\text { proBNP }\end{array}$ & $\begin{array}{l}\text { log MR- } \\
\text { proANP }\end{array}$ & $\begin{array}{l}\text { log MR- } \\
\text { proADM }\end{array}$ & $\begin{array}{l}\log \text { CT- } \\
\text { proET-1 }\end{array}$ & $\begin{array}{l}\log \text { CT- } \\
\text { proAVP }\end{array}$ \\
\hline LAVI & $r$ & $0,242^{\star \star}$ & $0,232^{*}$ & $-0,540$ & $-0,720$ & 0,137 \\
\hline & $p$ & 0,007 & 0,010 & 0,555 & 0,430 & 0,134 \\
\hline LA(ES) & r & 0,138 & 0,132 & $-0,053$ & $-0,093$ & $0,235^{\star \star}$ \\
\hline & $p$ & 0,125 & 0,141 & 0,552 & 0,300 & 0,008 \\
\hline A- Welle (MD) & $r$ & 0,004 & $-0,029$ & 0,081 & $0,176^{\star}$ & 0,032 \\
\hline & $p$ & 0,968 & 0,747 & 0,368 & 0,050 & 0,719 \\
\hline$a^{\prime}-$ Welle med. & r & $-0,336^{\star \star *}$ & $-0,132$ & $-0,254^{\star \star}$ & $-0,130$ & 0,136 \\
\hline Mitralanulus (GD) & $p$ & 0,000 & 0,141 & 0,004 & 0,147 & 0,129 \\
\hline$e^{\prime}-\quad$ Welle med. & r & $-0,263^{\star *}$ & $-0,131$ & $-0,268^{\star \star}$ & $-0,267^{\star \star}$ & 0,102 \\
\hline Mitralanulus (GD) & $p$ & 0,003 & 0,145 & 0,003 & 0,003 & 0,258 \\
\hline$V p$ & $r$ & $-0,163$ & $-0,059$ & $-0,016$ & $-0,118$ & 0,095 \\
\hline
\end{tabular}




\begin{tabular}{|c|c|c|c|c|c|c|}
\hline & $p$ & 0,069 & 0,517 & 0,858 & 0,189 & 0,292 \\
\hline \multirow[t]{2}{*}{ E/e' medial } & $r$ & $0,239^{\star \star}$ & $0,209^{*}$ & 0,144 & 0,131 & $-0,119$ \\
\hline & $p$ & 0,007 & 0,019 & 0,108 & 0,144 & 0,185 \\
\hline \multirow[t]{2}{*}{ LVEF [\%] } & $r$ & $-0,051$ & 0,032 & 0,173 & 0,109 & $-0,095$ \\
\hline & $\mathrm{p}$ & 0,572 & 0,723 & 0,054 & 0,227 & 0,293 \\
\hline \multirow[t]{2}{*}{ LVMI } & $r$ & 0,002 & $-0,071$ & $-0,100$ & $-0,052$ & 0,021 \\
\hline & $p$ & 0,983 & 0,431 & 0,268 & 0,567 & 0,813 \\
\hline \multirow[t]{2}{*}{$E / A$} & $r$ & 0,063 & 0,131 & $-0,077$ & $-0,185^{\star}$ & $-0,060$ \\
\hline & $p$ & 0,487 & 0,146 & 0,393 & 0,039 & 0,508 \\
\hline
\end{tabular}

${ }^{*} \mathrm{p}<0,05, \quad{ }^{* *} \mathrm{p}<0,01, \quad{ }^{* * *} \mathrm{p}<0,001, \quad \mathrm{p}=$ Signifikanz $\quad(2$-seitig), $\quad r=$ Korrelationskoeffizient, $\quad \mathrm{MD}=$ Mitralisdoppler, GD= Gewebedoppler

\subsection{Gewichtung der Zusammenhänge von verschiedenen echokardiographischen und neurohumoralen Faktoren mit Parametern der Belastungsfähigkeit}

Die in der Tabelle 13 untersuchte Multiple Regression der peak $\mathrm{VO}_{2}$ weist wie bei der maximalen Gehstrecke einen Zusammenhang mit dem Geschlecht $(p=0,004)$ und Alter $(p=0,016)$ der Patienten auf. Weiterhin haben auch der BMI $(p=0,006)$ und die Hormone log NT-proBNP $(p=0,001)$ und log MR-proANP $(p=0,002)$ einen signifikant direkten Einfluss auf den Belastungsparameter peak $\mathrm{VO}_{2}$. Die beiden hier untersuchten Echoparameter $E / e^{\prime}$ und $(p=0,64)$ der LAVI $(p=982)$ zeigen jedoch keinen nachweisbaren Zusammenhang mit der peak $\mathrm{VO}_{2}$. 
Tabelle 13: Multiple Regression der Peak $\mathrm{VO}_{2}$

\begin{tabular}{|c|c|c|c|c|c|}
\hline & Nicht standardisierte Koeff & zienten & $\begin{array}{l}\text { Standardisierte } \\
\text { Koeffizienten }\end{array}$ & & \\
\hline & Regressionskoeffizient B & Standardfehler & Beta & $\bar{T}$ & $p$ \\
\hline Konstante & 47,582 & 18,510 & & 2,571 & 0,012 \\
\hline Geschlecht & $-3,572$ & 1,218 & $-0,299$ & $-2,932$ & 0,004 \\
\hline Alter [J] & $-0,167$ & 0,068 & $-0,216$ & $-2,443$ & 0,016 \\
\hline BMI [kg/m²] & $-0,380$ & 0,135 & $-0,268$ & $-2,815$ & 0,006 \\
\hline E/e' medial & 0,071 & 0,152 & 0,039 & 0,469 & 0,640 \\
\hline LAVI & $-0,006$ & 0,067 & $-0,008$ & $-0,090$ & 0,928 \\
\hline $\begin{array}{l}\log N T- \\
\text { proBNP }\end{array}$ & $-5,464$ & 1,671 & $-0,361$ & $-3,270$ & 0,001 \\
\hline $\begin{array}{l}\log M R- \\
\text { proANP }\end{array}$ & 12,029 & 3,694 & 0,368 & 3,256 & 0,002 \\
\hline $\begin{array}{l}\text { log MR- } \\
\text { proADM }\end{array}$ & $-5,286$ & 7,165 & $-0,091$ & $-0,738$ & 0,462 \\
\hline $\begin{array}{l}\log \mathrm{CT}- \\
\text { proET1 }\end{array}$ & $-10,199$ & 7,360 & $-0,152$ & $-1,386$ & 0,169 \\
\hline $\begin{array}{l}\log C T- \\
\text { proAVP }\end{array}$ & 1,233 & 1,776 & 0,061 & 0,694 & 0,489 \\
\hline \multicolumn{6}{|c|}{$\mathrm{p}=$ Signifikanz (2-seitig) } \\
\hline
\end{tabular}


Spiroergometrie erhobene anaerobe Schwelle zeigt sich direkt durch das Geschlecht $(p=0,001)$ und das Alter $(p=0,022)$ sowie durch log NT-proBNP $(p=0,039)$ und log MR-proANP $(p=0,002)$ beeinflusst.

Tabelle 14: Multiple Regression der anaerobe Schwelle in der Spiroergometrie

\begin{tabular}{|c|c|c|c|c|c|}
\hline & Nicht standardisierte Koef & zienten & $\begin{array}{l}\text { Standardisierte } \\
\text { Koeffizienten }\end{array}$ & & \\
\hline & Regressionskoeffizient B & Standardfehler & Beta & $\bar{T}$ & $\mathbf{p}$ \\
\hline Konstante & 186,128 & 123,585 & & 1,506 & 0,135 \\
\hline Geschlecht & $-27,057$ & 8,135 & $-0,352$ & $-3,326$ & 0,001 \\
\hline Alter [J] & $-1,060$ & 0,457 & $-0,213$ & $-2,322$ & 0,022 \\
\hline BMI $\left[\mathrm{kg} / \mathrm{m}^{2}\right]$ & 0,341 & 0,901 & 0,037 & 0,379 & 0,705 \\
\hline E/e' medial & 1,048 & 1,012 & 0,089 & 1,035 & 0,303 \\
\hline LAVI & $-0,720$ & 0,448 & $-0,147$ & $-1,608$ & 0,111 \\
\hline $\begin{array}{l}\log N T- \\
\text { proBNP }\end{array}$ & $-23,325$ & 11,156 & $-0,240$ & $-2,091$ & 0,039 \\
\hline $\begin{array}{l}\text { log MR- } \\
\text { proANP }\end{array}$ & 78,584 & 24,666 & 0,373 & 3,186 & 0,002 \\
\hline $\begin{array}{l}\text { log MR- } \\
\text { proADM }\end{array}$ & $-44,957$ & 47,837 & $-0,120$ & $-0,940$ & 0,349 \\
\hline $\begin{array}{l}\text { log MR- } \\
\text { proET1 }\end{array}$ & $-81,136$ & 49,138 & $-0,188$ & $-1,651$ & 0,102 \\
\hline $\log A V P$ & 15,408 & 11,857 & 0,119 & 1,299 & 0,197 \\
\hline
\end{tabular}


Bei der Regressionsanalyse von $\mathrm{ATVO}_{2}$ in Tabelle 15 ist zu erkennen, dass lediglich log NT-proBNP $(p=0,001)$ und log MR-proANP $(p=0,001)$ einen direkten signifikanten Einfluss auf $\mathrm{ATVO}_{2}$ haben. Wiederum zeigt sich auch hier, dass E/é und der LAVI keinen Zusammenhang mit $\mathrm{ATVO}_{2}$ aufweisen.

Tabelle 15: Multiple Regression der $\mathrm{ATVO}_{2}$

\begin{tabular}{|c|c|c|c|c|c|}
\hline & Nicht standardisierte Koef & zienten & $\begin{array}{l}\text { Standardisierte } \\
\text { Koeffizienten }\end{array}$ & & \\
\hline & Regressionskoeffizient B & Standardfehler & Beta & $\mathbf{T}$ & $p$ \\
\hline Konstante & 35,445 & 17,961 & & 1,973 & 0,051 \\
\hline Geschlecht & $-2,510$ & 1,182 & $-0,234$ & $-2,123$ & 0,036 \\
\hline Alter [J] & $-0,117$ & 0,066 & $-0,168$ & $-1,762$ & 0,081 \\
\hline BMI $\left[\mathrm{kg} / \mathrm{m}^{2}\right]$ & $-0,212$ & 0,131 & $-0,167$ & $-1,620$ & 0,108 \\
\hline E/e' medial & 0,020 & 0,147 & 0,012 & 0,134 & 0,893 \\
\hline LAVI & $-0,095$ & 0,065 & $-0,139$ & $-1,459$ & 0,147 \\
\hline $\begin{array}{l}\log N T- \\
\text { proBNP }\end{array}$ & $-5,322$ & 1,621 & $-0,391$ & $-3,283$ & 0,001 \\
\hline $\begin{array}{l}\log M R- \\
\text { proANP }\end{array}$ & 12,633 & 3,585 & 0,430 & 3,524 & 0,001 \\
\hline $\begin{array}{l}\text { log MR- } \\
\text { proADM }\end{array}$ & $-3,442$ & 6,952 & $-0,066$ & $-0,495$ & 0,621 \\
\hline $\begin{array}{l}\log \text { CT- } \\
\text { proET1 }\end{array}$ & $-11,311$ & 7,141 & $-0,188$ & $-1,584$ & 0,116 \\
\hline $\begin{array}{l}\log \mathrm{CT}- \\
\text { proAVP }\end{array}$ & 1,499 & 1,723 & 0,083 & 0,870 & 0,386 \\
\hline
\end{tabular}


Tabelle 16: Multiple Regression der Gehstrecke

\begin{tabular}{|c|c|c|c|c|c|}
\hline & Nicht standardisierte Koef & zienten & $\begin{array}{c}\text { Standardisierte } \\
\text { Koeffizienten }\end{array}$ & & \\
\hline & Regressionskoeffizient B & Standardfehler & Beta & $\bar{T}$ & $\bar{p}$ \\
\hline Konstante & 1101,181 & 326,700 & & 3,371 & 0,001 \\
\hline Geschlecht & $-66,899$ & 21,315 & $-0,346$ & $-3,139$ & 0,002 \\
\hline Alter [J] & $-2,606$ & 1,189 & $-0,210$ & $-2,191$ & 0,031 \\
\hline BMI $\left[\mathrm{kg} / \mathrm{m}^{2}\right]$ & $-3,909$ & 2,341 & $-0,172$ & $-1,670$ & 0,098 \\
\hline E/e' medial & 2,376 & 2,624 & 0,081 & 0,905 & 0,367 \\
\hline LAVI & $-0,358$ & 1,163 & $-0,029$ & $-0,308$ & 0,759 \\
\hline $\begin{array}{l}\log N T- \\
\text { proBNP }\end{array}$ & $-40,172$ & 28,993 & $-0,165$ & $-1,386$ & 0,169 \\
\hline $\begin{array}{l}\log M R- \\
\text { proANP }\end{array}$ & 105,550 & 64,573 & 0,200 & 1,635 & 0,105 \\
\hline $\begin{array}{l}\text { log MR- } \\
\text { proADM }\end{array}$ & $-85,577$ & 126,292 & $-0,092$ & $-0,678$ & 0,499 \\
\hline $\begin{array}{l}\log \mathrm{CT}- \\
\text { proET1 }\end{array}$ & $-194,769$ & 128,265 & $-0,181$ & $-1,518$ & 0,132 \\
\hline $\begin{array}{l}\log C T- \\
\text { proAVP }\end{array}$ & 15,385 & 30,742 & 0,048 & 0,500 & 0,618 \\
\hline \multicolumn{6}{|c|}{$\mathrm{p}=$ Signifikanz (2-seitig) } \\
\hline
\end{tabular}


$(p=0,098)$ und log MR-proANP $(p=0,105)$ feststellen. Wider Erwarten konnte kein direkter Einfluss der restlichen humoralen Aktivierung auf die maximale Gehstrecke nachgewiesen werden. 


\section{Diskussion}

In den vergangenen drei Jahrzehnten ist immer deutlicher geworden, dass der DHF unbedingt mehr Aufmerksamkeit geschenkt werden muss: Da es sich um eine Erkrankung handelt, die mit der Häufigkeitsrelation und der schlechten Prognose der SHF gleichzusetzen ist, gilt es zukünftig die Zusammenhänge der klinischen Ausprägung und der direkten Veränderung am Herzen sowie der neurohumoralen Aktivierung besser zu verstehen.

Bisher wurde der Einfluss der neurohumoralen Aktivierung hinsichtlich der Beziehung zur Belastbarkeit von Patienten mit einer DD und einer DHF noch nicht untersucht. Zu diesem Zweck wurden in der vorliegenden Arbeit die Hormone bzw. Hormonfragmente NT-proBNP, MR-proANP, MR-proADM, CT-proET1 und CT-proAVP auf einen Zusammenhang mit der submaximalen und maximalen Belastbarkeit analysiert. Im Folgenden sollen die Ergebnisse dieser Arbeit bewertet und in den bisherigen Wissensstand der Forschung zum Thema eingeordnet werden.

\subsection{Patientencharakteristik}

Aus epidemiologischen Studien ist bereits bekannt, dass Patienten mit einer DD und DHF zusätzlich an weiteren Krankheiten leiden. Diese beinträchtigen sowohl direkt als auch indirekt die hier zu untersuchende Belastbarkeit der Patienten. Daher ist es von enormer Bedeutung, durch Ein- und Ausschlusskriterien ein für die DD und DHF typisches Patientenkollektiv auszuwählen.

Das untersuchte 201-Patienten-starke Kollektiv der vorliegenden Arbeit setzt sich aus konsekutiv rekrutierten Patienten zusammen und wurde anhand von echokardiographischen Daten und der NYHA-Klassifikation in zwei Gruppen eingeteilt: Die erste Gruppe besteht aus 14 Patienten mit einer echokardiographisch nachgewiesenen DD, ohne subjektive Belastungseinschränkung. In der zweiten Gruppe befinden sich 112 Patienten, die durch das Vorliegen einer DD mit einer Belastungseinschränkung im Sinne einer NYHA>1 charakterisiert sind, also Patienten mit einer DHF.

Um zu zeigen, dass es sich bei dem vorgestellten Patientenkollektiv um ein für die DHF typisches handelt, werden nun im Folgenden die demographischen Daten der Patienten mit den Daten aus anderen Studien verglichen: Insgesamt wurden 61 Männer (48,4\%) und 65 Frauen $(51,6 \%)$ 
untersucht. Das entspricht einer nahezu ausgeglichenen Geschlechterverteilung. In der Studie von Tschöpe et al. (2005) hingegen ist das männliche Geschlecht mit 55\% leicht überrepräsentiert, bei einer ähnlichen Patientenzahl von $n=118$. In einer weiteren Studie von Redfield et al. (2004) ist die Anzahl der Männer mit 48\% aber identisch zu der in dieser Studie. Die Gesamtzahl der Probanden von Redfield et al. betrug $n=2042$. (Redfield et al. 2004, Tschöpe et al. 2005)

Nicht zuletzt wurde aufgrund der angesetzten Belastungstests besonderes Augenmerk auf das Gewicht der Patienten gelegt. Ein erhöhter BMI und das somit einhergehende Übergewicht ist ein typischer RF für eine DD (Van Putte-Katier et al. 2008). Die Adipositas ist demnach eine der häufigsten Begleiterkrankungen der DHF, wie unter anderem auch Studien von Klapholz et al. und Owan et al. belegen (Klapholz et al. 2004, Owan et al. 2006). Der durchschnittliche BMI der DD- und DHF-Gruppe lag bei immerhin $30,1 \mathrm{~kg} / \mathrm{m}^{2}$ und $30,4 \mathrm{~kg} / \mathrm{m}^{2}$. Damit sind beide Gruppen miteinander vergleichbar. Mit einem durchschnittlichen BMI von $30,3 \mathrm{~kg} / \mathrm{m}^{2}$ sind die hier ermittelten Werte in etwa mit denen von Redfield et al. (2004), der einen mittleren BMI von $28,4 \mathrm{~kg} / \mathrm{m}^{2}$ vorfand, gleichrangig (Redfield et al. 2004). Die Daten von Tschöpe et al. (2005) hingegen fallen mit $26,1 \mathrm{~kg} / \mathrm{m}^{2}$ deutlich niedriger aus. Ein Grund hierfür könnte das mit 49 Jahren geringere Durchschnittsalter der von Tschöpe et al. untersuchten Patienten sein. Bei einem Durchschnittsalter von 61,7 Jahren sind die von uns untersuchten Patienten also mit denen von Redfield et al. (2004) gleichzusetzen: Hier betrug das gerundete Durchschnittsalter ebenfalls 62 Jahre. Wie bei den oben gezeigten, epidemiologischen Daten handelt es sich um ein sehr repräsentatives Kollektiv für Patienten mit einer DD und DHF.

Auch erhöhter Blutdruck spielt eine entscheidende Rolle in der Charakteristika von DHF-Patienten (Owan et al. 2006): Laut einer Studie von Owan et al. (2006) haben Patienten mit einer DHF signifikant häufiger einen Hypertonus als Patienten mit einer SHF. Der durchschnittliche systolische Blutdruck in dem hier vorliegenden Patientenkollektiv betrug $141,2 \mathrm{mmHg}$, der diastolische $86 \mathrm{mmHg}$. Auch Fischer et al. (2003) stellten bei ihren Patienten mit einer anomalen diastolischen Funktion einen durchschnittlichen RR von 140/84 mmHg fest. Diese, vor allem systolisch erhöhten RR-Werte, decken sich mit der Erkenntnis, dass bei Hypertonikern eine erhöhte Prävalenz der DD vorliegt (Almuntaser et al. 2007, Zanchetti et al. 2007). In der DD-Gruppe lag bei 92,9\% und in der DHF-Gruppe bei $84,8 \%$ der Patienten ein diagnostizierter Hypertonus vor. Und auch in der größten zum Thema DHF durchgeführten Medikamentenstudie, I-Preserve, lag der Anteil der Hypertoniker bei 88,5\% (Massie et al. 2008). In diese Studie schloss man 4128 symptomatische Patienten mit einer NYHA II-IV, einer 
LVEF $\geq 45 \%$ und einem Alter $\geq 60$ Jahren ein und behandelte sie in der Placebo-kontrollierten Studie vollkommen erfolglos mit einem Angiotensin-II-Rezeptorantagonist. Dieses Kollektiv ähnelt der Charakteristik der DHF-Gruppe und ist damit besonders für Vergleiche geeignet.

Neben der Hypertonie sind aber auch noch andere nennenswerte Erkrankungen eng mit der DHF verbunden: Unter anderem wurde in dem hier untersuchten Kollektiv zusätzlich eine vermehrte Neigung zur Hyperlipoproteinämie festgestellt. In der DD-Gruppe lag die Anzahl der Erkrankten bei immerhin $35,7 \%$. Und in der DHF-Gruppe war diese mit 49,1\% sogar noch etwas höher. Auch bei Tschöpe et al. (2005) zeigte sich mit 44\% ein vergleichbarer Wert bei den Patienten mit einer DD. Dass es sich bei der Hyperlipoproteinämie um einen RF der DD handelt, belegte auch bereits Elesber et al. (2007).

Nicht zu vernachlässigen ist die Tatsache, dass auch Diabetiker nach Studienergebnissen von Wachter et al. (2007) eine höhere Prävalenz für die Entwicklung einer DD zeigen. Demzufolge ist also auch der Diabetes mellitus ein zusätzlicher und absolut relevanter RF für die DHF. Dies deckt sich mit den in der vorliegenden Studie erhobenen Werten: Bei immerhin 16,1\% der DHF-Patienten konnte ein eindeutiger Diabetes mellitus diagnostiziert werden. Ähnlich sind auch die Ergebnisse von Tschöpe et al. (2005): 13\% der Patienten wiesen einen Diabetes mellitus auf.

Obwohl die KHK, ein Ml in der Anamnese sowie eine bestehende COPD eng mit dem typischen DHFPatientenkollektiv verbunden ist, haben wir uns entschlossen diese Begleiterkrankungen ab einem gewissen Schweregrad auszuschließen. So lässt sich einer zu großen Limitierung der Belastbarkeit durch diese Erkrankungen entgegenwirken. Dies erklärt auch die in der vorliegenden Studie vorgefundene niedrige Anzahl der Patienten mit KHK (DD 0\%, DHF 21,4\%), mit einem MI in der Anamnese (DD 0\%, DHF 6,3\%), mit einer COPD (DD 0\%, DHF 6,3\%) sowie einer pAVK (DD 0\%, DHF 1,8\%): Als Ausschlusskriterien wurden im Speziellen eine bestehende und signifikante Koronarstenose $>50 \%$ sowie ein $\mathrm{Ml}$ in den zurückliegenden drei Monaten definiert. Diese Kriterien wurden ebenfalls in der oben erwähnten I-Preserve-Studie angewendet. Zudem waren für die korrekte Durchführung des 6-Minuten-Gehtests und der Spiroergometrie Patienten mit einer klinisch symptomatischen PAVK und einer nachgewiesenen Lungenerkrankung mit Einschränkung der VC $<80 \%$ und $\mathrm{FEV} 1<80 \%$ von der Studie ausgenommen. Diese Faktoren waren für eine korrekte Durchführung der Belastungsuntersuchungen unabdingbar, da die Belastbarkeit nur durch die DD und nicht durch weitere Erkrankungen eingeschränkt werden sollte. In Bezug auf die in den 
vorangegangenen Absätzen beleuchteten Komorbiditäten wurde gezeigt, dass es sich in dieser Studie um ein äußerst repräsentatives Kollektiv handelt.

Die klinischen Symptome der hier untersuchten Patienten sind aufgrund der symptomatischen und asymptomatischen Gruppenverteilung bereits vorgezeichnet. Da die beiden Kollektive anhand der NYHA-Klassifikation eingeteilt wurden, ergibt sich, dass zwar 100\% der DHF-Gruppe, aber kein Patient aus der DD-Gruppe eine Belastungsdyspnoe aufzeigen. Die Nykturie stellt sich sowohl in der DD- als auch in der DHF-Gruppe als ein häufiges klinisches Symptom dar. Aufgrund der hier untersuchten älteren Patienten ist die bestehende Nykturie nicht allein auf die HF zurückzuführen. Weiterhin tritt die individuell empfundene Müdigkeit und Leistungsschwäche bei $73 \%$ der Patienten im DHF-Kollektiv auf. In der DD-Gruppe handelt es sich um subjektiv asymptomatische Patienten, daher sind die signifikanten Unterschiede zwischen DD- und DHF-Kollektiv weder bei der Belastungsdyspnoe, bei Ödemen, beim nächtlichem Husten, bei der paroxysmalen nächtlicher Dyspnoe, bei der Orthopnoe noch bei der Ruhedyspnoe verwunderlich. Die in diesem Kollektiv vorgefundenen klinischen Herzinsuffizienzsymptome sprechen für ein sehr gut ausgewähltes Patientenkollektiv.

Die am häufigsten verordnete Substanz bei den in dieser Studie untersuchten Patienten mit kardiovaskulärer Indikation war ein Betablocker. 57,1\% in der DHF- und 21,4\% in der DD-Gruppe hatten diesen in der Vormedikation. Außerdem 58\% der 4128 in die I-Preserve Studie eingeschlossenen Patienten. Im Gesamtkollektiv von Redfield et al. (2004) nahmen dagegen nur $14,5 \%$ der Patienten einen Betablocker ein. Dies ist darauf zurückzuführen, dass Redfield nicht nur symptomatische, sondern auch asymptomatische Patienten eingeschlossen hatte. Deshalb ist der prozentuale Wert zu der DD-Gruppe vergleichbar niedrig. Für die ACE-Hemmer ergibt sich ein ähnliches Bild: 9\% der Patienten von Redfield et al. (2004) stehen 46,4\% in der DHF und 35,7\% der DD-Patienten gegenüber. Die Therapie mit Diuretika ist nur bedingt vergleichbar, da Redfield et al. (2004) diese allgemein und mit insgesamt 17\% erfasst haben, während hier eine genaue Aufschlüsselung nach Substanzuntergruppen zu finden ist. Allein Thiazide erhielten 36,6\% der DHFund sogar $42,9 \%$ der DD-Patienten. Der Grund für die vermehrte Einnahme von Medikamenten in diesem Kollektiv ist vermutlich der Rekrutierungsart zu zuschreiben. Die hier ausgewählten Patienten waren zum Zeitpunkt des Studieneinschluss bereits kardiologisch vorbehandelt, während Redfield et al. (2004) ihre Patienten aus einem Krankenregister auf Zufallsbasis auswählten. Ein weiterer Grund 
könnte sein, dass es sich bei den hier untersuchten Patienten zumindest in der DHF-Gruppe um ein hochsymptomatisches Patientenkollektiv handelt, welches entsprechend therapiert wurde. Dies belegt auch die Gegenüberstellung mit dem Patientenkollektiv der I-Preserve-Studie. Auch hier wurden hochsymptomatische Patienten untersucht.

Der Vergleich der erhobenen Echoparameter zwischen den einzelnen Studien ist aufgrund der unterschiedlichen Schemata für die Diagnostik der DHF nur bedingt möglich. In der hier vorliegenden Studie kam ein Schema zur Beurteilung der DD zum Einsatz, dass an der Universitätsmedizin Göttingen etabliert wurde (siehe 2.8). Die Einteilung der Patienten wird, abgesehen von der LVEF, sowohl anhand des E/A-Verhältnisses vorgenommen, als auch anhand des Verhältnisses von E/e'. Weiterhin werden das S/D- und das E/A-Verhältnis unter Valsalva-Manöver untersucht. Tschöpe et al. (2005) dagegen setzten zwar ebenfalls einen Gewebedoppler ein, beurteilten allerdings anstatt des E/e'- das E'/A‘-Verhältnis. Zusätzlich wurde neben dem S/D-Verhältnis die Dezelerationszeit zur Stadieneinteilung hinzugezogen. Redfield et al. (2003) hingegen verwendeten ein Schema, das mit dem in dieser Studie angewendeten weitgehend vergleichbar ist (Redfield et al. 2003). Auch hier kam das E/e'-Verhältnis zum Einsatz, und es fand eine Unterteilung des restriktiven Stadiums in reversibel und irreversibel anhand des Valsalva-Manövers statt. Fischer et al. (2003) hingegen verwendeten das, 1998 von der „European Study Group on Diastolic Heart Failure“ vorgeschlagene, EchokardiographieSchema. Die Einteilung der DHF erfolgt hier ebenfalls nach der LVEF ( $\geq 45 \%)$. Danach wurden das E/A-Verhältnis sowie die IVRT in Abhängigkeit vom Alter der Patienten betrachtet.

Trotz dieser unterschiedlich genutzten Schemata ist der Vergleich zwischen den einzelnen Studienkollektiven möglich. Die hier durchschnittlich ermittelten LVEF-Werte von 66,9\% in der DDund $68,8 \%$ in der DHF-Gruppe sind mit den $68 \%$ der DHF-Patienten von Tschöpe et al. (2005) und den $64,6 \%$ der DD-Patienten von Fischer et al. (2003) vergleichbar. Alle hier gemessenen LVEFWerte sind ein Zeichen für eine erhaltene systolische Funktion. An dieser Stelle ist nochmals zu erwähnen, dass eine LVEF $\geq 50 \%$ ein Einschlusskriterium für diese Studienpopulation darstellte. Auch der in dieser Studie im Mittel gemessene LA(ES) von 40,6 mm in der DD- und 44,4mm in der DHFGruppe ähnelt den 42,1mm von Fischer et al. (2003). Diese Werte entsprechen einem vergrößerten linken Vorhof, was für eine DD und DHF typisch ist. Außerdem ist bekannt, dass ein erhöhter LADiameter mit einer verschlechterten Prognose assoziiert ist (Rossi et al. 2006). Durch die verspätete Relaxation des linken Ventrikel kommt es zu einem umgekehrten E/A-Verhältnis, dass sich sowohl in 
dieser Studie mit 0,9 in der DHF-Gruppe sowie mit 0,85 in der DD-Gruppe von Fischer et. al. (2003) wiederfindet.

Nachdem nun die demographischen Daten, die klinische Symptomatik, die RF, die Medikation und die Echoparameter diskutiert und beleuchtet wurden, kann abschließend festgehalten werden, dass es sich bei den 126 Patienten um ein typisches Kollektiv aus DD- und DHF-Patienten handelt. Sämtliche Patientencharakteristika waren problemlos mit denen aus anderen vorliegenden Studien zum Thema DD und DHF vergleichbar.

\subsection{Belastbarkeit bei Patienten mit einer diastolischen Dysfunktion und einer diastolischen Herzinsuffizienz}

Im aktuellen Konsensus-Papier der ESC wurde auf die Unterschiede in der Ausprägung der Symptome zwischen stationären und ambulanten Patienten hingewiesen. Darin wird betont, dass ambulante Patienten mit einer DHF oft nur eine Belastungsdyspnoe ohne sichtbare Zeichen einer Kongestion zeigen, während stationäre Patienten zu ausgeprägten Symptomen und Zeichen der Herzinsuffizienz neigen (Paulus et al. 2007). Im Rahmen dieser Studie wurde die Belastbarkeit ausschließlich von ambulanten Patienten anhand von zwei verschiedenen Belastungstests untersucht. Zum einen handelte es sich hierbei um einen submaximalen Belastungstest, den 6-Minuten-Gehtest. Weiterhin, um Rückschlüsse auf die Leistungsfähigkeit des kardiopulmonalen Systems ziehen zu können, wurde eine Spiroergometrie durchgeführt. Diese Untersuchung gilt als Goldstandard zur Messung der Belastbarkeit bei Gesunden sowie bei kardiologisch Erkrankten.

In den Untersuchungen zeigten sich gravierenden Unterschiede in der Belastbarkeit der beiden Patientenkollektive. Im 6-Minuten-Gehtest, als valider Test zur ersten Quantifizierung einer bestehenden Herzinsuffizienz (Guazzi et al. 2009), zeigte sich eine Diskrepanz zwischen den DD- und den DHF-Patienten $(663,9 \mathrm{~m} \pm 52,8$ vs. $537,6 \mathrm{~m} \pm 92,3)$ auf dem Signifikanzniveau von $<0,001$. Diese ist darauf zurückzuführen, dass es sich bei den DD-Patienten um Patienten ohne subjektive Belastungseinschränkung mit NYHA I handelt.

Auch in der Spiroergometrie zeigte sich eine signifikant schlechtere Belastbarkeit der DHF-Gruppe. Die peak $\mathrm{VO}_{2}$ sinkt bei den DHF- im Gegensatz zu den DD-Patienten von $30,5 \pm 8,4$ auf $16,0 \pm 4,0$ $\mathrm{ml} / \mathrm{kg} / \mathrm{min}$. Weitere signifikante Unterschiede zwischen den beiden Gruppen finden sich bei der 
verkürzten Belastungsdauer, der erniedrigten anaeroben Schwelle, der reduzierten Ventilation sowie bei der chronotropen Inkompetenz der DHF-Patienten. Auffällig war weiterhin, dass selbst im Ruhezustand ein deutlicher Unterschied zwischen beiden Kollektiven im Bezug auf den RQ zu erkennen war (DD 0,83 $\pm 0,06$ vs. DHF 0,87 $\pm 0,07$ ). Dieser Trend setzte sich während und nach der Belastung fort. Bis zum heutigen Zeitpunkt liegen noch keine vergleichbaren Daten aus anderen Studien vor, die die Belastbarkeit von Patienten mit einer DD der Belastbarkeit von DHF-Patienten gegenüberstellen.

Anhand dieser Untersuchungen wurde gezeigt, dass es sich bei den DHF-Patienten um Patienten mit einer massiv schlechteren objektiven Belastbarkeit gegenüber DD-Patienten handelt.

\subsection{Mechanismen der Belastungseinschränkung}

Es gab in vorangegangenen Studien unterschiedlichste Ansätze, um die eingeschränkte Belastbarkeit von Patienten mit einer DHF zu erklären. Kitzman postulierte bereits 2002, dass ein Grund der herabgesetzten Belastbarkeit von DHF-Patienten ein Versagen des Frank-Sarling-Mechanismus mit daraus resultierender verringerter Herzfrequenz, vermindertem Herzzeitvolumen und einer Zunahme des linksventrikulären Füllungsdruck ist (Kitzman 2002). Andere Studien widmeten sich den echokardiographischen Parametern der diastolischen Funktion und untersuchten zum Beispiel die Einflüsse von einem veränderten E/é und linksventrikulären diastolischen Druck in Ruhe sowie bei Belastung (Burgess et al. 2006). Bisher gab es allerdings keine Studie, die die neurohumorale Aktivierung bei Patienten mit einer DD und DHF im Bezug auf die Belastbarkeit dieser Patienten untersuchte. Eine Untersuchung dieses Zusammenhangs ist Schwerpunkt der vorliegenden Arbeit.

\subsection{Einfluss der diastolischen Funktion auf die Belastbarkeit von Patienten mit einer diastolischen Dysfunktion und diastolischen Herzinsuffizienz}

Der folgende Abschnitt widmet sich der Frage nach dem direkten Einfluss von Echokardiographieparametern auf die Belastbarkeit von Patienten mit einer DD und einer DHF. Dazu wird besonderes Augenmerk auf die Parameter der diastolischen Funktion gelegt.

Das E/é Verhältnis als Leitparameter der diastolischen Funktion besitzt eine zentrale Rolle bei der nicht-invasiven Diagnostik der DHF (Kasner et al. 2007). Bereits Burgess et. al untersuchten 2006 den 
Zusammenhang zwischen E/é und der Belastbarkeit bei Patienten mit einer erhaltenen LVEF und stabiler Angina pectoris. Hier zeigte sich, dass das E/é Verhältnis nur sehr bescheiden mit der Belastbarkeit von Patienten korreliert (Burgess et al. 2006). Genau die gleiche Erkenntnis haben wir in der hier vorliegenden Studie erlangt. Auch hier zeigt sich, dass E/é keinen signifikanten Zusammenhang mit den untersuchten Belastungsparametern aufzeigt. Diese Beziehung fehlt sowohl bei der durchgeführten Spiroergometrie, als auch bei dem 6-Minuten-Gehtest. Zudem zeigt, als ein systolischer Parameter, auch die LVEF keine signifikante Verbindung zu diesen Parametern. Hierbei ist zu beachten, dass in dieser Studie nur Patienten mit einer erhaltenen LVEF $(>50 \%)$ untersucht wurden. Es ist seit langem bekannt, dass die unter Ruhebedingungen ermittelte LVEF keine suffizienten Rückschlüsse auf die funktionelle Kapazität von Patienten mit einer HF zulässt (Franciosa et al. 1981). Dies ist darauf zurückzuführen, dass die Ruhe-LVEF die systolische Funktion unter Belastung nur unzureichend wiedergibt und auch Störungen der diastolischen Funktion nicht erfasst werden (Lele et al. 1996). Echokardiographische Werte, die signifikant mit der Spiroergometrie in Verbindung stehen, sind der LVMI und die á-Welle. Diese beiden Werte korrelieren sowohl mit der anaeroben Schwelle der $\mathrm{ATVO}_{2}$ als auch der peak $\mathrm{VO}_{2}$. Dieses Ergebnis stimmt mit bereits vorangegangenen Studien überein. Hier wurde gezeigt, dass der LVMI, der als echokardiographischer Hinweis auf eine diastolische Dysfunktion anzusehen ist, bei Patienten mit einer linksventrikulären Hypertrophie signifikant mit der peak $\mathrm{VO}_{2}$ korreliert (Fu et al. 2008). Die linksatriale Funktion ist eng mit der linksventrikulären Füllung und folglich mit der kardialen Leistungsfähigkeit verknüpft. Für den LA(ES) konnte eine signifikante Korrelation zur anaeroben Schwelle und zum 6-Minuten-Gehtest nachgewiesen werden. In einer Studie von Terzi et al. (2005) konnte ebenfalls gezeigt werden, dass der LA(ES) mit der anaeroben Schwelle signifikant in Beziehung steht. In dieser Analyse wurden Patienten mit einer Dilatativen Kardiomyopathie untersucht. Es zeigte sich zusätzlich ein Zusammenhang mit der peak $\mathrm{VO}_{2}$, der in der vorliegenden Arbeit nicht zu erkennen war (Terzi et al. 2005). In der Arbeit von Terzi et al. (2005) wurden keine weiteren Aussagen über die diastolischen Funktionsstörungen der Patienten gemacht, was den direkten Vergleich erschwert.

Das mittels Pulswellen-Doppler-Echokardiographie ermittelte E/A-Verhältnis zeigt eine signifikante Beziehung nur zu der anaeroben Schwelle. Ein Zusammenhang mit weiteren Belastungsparametern fehlte komplett. Im Gegensatz zu diesen Ergebnissen zeigten Gardin et al. (2009) eine Korrelation zwischen dem E/A-Verhälnis, der peak VO2 und dem 6-Minuten-Gehtest (Gardin et al. 2009). In dieser Studie wurden Patienten mit einer kombinierten SHF und einer DD untersucht. Das 
Durchschnittsalter der Patienten lag mit 59 Jahren deutlich unter denen in dieser Arbeit vorgestellten Patienten. Weiterhin zeigte die Studie von Gardin et al. (2005) mit einem Anteil von 28\% Frauen ein geschlechterspezifisch sehr unausgeglichenes Patientenkollektiv. Übereinstimmend mit der vorliegenden Studie fehlte auch hier der Zusammenhang zwischen den Belastungsparametern und der LVEF (mittlere LVEF 25\%).

Es finden sich nur punktuelle Zusammenhänge zwischen der Belastbarkeit der Patienten und der in Ruhe gemessenen diastolischen Funktion. Damit rückt der Einfluss der erhobenen diastolischen Funktion trotz diagnostischer Bedeutung auf die Leitungsfähigkeit der Patienten mit einer DHF weiter in den Hintergrund.

\subsection{Einfluss der neurohumoralen Aktivierung auf die Belastbarkeit}

Im folgenden Abschnitt soll der Frage nachgegangen werden, welchen Einfluss die neurohumorale Aktivierung auf die Belastbarkeit der hier untersuchten Patienten hat. Zu diesem Zweck wurde ein drittes Kollektiv aus 75 Patienten ohne DD, ohne RF und mit erhaltener, systolischer Funktion sowie ohne Einschränkung der Belastbarkeit generiert (KG).

Wie in der Tabelle 9 gesehen, haben die Patienten mit einer DHF eine signifikante Steigerung der neurohumoralen Aktivierung im Vergleich zur KG-Gruppe. Diese signifikanten Unterschiede fehlen zwischen der DD- und KG-Gruppe bis auf MR-proANP völlig. Damit haben wir gezeigt, dass symptomatische Patienten einen wesentlich höheren Neurohormonspiegel haben als asymptomatische Patienten.

In der einzelnen Analyse der Peptidkonzentrationen zeigte sich eine signifikante Erhöhung der NTproBNP-Werte in der DHF- gegenüber der KG- und DD-Gruppe. Auch bei MR-proANP, MR-proADM und CT-proET1 ist ein signifikanter Anstieg der Serumkonzentration im Vergleich zur KG-Gruppe zu erkennen. Allein in der Auswertung der CT-proAVP-Werte konnte ein Anstieg in der DD- im Vergleich zu der KG-Gruppe, jedoch ein Abfall in der DHF-Gruppe gesehen werden.

NT-proBNP ist ein Peptid, dessen Veränderungen im Rahmen der DHF bereits vergleichsweise oft Gegenstand klinischer Studien waren. Tschöpe et al. (2005) beispielsweise wiesen bei ihren Patienten mit verzögerter Relaxation und bestehender Belastungsdyspnoe eine Erhöhung im Mittelwert von $151,6 \mathrm{pg} / \mathrm{ml}$ gegenüber der Kontrollgruppe mit $51,89 \mathrm{pg} / \mathrm{ml}$ nach. Diese Werte sind mit den hier 
erhobenen komparabel. In diesem Patientenkollektiv hatte die KG einen mittleren NT-proBNP-Spiegel von $81,58 \mathrm{pg} / \mathrm{ml}$. In der asymptomatischen DD-Gruppe wurden $76,62 \mathrm{pg} / \mathrm{ml}$ und in der symptomatischen DHF-Gruppe $171,93 \mathrm{pg} / \mathrm{ml}$ gemessen. In der Studie von Tschöpe et al. (2005) wurde mit Elecsys $\AA^{\circledR}$ von Roche Diagnostics, Germany, die gleiche Nachweismethode für NT-proBNP verwendet wie in der vorliegenden Studie. Der etwas ausgeprägtere NT-proBNP-Spiegel in der symptomatischen Gruppe könnte seinen Ursprung in der Studiendurchführung haben. Bei Tschöpe et al. (2005) wurden 48 Stunden vor der Untersuchung sämtliche Diuretika, Betablocker, Kalziumantagonisten sowie ACE-Hemmer und AT1-Antagonisten pausiert (Tschöpe et al. 2005). Dies könnte nach Falcao et al. zu einer Verschiebung der NT-proBNP-Werte geführt haben (Falcao et al. 2004). Lubien et al. untersuchten den BNP-Spiegel von Patienten mit einer bestehenden symptomatischen DHF (Lubien et al. 2002). Bei diesem Patientenkollektiv wurde ein mittlerer BNPWert von $286 \mathrm{pg} / \mathrm{ml}$ gemessen. Der deutlich höhere Wert ist eventuell auf das in diesem Kollektiv höhere Durchschnittsalter von 71Jahren zurückzuführen. In einer Studie von McDonagh et al. wurde belegt, dass mit steigendem Lebensalter auch die NT-proBNP-Konzentration im Blut ansteigt (McDonagh et al. 2004). Damit haben wir gezeigt, dass die von uns gemessenen Werte gut mit denen von anderen Studien vergleichbar sind.

Der Zusammenhang zwischen NT-proBNP und Belastungsparametern bei Patienten mit einer DHF war bis zum heutigen Tag nur marginal Gegenstand von Studien. So fanden Tschöpe et al. (2005) einen Bezug zwischen der NYHA-Klassifikation und dem NT-proBNP-Spiegel bei Patienten mit einer DD. Weiterhin zeigte das BNP eine negative Korrelation mit ausgewählten Spiroergometriedaten bei Patienten mit Dyspnoe und isolierter DD in einer Studie von Eroglu et al. (2007). Durch die hier ermittelten Daten werden die bisherigen Erkenntnisse weiter untermauert. Auch in diesem Patientenkollektiv zeigte sich eine negative Korrelation von Spiroergometriedaten und dem NTproBNP. Im Einzelnen bedeutete dies einen signifikanten Zusammenhang zwischen NT-proBNP und der anaeroben Schwelle, der peak $\mathrm{VO}_{2}$ und der $\mathrm{ATVO}_{2}$. Eroglu et al. (2007) konnten für die peak $\mathrm{VO}_{2}$ zwar keinen signifikanten Zusammenhang, wohl aber ein Trend nachweisen (Eroglu et al. 2007). In einer Studie von Wieczorek et al. (2003) wurde der Zusammenhang zwischen dem 6-Minuten-Gehtest und Patienten mit einer CHF untersucht und bestätigt. Auch bei dem Patientenkollektiv der vorliegenden Studie sah man eine Korrelation zwischen dem 6-Minuten-Gehtest und NT-proBNP. Mit Hilfe der multiplen Regression konnte weiterhin gezeigt werden, dass es sich bei NT-proBNP um eine unabhängige Größe im Bezug auf die Belastungsparameter handelt. Dies konnte für die peak $\mathrm{VO}_{2}$, die 
$\mathrm{ATVO}_{2}$ und die anaerobe Schwelle in der Spiroergometrie nachgewiesen werden. Anhand dieser Daten wurde gezeigt, dass NT-proBNP eine wichtige und zentrale Rolle bei der Ausprägung von klinischen Symptomen bei Patienten mit einer diastolischen Herzinsuffizienz spielt. Da ein signifikanter Unterschied zwischen den Patienten mit einer bestehenden DD $(76,62 \mathrm{pg} / \mathrm{ml})$ und DHF $(171,93 \mathrm{pg} / \mathrm{ml})$ existiert, ist davon auszugehen, dass NT-proBNP eine direkte Ursache der Symptomentwicklung ist.

Als ein weiteres Neurohormon wurde das MR-proANP untersucht. Bei MR-proANP handelt es sich um ein Fragment aus dem atrialen, natriuretischen Peptid (ANP). Dieses war bisher kaum Gegenstand von aktuellen Studien, die sich mit der DD oder der DHF beschäftigten. In der hier vorliegenden Untersuchung zeigt sich ein signifikanter Anstieg der MR-proANP-Werte von der KG- zur DHF-Gruppe $(69,53 \pm 23,1$ vs. $107,05 \pm 46,89 \mathrm{pmol} / \mathrm{l})$. Ein weiterer, jedoch nicht aussagekräftiger Anstieg, ist im Übergang von der DD zur DHF-Gruppe zu erkennen (92,86 $\pm 35,71$ vs. $107,05 \pm 46,89$ pmol//). In einer klinischen Studie von Gegenhuber et al. (2006) wurden 251 Patienten mit Dyspnoe untersucht. Bei 137 der Patienten wurde eine dekompensierte Herzinsuffizienz als Hauptursache der Beschwerden angesehen. Diese Patienten wiesen mit 338pmol// einen signifikant höheren Mittelwert für MR-proANP auf als die übrigen 114. Eine mögliche Ursache für die deutlich höheren Werte könnte der übermäßig große Anteil von Patienten mit erniedrigter LVEF sein.

Der in dieser Studie weiterhin untersuchte Zusammenhang zwischen MR-proANP und den spiroergometrischen Belastungsparametern sowie dem 6-Minuten-Gehtest zeigte in keinem der in Tabelle 11 aufgeführten Parameter eine Korrelation. Damit ist MR-proANP das einzige der fünf hier untersuchten Hormone, welches nicht mit den hier untersuchten Belastungsparametern korreliert. Interessanterweise zeigt MR-proANP aber zusammen mit NT-proBNP in der multiplen Regression einen unabhängigen und direkten Einfluss auf die peak $\mathrm{VO}_{2}$, die $\mathrm{ATVO}_{2}$ sowie die anaerobe Schwelle. Damit stellt sich ein Einfluss auf die Belastbarkeit von Patienten mit einer DD beziehungsweise einer DHF dar. Eine nähere Untersuchung in folgenden Studien ist anzustreben.

Wie bereits bei MR-proANP dargelegt, zeigt auch das MR-proADM einen signifikanten Serumanstieg von der KG-Gruppe zur DHF-Gruppe $(0,46 \pm 0,09$ vs. $0,58 \pm 0,15 \mathrm{nmol} / \mathrm{l})$. Der ebenfalls vorhandene Anstieg zwischen dem DD- und dem DHF-Kollektiv ist nicht signifikant, kann aber als Trend gewertet werden $(0,51 \pm 0,12$ vs. $0,58 \pm 0,15 \mathrm{nmol} / \mathrm{l})$. 
In der Untersuchung zwischen MR-proADM und den Belastungsparametern stellte sich heraus, dass diese Werte hochsignifikant miteinander korrelieren. Das Signifikanzniveau befand sich bei maximal 0,001. Damit wird ein Zusammenhang zwischen dem MR-proADM und der Belastbarkeit von Patienten gezeigt. Diese Assoziation besteht auch trotz anderer Einflussgrößen. Dass MR-proADM mit der Belastbarkeit von Patienten im Sinne von NYHA-Stadien zusammenhängt, zeigte auch Gombos et al. (2009). Hier wurden 186 Patienten mit einer reduzierten EF $(<45 \%)$ untersucht. Auch Yu et al. (2001) fanden eine signifikante Erhöhung der Adrenomedullinkonzentration bei Patienten mit einer DD gegenüber gesunden Kontrollpatienten. In der Studie von Yu et al. (2001) wurde nicht das Fragment MR-proADM, sondern Adrenomedullin direkt bestimmt, was eine Vergleichbarkeit aufgrund unterschiedlicher Messmethoden erschwert (Yu et al. 2001).

Wie auch bei vorangegangenen Hormonen, macht die aktuelle Studienlage keine Aussagen über den Zusammenhang zwischen CT-proET1 und der DD. Damit ist die hier vorliegende Studie die erste zu diesem Thema. Die hier gemessenen Werten zeigen abermals einen signifikanten Anstieg der CTproET1-Konzentration in der DHF- gegenüber der KG-Gruppe (59,55 $\pm 12,74$ vs. 52,19 $\pm 12,74 \mathrm{pmol} / \mathrm{l})$. Im Vergleich zur KG-Gruppe sieht man auch eine Steigerung zur DD-Gruppe $(53,43 \pm 10,21 \mathrm{pmol} / \mathrm{l})$, jedoch keine signifikante. Nachdem der Nachweis einer relevanten Korrelation vom gesunden Patientenkollektiv zu dem mit einer diagnostizierten DHF gezeigt wurde, untersuchte man, ob CTproET1 einen Zusammenhang mit Belastungsparametern aufweist. Dabei fiel auf, dass CT-proET1 hochsignifikant mit Parametern aus der Spiroergometrie und dem 6-Minuten-Gehtest korreliert. In der weiterhin durchgeführten multiplen Regression konnte jedoch keine direkte Beziehung zwischen CTproET1 und den Belastungsparametern peak $\mathrm{VO}_{2}, \mathrm{ATVO}_{2}$, anaerobe Schwelle sowie dem 6-MinutenGehtest nachgewiesen werden.

Welchen Einfluss CT-proET1 auf die Entwicklung von klinischen Symptomen im Rahmen einer diastolischen Herzinsuffizienz hat, sollte weiterhin Gegenstand zukünftiger Studien sein. In zurückliegenden Untersuchungen wurde bereits versucht, mit dem ET1-Rezeptorantagonisten Tezosentan Symptome einer akuten Herzinsuffizienz zu therapieren. Dabei konnte jedoch keine Verbesserung der Symptomatik festgestellt werden (McMurray et al. 2007).

In einer Studie von Stoiser et al. 2006 wurde ein Kollektiv von Patienten mit einer fortgeschrittenen HF im NYHA Stadium III-IV untersucht. Dabei ließ sich, kontrovers zu den hier erhobenen Werten, ein deutlich erhöhter CT-proAVP-Spiegel bei Patienten mit ausgeprägten klinischen Symptomen 
nachweisen. In dem in dieser Arbeit beobachteten Patientenkollektiv zeigte sich sogar ein Rückgang der CT-proAVP-Konzentration in der DD-Gruppe gegenüber der symptomatischen DHF-Gruppe (6,24 $\pm 4,0$ vs. $5,09 \pm 3,46$ ), vermutlich aufgrund der geringen Patientenzahl im DD-Kollektiv. Die Werte nach Stoiser et al. (2006) lagen mit den gleichen Labormaterialien und der Messmethode der Firma B.R.A.H.M.S. AG Hennigsdorf mit 19,7 pmol/l erheblich über den hier ermittelten Werten (Morgenthaler et al. 2006, Stoiser et al. 2006).

Nach der Betrachtung aller hier untersuchten Hormone ist festzuhalten, dass Patienten mit einer DHF eine breite neurohumorale Aktivierung haben, und dass diese Aktivierung einen direkten Einfluss auf die Belastbarkeit der Patienten hat. Dieser Effekt auf die Belastungsfähigkeit ist größer ist als die Parameter der diastolischen Funktion.

Aufgrund der spärlichen Studienlage der neurohumoralen Aktivierung bei der DD und der DHF, sollten diese Ergebnisse durch weitere Studien bestätigt werden.

\subsection{Limitierung der Arbeit}

Die vorliegende Arbeit ist nach heutigem Wissensstand die erste, die sich mit der den Ursachen der eingeschränkten Belastbarkeit von Patienten mit einer DD und der DHF beschäftigt. Was den Vergleich mit anderen Studien erschwert, ist das international nicht einheitliche Diagnoseschema für die DHF. Die hier angewandte Echokardiographie wurde zusammen mit einem Gewebedoppler durchgeführt. Auch die nicht einheitlichen Bestimmungsmethoden der neurohumoralen Aktivierung beeinträchtigen die Gegenüberstellung der gemessenen Werte. Weiterhin ist noch offen, ob es von Vorteil ist, die Hormone in ihrer ursprünglichen Form zu bestimmen oder die von innen abgespaltenen Fragmente. Darüber hinaus werden die Belastungsparameter sowohl in der Spiroergometrie als auch für den 6-Minuten-Gehtest verglichen mit anderen Studien nach unterschiedlichen Protokollen durchgeführt. Für folgende Studien könnte eine Belastungsechokardiographie mehr Aufschluss über das Verhalten der diastolischen Parameter am Herzen während der Belastung geben. In der hier vorliegenden Studie wurden die Parameter der diastolischen Funktion in Ruhe bestimmt. 


\section{$5 \quad$ Zusammenfassung}

Herzinsuffizienz mit einer primären Störung der diastolischen Funktion bei gleichzeitig erhaltener oder nur leicht eingeschränkter linksventrikulärer Ejektionsfraktion wird als DHF definiert (Paulus et al. 2007). Je nach Vorselektion leiden mehr als 50\% der Patienten mit Zeichen und Symptomen der HF an einer DHF (Redfield et al. 2003, Hogg et al. 2004, Owan et al. 2006). Möglicherweise auch im Zusammenhang mit typischen RF (Hypertonus, Diabetes mellitus) nahm der relative Anteil der DHF gegenüber der SHF in den vergangenen Jahrzehnten deutlich zu (Owan et al. 2006).

In dieser Studie wurde ein Patientenkollektiv von 201 Patienten untersucht. Die Patienten wurden anhand von echokardiographischen Daten und der NYHA-Klassifikation in zwei Gruppen eingeteilt: Die Gruppe der DD bestand aus 14 Patienten mit einer echokardiographisch nachgewiesenen DD und ohne subjektive Belastungseinschränkungen. In der DHF-Gruppe befanden sich 112 Patienten mit einer nachgewiesenen DD und einer eingeschränkten Belastbarkeit (NYHA>I) sowie weiteren klinischen Symptomen der HI. Alle Patienten besaßen eine erhaltene LVEF. Der Grenzwert lag hier bei $50 \%$. Ausgeschlossen wurden alle Patienten mit leistungsmindernden Begleiterkrankungen wie KHK, Klappenfehlern und COPD. Um die neurohumorale Aktivierung besser klassifizieren zu können, wurde zusätzlich eine gesunde Kontrollgruppe mit 75 Patienten generiert. Diese Patienten wiesen alle eine erhaltene diastolische wie auch systolische Funktion auf.

Die Arbeit beschäftigte sich mit der Frage, welche Parameter Einfluss auf die Belastbarkeit und die klinische Symptomatik von Patienten mit einer DD und einer DHF haben. Zu diesem Zweck wurden die Patienten aus der DD- und aus der DHF-Gruppe mittels des 6-Minuten-Gehtests und einer Spiroergometrie belastet. Weiterhin wurde die neurohumorale Aktivierung anhand der Labormarker NT-proBNP, MR-proANP, MD-proADM, CT-proET1 und CT-proAVP gemessen sowie eine ausführliche Echokardiographie durchgeführt.

Die Auswertungen ergaben, dass Patienten mit einer DHF eine hochgradig reduzierte maximale und submaximale Belastbarkeit im Vergleich zu Patienten mit einer DD aufzeigen. Anhand prognostisch relevanter Leitparameter der diastolischen Funktion wie E/é und LAVI zeigten sich keine Unterschiede zwischen der DD- und DHF-Gruppe. In den Laboranalysen konnte jedoch eine ausgeprägte signifikante, neurohumorale Aktivierung der DHF-Patienten im Vergleich zur Kontrollgruppe gezeigt 
werden. Dieser Unterschied fehlt zwischen der KG- und DD- Gruppe fast völlig. Obwohl in der Echokardiographie nur marginale Unterschiede zwischen den beiden Gruppen zu erkennen waren, so zeigte sich dennoch in der bivariaten Korrelation ein gewisser Zusammenhang zwischen diastolischer Funktion und Belastbarkeit. Diese Assoziation zur Belastbarkeit war bei der neurohumoralen Aktivierung wesentlich stärker und vor allem signifikant ausgeprägt. Diese Beziehungen lassen sich anhand einer durchgeführten multiplen Regression untermauern. Hier zeigen sowohl NT-proBNP wie auch MR-proANP einen signifikanten, unabhängig von demographischen Daten, direkten Zusammenhang mit der Belastbarkeit. Dieser kann für die diastolische Funktion nicht nachgewiesen werden.

Zusammenfassend kann festgehalten werden, dass Patienten mit DHF im Vergleich zu DD schlechter belastbar sind und eine neurohumorale Überaktivierung trotz vergleichbarer Einschränkungen der diastolischen Funktion aufweisen. Patienten mit einer DHF haben außerdem eine signifikant erhöhte neurohumorale Aktivierung im Vergleich zur KG. Diese neurohumorale Aktivierung hat im Gegensatz zur diastolischen Funktion einen direkten Einfluss auf die Belastbarkeit.

Bei Patienten mit DD und DHF spielt, unabhängig von der diastolischen Funktion und demographischen Faktoren, die neurohumorale Aktivierung eine Schlüsselrolle in der Pathophysiologie der eingeschränkten Belastbarkeit. 


\section{$6 \quad$ Literaturverzeichnis}

Ahmed SH, Clark LL, Pennington WR, Webb CS, Bonnema DD, Leonardi AH, McClure CD, Spinale FG and Zile MR (2006): Matrix metalloproteinases/tissue inhibitors of metalloproteinases: relationship between changes in proteolytic determinants of matrix composition and structural, functional, and clinical manifestations of hypertensive heart disease. Circulation 113, 2089-2096

Almuntaser I, Brown A, Murphy R, Crean P, King G, Mahmud A and Feely J (2007): Comparison of echocardiographic measures of left ventricular diastolic function in early hypertension. Am J Cardiol $\underline{100}, 1771-1775$

Arias MA, Garcia-Rio F, Alonso-Fernandez A, Mediano O, Martinez I and Villamor J (2005): Obstructive sleep apnea syndrome affects left ventricular diastolic function: effects of nasal continuous positive airway pressure in men. Circulation $\underline{112}, 375-383$

Bergler-Klein J, Klaar U, Heger M, Rosenhek R, Gabriel H, Binder T, Pacher R, Maurer G and Baumgartner $H$ (2006): Big endothelin-1 is not a predictor in aortic stenosis, but is related to arterial blood pressure. Int J Cardiol $\underline{113}, 174-180$

Bergstrom A, Andersson B, Edner M, Nylander E, Persson H and Dahlstrom U (2004): Effect of carvedilol on diastolic function in patients with diastolic heart failure and preserved systolic function. Results of the Swedish Doppler-echocardiographic study (SWEDIC). Eur J Heart Fail $\underline{6}$, 453-461

Bhatia RS, Tu JV, Lee DS, Austin PC, Fang J, Haouzi A, Gong Y and Liu PP (2006): Outcome of heart failure with preserved ejection fraction in a population-based study. N Engl J Med $\underline{355}, 260-269$

Bittner V, Weiner DH, Yusuf S, Rogers WJ, McIntyre KM, Bangdiwala SI, Kronenberg MW, Kostis JB, Kohn RM, Guillotte M (1993): Prediction of mortality and morbidity with a 6-minute walk test in patients with left ventricular dysfunction. SOLVD Investigators. JAMA 270, 1702-1707

Borbely A, van der Velden J, Papp Z, Bronzwaer JG, Edes I, Stienen GJ and Paulus WJ (2005): Cardiomyocyte stiffness in diastolic heart failure. Circulation 111, 774-781

Buckley MG, Marcus NJ and Yacoub MH (1999): Cardiac peptide stability, aprotinin and room temperature: importance for assessing cardiac function in clinical practice. Clin Sci (Lond) $\underline{97}, 689-695$

Burgess MI, Jenkins C, Sharman JE and Marwick TH (2006): Diastolic stress echocardiography: hemodynamic validation and clinical significance of estimation of ventricular filling pressure with exercise. J Am Coll Cardiol 47, 1891-1900

Burnett JC, Jr., Kao PC, Hu DC, Heser DW, Heublein D, Granger JP, Opgenorth TJ and Reeder GS (1986): Atrial natriuretic peptide elevation in congestive heart failure in the human. Science $231,1145-$ 1147

Cleland JG, Tendera M, Adamus J, Freemantle N, Polonski L and Taylor J (2006): The perindopril in elderly people with chronic heart failure (PEP-CHF) study. Eur Heart J 27, 2338-2345

de Bold AJ, Borenstein HB, Veress AT and Sonnenberg H (1981): A rapid and potent natriuretic response to intravenous injection of atrial myocardial extract in rats. Life Sci $\underline{28}, 89-94$ 
de Bree FM and Burbach JP (1998): Structure-function relationships of the vasopressin prohormone domains. Cell Mol Neurobiol $\underline{18}, 173-191$

de Simone G, Gottdiener JS, Chinali M and Maurer MS (2008): Left ventricular mass predicts heart failure not related to previous myocardial infarction: the Cardiovascular Health Study. Eur Heart J $\underline{29}$, 741-747

Demers C, McKelvie RS, Negassa A and Yusuf S (2001): Reliability, validity, and responsiveness of the six-minute walk test in patients with heart failure. Am Heart J $\underline{142}, 698-703$

Edelmann F, Schmidt AG, Gelbrich G, Binder L, Herrmann-Lingen C, Halle M, Hasenfuss G, Wachter $\mathrm{R}$ and Pieske $\mathrm{B}$ Rationale and design of the 'aldosterone receptor blockade in diastolic heart failure' trial: a double-blind, randomized, placebo-controlled, parallel group study to determine the effects of spironolactone on exercise capacity and diastolic function in patients with symptomatic diastolic heart failure (Aldo-DHF). Eur J Heart Fail 12, 874-882

Elesber AA, Redfield MM, Rihal CS, Prasad A, Lavi S, Lennon R, Mathew V, Lerman LO and Lerman A (2007): Coronary endothelial dysfunction and hyperlipidemia are independently associated with diastolic dysfunction in humans. Am Heart J $\underline{153}, 1081-1087$

Elmas E, Lang S, Dempfle CE, Kalsch T, Papassotiriou J, Morgenthaler NG, Borggrefe M and Brueckmann M (2008): Diagnostic performance of mid-regional pro-adrenomedullin as an analyte for the exclusion of left ventricular dysfunction. Int J Cardiol $\underline{128}, 107-111$

Emori T, Hirata Y, Imai T, Eguchi S, Kanno K and Marumo F (1993): Cellular mechanism of natriuretic peptides-induced inhibition of endothelin-1 biosynthesis in rat endothelial cells. Endocrinology 133 , 2474-2480

Eroglu S, Yildirir A, Bozbas H, Aydinalp A, Ulubay G, Eldem O, Simsek V, Ozin B and Muderrisoglu H (2007): Brain natriuretic peptide levels and cardiac functional capacity in patients with dyspnea and isolated diastolic dysfunction. Int Heart J $\underline{48}, 97-106$

Falcao LM, Pinto F, Ravara L and van Zwieten PA (2004): BNP and ANP as diagnostic and predictive markers in heart failure with left ventricular systolic dysfunction. J Renin Angiotensin Aldosterone Syst $\underline{5}, 121-129$

Fischer M, Baessler A, Hense HW, Hengstenberg C, Muscholl M, Holmer S, Doring A, Broeckel U, Riegger $G$ and Schunkert H (2003): Prevalence of left ventricular diastolic dysfunction in the community. Results from a Doppler echocardiographic-based survey of a population sample. Eur Heart J 24, 320-328

Fletcher GF, Balady GJ, Amsterdam EA, Chaitman B, Eckel R, Fleg J, Froelicher VF, Leon AS, Pina IL, Rodney R (2001): Exercise standards for testing and training: a statement for healthcare professionals from the American Heart Association. Circulation 104, 1694-1740

Franciosa JA, Park M and Levine TB (1981): Lack of correlation between exercise capacity and indexes of resting left ventricular performance in heart failure. Am J Cardiol $\underline{47}$, 33-39

Francis GS, Benedict C, Johnstone DE, Kirlin PC, Nicklas J, Liang CS, Kubo SH, Rudin-Toretsky E and Yusuf S (1990): Comparison of neuroendocrine activation in patients with left ventricular dysfunction with and without congestive heart failure. A substudy of the Studies of Left Ventricular Dysfunction (SOLVD). Circulation 82, 1724-1729 
Fu LH, Ye PX, Sun ZL, Xiang YF and Zhu XZ (2008): [Reduced cardiopulmonary exercise capacity in patients with essential hypertension: impact of left ventricular hypertrophy]. Zhonghua Xin Xue Guan Bing Za Zhi $\underline{36}$, 718-721

Garcia MJ, Thomas JD and Klein AL (1998): New Doppler echocardiographic applications for the study of diastolic function. J Am Coll Cardiol $\underline{32}, 865-875$

Gardin JM, Leifer ES, Fleg JL, Whellan D, Kokkinos P, Leblanc MH, Wolfel E and Kitzman DW (2009): Relationship of Doppler-Echocardiographic left ventricular diastolic function to exercise performance in systolic heart failure: the HF-ACTION study Am Heart J. 158, S45-52

Gegenhuber A, Struck J, Dieplinger B, Poelz W, Pacher R, Morgenthaler NG, Bergmann A, Haltmayer $M$ and Mueller T (2007): Comparative evaluation of B-type natriuretic peptide, mid-regional pro-A-type natriuretic peptide, mid-regional pro-adrenomedullin, and Copeptin to predict 1 -year mortality in patients with acute destabilized heart failure. J Card Fail $\underline{13}, 42-49$

Guazzi M, Dickstein K, Vicenzi M and Arena R (2009): Six-minute walk test and cardiopulmonary exercise testing in patients with chronic heart failure: a comparative analysis on clinical and prognostic insights. Circ Heart Fail 2, 549-555

Guyatt GH, Sullivan MJ, Thompson PJ, Fallen EL, Pugsley SO, Taylor DW and Berman LB (1985): The 6-minute walk: a new measure of exercise capacity in patients with chronic heart failure. Can Med Assoc J 132, 919-923

Hasenfuss G and Pieske B (2002): Calcium cycling in congestive heart failure. J Mol Cell Cardiol $\underline{34}$, 951-969

Ho KK, Pinsky JL, Kannel WB and Levy D (1993): The epidemiology of heart failure: the Framingham Study. J Am Coll Cardiol $\underline{22}, 6 \mathrm{~A}-13 \mathrm{~A}$

Hogg K, Swedberg K and McMurray J (2004): Heart failure with preserved left ventricular systolic function; epidemiology, clinical characteristics, and prognosis. J Am Coll Cardiol $\underline{43}$, 317-327

Hunt SA, Abraham WT, Chin MH, Feldman AM, Francis GS, Ganiats TG, Jessup M, Konstam MA, Mancini DM, Michl K (2005): ACC/AHA 2005 Guideline Update for the Diagnosis and Management of Chronic Heart Failure in the Adult: a report of the American College of Cardiology/American Heart Association Task Force on Practice Guidelines (Writing Committee to Update the 2001 Guidelines for the Evaluation and Management of Heart Failure): developed in collaboration with the American College of Chest Physicians and the International Society for Heart and Lung Transplantation: endorsed by the Heart Rhythm Society. Circulation 112, e154-235

Ichiki Y, Kitamura K, Kangawa K, Kawamoto M, Matsuo H and Eto T (1994): Distribution and characterization of immunoreactive adrenomedullin in human tissue and plasma. FEBS Lett $\underline{338}, 6-10$

Iglarz M and Schiffrin EL (2003): Role of endothelin-1 in hypertension. Curr Hypertens Rep $\underline{5}, 144-148$

Inoue A, Yanagisawa M, Kimura S, Kasuya Y, Miyauchi T, Goto K and Masaki T (1989): The human endothelin family: three structurally and pharmacologically distinct isopeptides predicted by three separate genes. Proc Natl Acad Sci U S A $\underline{86}, 2863-2867$

Iribarren C, Karter AJ, Go AS, Ferrara A, Liu JY, Sidney S and Selby JV (2001): Glycemic control and heart failure among adult patients with diabetes. Circulation $\underline{103}, 2668-2673$ 
Irzmanski R, Banach M, Piechota M, Kowalski J, Barylski M, Cierniewski C and Pawlicki L (2007): Atrial and brain natriuretic peptide and endothelin-1 concentration in patients with idiopathic arterial hypertension: the dependence on the selected morphological parameters. Clin Exp Hypertens 29 , $149-164$

Jalil JE, Doering CW, Janicki JS, Pick R, Shroff SG and Weber KT (1989): Fibrillar collagen and myocardial stiffness in the intact hypertrophied rat left ventricle. Circ Res $\underline{64}, 1041-1050$

Karl J, Borgya A, Gallusser A, Huber E, Krueger K, Rollinger W and Schenk J (1999): Development of a novel, N-terminal-proBNP (NT-proBNP) assay with a low detection limit. Scand J Clin Lab Invest Suppl $\underline{230}, 177-181$

Kasner M, Westermann D, Steendijk P, Gaub R, Wilkenshoff U, Weitmann K, Hoffmann W, Poller W, Schultheiss HP, Pauschinger M (2007): Utility of Doppler echocardiography and tissue Doppler imaging in the estimation of diastolic function in heart failure with normal ejection fraction: a comparative Doppler-conductance catheterization study. Circulation 116, 637-647

Katz AM and Zile MR (2006): New molecular mechanism in diastolic heart failure. Circulation 113, 1922-1925

Khan SQ, Dhillon O, Struck J, Quinn P, Morgenthaler NG, Squire IB, Davies JE, Bergmann A and Ng LL (2007): C-terminal pro-endothelin-1 offers additional prognostic information in patients after acute myocardial infarction: Leicester Acute Myocardial Infarction Peptide (LAMP) Study. Am Heart J 154, 736-742

Kitamura K, Kangawa K, Kawamoto M, Ichiki Y, Nakamura S, Matsuo H and Eto T (1993):

Adrenomedullin: a novel hypotensive peptide isolated from human pheochromocytoma. Biochem Biophys Res Commun 192, 553-560

Kitzman DW (2002): Diastolic heart failure in the elderly. Heart Fail Rev $\underline{7}, 17-27$

Klapholz M, Maurer M, Lowe AM, Messineo F, Meisner JS, Mitchell J, Kalman J, Phillips RA, Steingart R, Brown EJ, Jr. (2004): Hospitalization for heart failure in the presence of a normal left ventricular ejection fraction: results of the New York Heart Failure Registry. J Am Coll Cardiol $\underline{43}$, 1432-1438

Kobayashi K, Kitamura K, Etoh T, Nagatomo Y, Takenaga M, Ishikawa T, Imamura T, Koiwaya Y and Eto T (1996): Increased plasma adrenomedullin levels in chronic congestive heart failure. Am Heart $J$ $\underline{131}, 994-998$

Lele SS, Macfarlane D, Morrison S, Thomson H, Khafagi F and Frenneaux M (1996): Determinants of exercise capacity in patients with coronary artery disease and mild to moderate systolic dysfunction. Role of heart rate and diastolic filling abnormalities. Eur Heart $\mathrm{J} \underline{17}, 204-212$

Lerman A, Gibbons RJ, Rodeheffer RJ, Bailey KR, McKinley LJ, Heublein DM and Burnett JC, Jr. (1993): Circulating N-terminal atrial natriuretic peptide as a marker for symptomless left-ventricular dysfunction. Lancet $\underline{341}, 1105-1109$

Levey AS, Bosch JP, Lewis JB, Greene T, Rogers N and Roth D (1999): A more accurate method to estimate glomerular filtration rate from serum creatinine: a new prediction equation. Modification of Diet in Renal Disease Study Group. Ann Intern Med 130, 461-470

Li D, Shinagawa K, Pang L, Leung TK, Cardin S, Wang Z and Nattel S (2001): Effects of angiotensinconverting enzyme inhibition on the development of the atrial fibrillation substrate in dogs with ventricular tachypacing-induced congestive heart failure. Circulation 104, 2608-2614 
Lim TK, Ashrafian H, Dwivedi G, Collinson PO and Senior R (2006): Increased left atrial volume index is an independent predictor of raised serum natriuretic peptide in patients with suspected heart failure but normal left ventricular ejection fraction: Implication for diagnosis of diastolic heart failure. Eur $\mathrm{J}$ Heart Fail $\underline{8}, 38-45$

Linke WA and Grutzner A (2008): Pulling single molecules of titin by AFM--recent advances and physiological implications. Pflugers Arch $\underline{456}, 101-115$

Liu JE, Palmieri V, Roman MJ, Bella JN, Fabsitz R, Howard BV, Welty TK, Lee ET and Devereux RB (2001): The impact of diabetes on left ventricular filling pattern in normotensive and hypertensive adults: the Strong Heart Study. J Am Coll Cardiol 37, 1943-1949

Lubien E, DeMaria A, Krishnaswamy P, Clopton P, Koon J, Kazanegra R, Gardetto N, Wanner E and Maisel AS (2002): Utility of B-natriuretic peptide in detecting diastolic dysfunction: comparison with Doppler velocity recordings. Circulation $\underline{105}, 595-601$

Luers C, Wachter R, Kleta S, Uhlir M, Koschack J, Scherer M, Binder L, Herrmann-Lingen C, Zapf A, Kulle B Natriuretic peptides in the detection of preclinical diastolic or systolic dysfunction. Clin Res Cardiol $\underline{99}, 217-226$

Maeda S, Jesmin S, lemitsu M, Otsuki T, Matsuo T, Ohkawara K, Nakata Y, Tanaka K, Goto K and Miyauchi T (2006): Weight loss reduces plasma endothelin-1 concentration in obese men. Exp Biol Med (Maywood) 231, 1044-1047

Maggioni AP, Latini R, Carson PE, Singh SN, Barlera S, Glazer R, Masson S, Cere E, Tognoni G and Cohn JN (2005): Valsartan reduces the incidence of atrial fibrillation in patients with heart failure: results from the Valsartan Heart Failure Trial (Val-HeFT). Am Heart J $\underline{149}, 548-557$

Masaki T (2004): Historical review: Endothelin. Trends Pharmacol Sci $\underline{25}$, 219-224

Massie BM, Carson PE, McMurray JJ, Komajda M, McKelvie R, Zile MR, Anderson S, Donovan M, Iverson E, Staiger C (2008): Irbesartan in patients with heart failure and preserved ejection fraction. N Engl J Med 359, 2456-2467

Masson S, Latini R, Anand IS, Barlera S, Judd D, Salio M, Perticone F, Perini G, Tognoni G and Cohn JN (2006): The prognostic value of big endothelin-1 in more than 2,300 patients with heart failure enrolled in the Valsartan Heart Failure Trial (Val-HeFT). J Card Fail 12, 375-380

McDonagh TA, Holmer S, Raymond I, Luchner A, Hildebrant P and Dargie HJ (2004): NT-proBNP and the diagnosis of heart failure: a pooled analysis of three European epidemiological studies. Eur $\mathrm{J}$ Heart Fail $\underline{6}$, 269-273

McMurray JJ, Ray SG, Abdullah I, Dargie HJ and Morton JJ (1992): Plasma endothelin in chronic heart failure. Circulation $\underline{85}, 1374-1379$

McMurray JJ, Teerlink JR, Cotter G, Bourge RC, Cleland JG, Jondeau G, Krum H, Metra M, O'Connor CM, Parker JD (2007): Effects of tezosentan on symptoms and clinical outcomes in patients with acute heart failure: the VERITAS randomized controlled trials. JAMA 298, 2009-2019

Meeran K, O'Shea D, Upton PD, Small CJ, Ghatei MA, Byfield PH and Bloom SR (1997): Circulating adrenomedullin does not regulate systemic blood pressure but increases plasma prolactin after intravenous infusion in humans: a pharmacokinetic study. J Clin Endocrinol Metab ⒉, 95-100 
Melenovsky V, Borlaug BA, Rosen B, Hay I, Ferruci L, Morell CH, Lakatta EG, Najjar SS and Kass DA (2007): Cardiovascular features of heart failure with preserved ejection fraction versus nonfailing hypertensive left ventricular hypertrophy in the urban Baltimore community: the role of atrial remodeling/dysfunction. J Am Coll Cardiol $\underline{49}, 198-207$

Morgenthaler NG, Struck J, Thomas B and Bergmann A (2004): Immunoluminometric assay for the midregion of pro-atrial natriuretic peptide in human plasma. Clin Chem $\underline{50}, 234-236$

Morgenthaler NG, Struck J, Alonso C and Bergmann A (2005): Measurement of midregional proadrenomedullin in plasma with an immunoluminometric assay. Clin Chem $\underline{51}, 1823-1829$

Morgenthaler NG, Struck J, Alonso C and Bergmann A (2006): Assay for the measurement of copeptin, a stable peptide derived from the precursor of vasopressin. Clin Chem $\underline{52}, 112-119$

Mueller T, Gegenhuber A, Poelz W and Haltmayer M (2003): Comparison of the Biomedica NTproBNP enzyme immunoassay and the Roche NT-proBNP chemiluminescence immunoassay: implications for the prediction of symptomatic and asymptomatic structural heart disease. Clin Chem $\underline{49}, 976-979$

Nakamura S, Naruse M, Naruse K, Kawana M, Nishikawa T, Hosoda S, Tanaka I, Yoshimi T, Yoshihara I, Inagami T (1991): Atrial natriuretic peptide and brain natriuretic peptide coexist in the secretory granules of human cardiac myocytes. Am J Hypertens $\underline{4}$, 909-912

Okura Y, Ohno Y, Ramadan MM, Suzuki K, Taneda K, Obata H, Tanaka K, Kashimura T, Ishizuka O, Kato K (2007): Characterization of outpatients with isolated diastolic dysfunction and evaluation of the burden in a Japanese community: Sado Heart Failure Study. Circ J $\underline{71}, 1013-1021$

Owan TE, Hodge DO, Herges RM, Jacobsen SJ, Roger VL and Redfield MM (2006): Trends in prevalence and outcome of heart failure with preserved ejection fraction. N Engl J Med $\underline{355}, 251-259$

Papassotiriou J, Morgenthaler NG, Struck J, Alonso C and Bergmann A (2006): Immunoluminometric assay for measurement of the $\mathrm{C}$-terminal endothelin-1 precursor fragment in human plasma. Clin Chem $\underline{52}, 1144-1151$

Paulus WJ, Tschope C, Sanderson JE, Rusconi C, Flachskampf FA, Rademakers FE, Marino P, Smiseth OA, De Keulenaer G, Leite-Moreira AF (2007): How to diagnose diastolic heart failure: a consensus statement on the diagnosis of heart failure with normal left ventricular ejection fraction by the Heart Failure and Echocardiography Associations of the European Society of Cardiology. Eur Heart J $\underline{28}, 2539-2550$

Piechota M, Banach M, Jacon A and Rysz J (2008): Natriuretic peptides in cardiovascular diseases. Cell Mol Biol Lett $\underline{13}, 155-181$

Pieske B and Wachter R (2008): Impact of diabetes and hypertension on the heart. Curr Opin Cardiol $\underline{23}, 340-349$

Pio R, Martinez A, Unsworth EJ, Kowalak JA, Bengoechea JA, Zipfel PF, Elsasser TH and Cuttitta F (2001): Complement factor $\mathrm{H}$ is a serum-binding protein for adrenomedullin, and the resulting complex modulates the bioactivities of both partners. J Biol Chem 276, 12292-12300

Preibisz JJ, Sealey JE, Laragh JH, Cody RJ and Weksler BB (1983): Plasma and platelet vasopressin in essential hypertension and congestive heart failure. Hypertension $\underline{5}$, 1129-138 
Redfield MM, Jacobsen SJ, Burnett JC, Jr., Mahoney DW, Bailey KR and Rodeheffer RJ (2003): Burden of systolic and diastolic ventricular dysfunction in the community: appreciating the scope of the heart failure epidemic. JAMA $\underline{289}, 194-202$

Redfield MM, Rodeheffer RJ, Jacobsen SJ, Mahoney DW, Bailey KR and Burnett JC, Jr. (2004): Plasma brain natriuretic peptide to detect preclinical ventricular systolic or diastolic dysfunction: a community-based study. Circulation $\underline{109}$, 3176-3181

Robertson GL, Mahr EA, Athar S and Sinha T (1973): Development and clinical application of a new method for the radioimmunoassay of arginine vasopressin in human plasma. J Clin Invest 52, 23402352

Rossi A, Cicoira M, Florea VG, Golia G, Florea ND, Khan AA, Murray ST, Nguyen JT, O'Callaghan P, Anand IS (2006): Chronic heart failure with preserved left ventricular ejection fraction: diagnostic and prognostic value of left atrial size. Int J Cardiol 110, 386-392

Schunkert H, Hense HW, Muscholl M, Luchner A, Kurzinger S, Danser AH and Riegger GA (1997): Associations between circulating components of the renin-angiotensin-aldosterone system and left ventricular mass. Heart $\underline{77}, 24-31$

Shah R (2007): Endothelins in health and disease. Eur J Intern Med 18, 272-282

Singh Ranger G (2002): The physiology and emerging roles of antidiuretic hormone. Int J Clin Pract $\underline{56}, 777-782$

Stahrenberg R, Edelmann F, Mende M, Kockskamper A, Dungen HD, Scherer M, Kochen MM, Binder L, Herrmann-Lingen C, Gelbrich G (2010): Association of glucose metabolism with diastolic function along the diabetic continuum. Diabetologia $\underline{53}, 1331-1340$

Stoiser B, Mortl D, Hulsmann M, Berger R, Struck J, Morgenthaler NG, Bergmann A and Pacher R (2006): Copeptin, a fragment of the vasopressin precursor, as a novel predictor of outcome in heart failure. Eur J Clin Invest $\underline{36}, 771-778$

Struck J, Morgenthaler NG and Bergmann A (2005): Proteolytic processing pattern of the endothelin-1 precursor in vivo. Peptides $\underline{26}, 2482-2486$

Sudoh T, Kangawa K, Minamino N and Matsuo H (1988): A new natriuretic peptide in porcine brain. Nature $\underline{332}, 78-81$

Sugo S, Minamino N, Kangawa K, Miyamoto K, Kitamura K, Sakata J, Eto T and Matsuo H (1994): Endothelial cells actively synthesize and secrete adrenomedullin. Biochem Biophys Res Commun $\underline{201}, 1160-1166$

Tahara A, Tomura Y, Wada K, Kusayama T, Tsukada J, Ishii N, Yatsu T, Uchida W and Tanaka A (1998): Effect of YM087, a potent nonpeptide vasopressin antagonist, on vasopressin-induced protein synthesis in neonatal rat cardiomyocyte. Cardiovasc Res $\underline{38}, 198-205$

Terzi S, Dayi SU, Akbulut T, Sayar N, Bilsel T, Tangurek B, Akgoz H, Kose H, Yilmazer S and Yesilcimen K (2005): Value of left atrial function in predicting exercise capacity in heart failure with moderate to severe left ventricular systolic dysfunction. Int Heart J $\underline{46}, 123-131$

Topol EJ, Traill TA and Fortuin NJ (1985): Hypertensive hypertrophic cardiomyopathy of the elderly. N Engl J Med 312, 277-283 
Tribouilloy C, Rusinaru D, Mahjoub H, Souliere V, Levy F, Peltier M, Slama M and Massy Z (2008): Prognosis of heart failure with preserved ejection fraction: a 5 year prospective population-based study. Eur Heart J $\underline{29}$, 339-347

Tschöpe C, Kasner M, Westermann D, Gaub R, Poller WC and Schultheiss HP (2005): The role of NT-proBNP in the diagnostics of isolated diastolic dysfunction: correlation with echocardiographic and invasive measurements. Eur Heart J 26, 2277-2284

Van Beneden R, Gurne O, Selvais PL, Ahn SA, Robert AR, Ketelslegers JM, Pouleur HG and Rousseau MF (2004): Superiority of big endothelin-1 and endothelin-1 over natriuretic peptides in predicting survival in severe congestive heart failure: a 7-year follow-up study. J Card Fail $\underline{10}$, 490-495

Van Putte-Katier N, Rooman RP, Haas L, Verhulst SL, Desager KN, Ramet J and Suys BE (2008): Early cardiac abnormalities in obese children: importance of obesity per se versus associated cardiovascular risk factors. Pediatr Res $\underline{64}, 205-209$

Vasan RS, Benjamin EJ and Levy D (1995): Prevalence, clinical features and prognosis of diastolic heart failure: an epidemiologic perspective. J Am Coll Cardiol 26, 1565-1574

Wachter R, Luers C, Kleta S, Griebel K, Herrmann-Lingen C, Binder L, Janicke N, Wetzel D, Kochen MM and Pieske B (2007): Impact of diabetes on left ventricular diastolic function in patients with arterial hypertension. Eur J Heart Fail $\underline{9}$, 469-476

Weitzberg E, Ahlborg G and Lundberg JM (1991): Long-lasting vasoconstriction and efficient regional extraction of endothelin-1 in human splanchnic and renal tissues. Biochem Biophys Res Commun $\underline{180}, 1298-1303$

Wieczorek SJ, Hager D, Barry MB, Kearney L, Ferrier A and Wu AH (2003): Correlation of B-type natriuretic peptide level to 6 -minwalk test performance in patients with left ventricular systolic dysfunction. Clin Chim Acta $\underline{328}, 87-90$

Xu D, Emoto N, Giaid A, Slaughter C, Kaw S, deWit D and Yanagisawa M (1994): ECE-1: a membrane-bound metalloprotease that catalyzes the proteolytic activation of big endothelin-1. Cell $\underline{78}$, 473-485

Yamamoto T, Kimura T, Ota K, Shoji M, Inoue M, Sato K, Ohta M and Yoshinaga K (1992): Central effects of endothelin-1 on vasopressin release, blood pressure, and renal solute excretion. Am J Physiol 262, E856-862

Yanagisawa M, Kurihara H, Kimura S, Tomobe Y, Kobayashi M, Mitsui Y, Yazaki Y, Goto K and Masaki T (1988): A novel potent vasoconstrictor peptide produced by vascular endothelial cells. Nature $\underline{332}, 411-415$

Yu CM, Cheung BM, Leung R, Wang Q, Lai WH and Lau CP (2001): Increase in plasma adrenomedullin in patients with heart failure characterised by diastolic dysfunction. Heart $\underline{86}, 155-160$

Zanchetti A, Cuspidi C, Comarella L, Rosei EA, Ambrosioni E, Chiariello M, Leonetti G, Mancia G, Pessina AC, Salvetti A (2007): Left ventricular diastolic dysfunction in elderly hypertensives: results of the APROS-diadys study. J Hypertens $\underline{25}$, 2158-2167

Zile MR and Brutsaert DL (2002): New concepts in diastolic dysfunction and diastolic heart failure: Part I: diagnosis, prognosis, and measurements of diastolic function. Circulation 105, 1387-1393 


\section{$7 \quad$ Abbildungsverzeichnis}

Abbildung 1: Der obere Teil zeigt das proANP, in der Mitte ist die Region der Aminosäuren 53-90 zu sehen, die als Angriffspunkt der Antikörper dient. Mit „tracer“ ist der markierte Antikörper bezeichnet, während "solid phase" den an das Gefäß gebundenen Antikörper darstellt (Morgenthaler et al. 2004).

Abbildung 2: Struktur des präpro-Adrenomedullins. MR-proADM kennzeichnet den mittelregionalen Teil des entstehenden pro-Adrenomedullin. (Morgenthaler et al. 2005) 32

Abbildung 3: Assayprinzip zum Nachweis von CT-proET-1. (Papassotiriou et al. 2006) 33

Abbildung 4: Struktur des präpro-Vasopressins mit Verdeutlichung des Assays. (Morgenthaler et al. 2006) 34

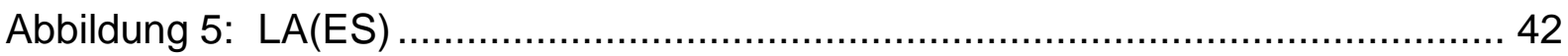

Abbildung 6: E/é medial..................................................................... 43

Abbildung 7: a'-Welle medialer Mitralanulus ................................................ 43

Abbildung 8: $e^{\prime}-$ Welle medialer Mitralanulus ..................................................... 44

Abbildung 9: A-Welle im Mitralisdoppler .................................................... 44

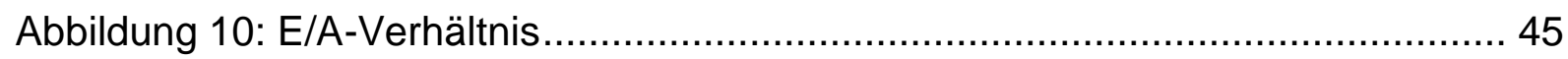

Abbildung 11: maximale Belastungsstufe bei der Spiroergometrie ....................... 47

Abbildung 12: maximale Herzfrequenz bei der Spiroergometrie ............................ 48

Abbildung 13: VE maximal bei der Spiroergometrie ...................................... 48

Abbildung 14: anaerobe Schwelle bei der Spiroergometrie ............................... 49

Abbildung 15: $\mathrm{ATVO}_{2}$ bei der Spiroergometrie ............................................. 49

Abbildung 16: peak $\mathrm{VO}_{2}$ bei der Spiroergometrie ......................................... 50

Abbildung 17: maximale Gehstrecke im 6-Minuten-Gehtest.............................. 50

Abbildung 18: Darstellung der Korrelation zwischen log NT-proBNP und der

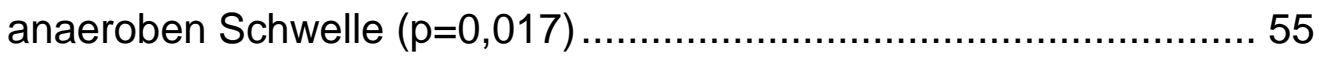

Abbildung 19: Darstellung der Korrelation zwischen log MR-proADM und der

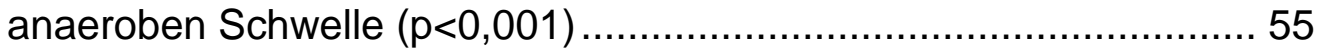

Abbildung 20: Darstellung der Korrelation zwischen log NT-proAVP und der

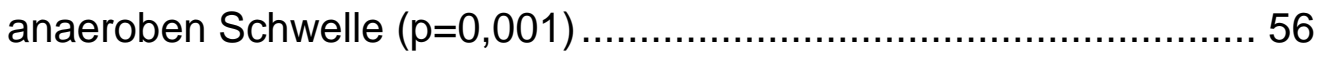

Abbildung 21: Darstellung der Korrelation zwischen log NT-proBNP und der peak VO2 $(p=0,028)$

Abbildung 22: Darstellung der Korrelation zwischen log MR-proADM und der peak VO2 $(p<0,001)$ 
Abbildung 23: Darstellung der Korrelation zwischen log CT-proAVP und der peak

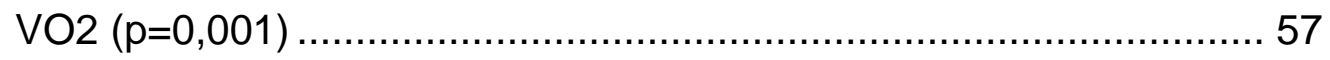

Abbildung 24: Darstellung der Korrelation zwischen log NT-proBNP und dem 6Minuten-Gehtest $(p=0,019)$.... 58

Abbildung 25: Darstellung der Korrelation zwischen log MR-proADM und dem 6Minuten Gehtest $(p<0,001)$. 58 


\section{Tabellenverzeichnis}

Tabelle 1: Einteilung des Schweregrades der diastolischen Dysfunktion nach KNHI

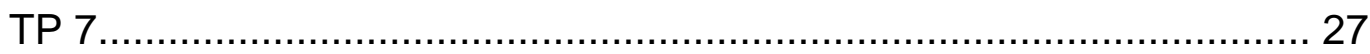

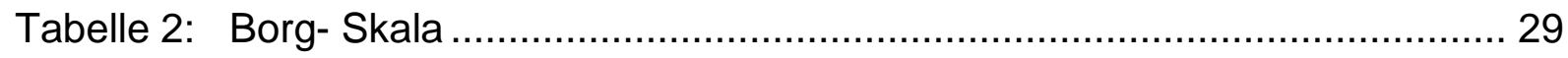

Tabelle 3: Klinische Charakterisierung des Patientenkollektivs ............................ 35

Tabelle 4: Häufigkeitsverteilung von Risikofaktoren in \% .................................. 36

Tabelle 5: Symptome der Herzinsuffizienz im Patientenkollektiv ........................... 38

Tabelle 6: Medikation im Gesamtkollektiv...................................................... 39

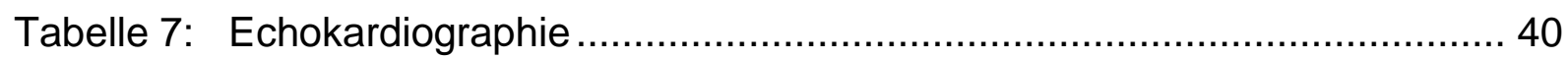

Tabelle 8: Spiroergometrie und 6- Minuten-Gehtest.......................................... 46

Tabelle 9: Neurohumorale Aktivierung …………..................................... 51

Tabelle 10: Korrelation zwischen ausgewählten Belastungs- und Echoparametern der diastolischen und systolischen Funktion....................................... 52

Tabelle 11: Korrelationen zwischen Belastungsparametern und der neurohumoralen Aktivierung

Tabelle 12: Korrelation zwischen der neurohumoralen Aktivierung und ausgewählten

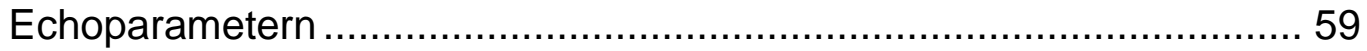

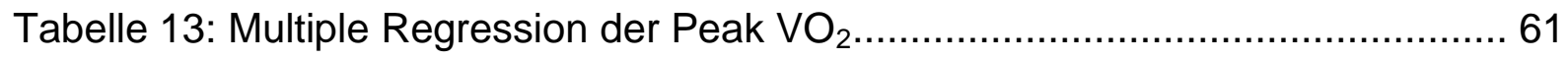

Tabelle 14: Multiple Regression der anaerobe Schwelle in der Spiroergometrie...... 62

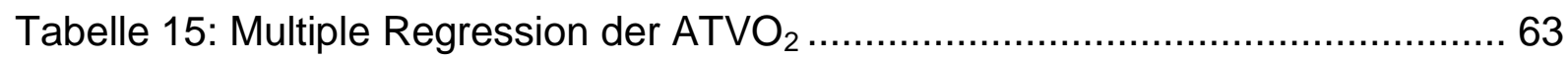

Tabelle 16: Multiple Regression der Gehstrecke ................................................. 64 
